\title{
WestVirginiaUniversity
}

THE RESEARCH REPOSITORY @ WVU

Graduate Theses, Dissertations, and Problem Reports

2002

\section{Phase equilibrium study of methane hydrate}

\author{
Rahul Shukla \\ West Virginia University
}

Follow this and additional works at: https://researchrepository.wvu.edu/etd

\section{Recommended Citation}

Shukla, Rahul, "Phase equilibrium study of methane hydrate" (2002). Graduate Theses, Dissertations, and Problem Reports. 1261.

https://researchrepository.wvu.edu/etd/1261

This Thesis is protected by copyright and/or related rights. It has been brought to you by the The Research Repository @ WVU with permission from the rights-holder(s). You are free to use this Thesis in any way that is permitted by the copyright and related rights legislation that applies to your use. For other uses you must obtain permission from the rights-holder(s) directly, unless additional rights are indicated by a Creative Commons license in the record and/ or on the work itself. This Thesis has been accepted for inclusion in WVU Graduate Theses, Dissertations, and Problem Reports collection by an authorized administrator of The Research Repository @ WVU. For more information, please contact researchrepository@mail.wvu.edu. 


\author{
Rahul Shukla
}

\author{
Thesis submitted to the \\ College of Engineering and Mineral Resources \\ at West Virginia University \\ in partial fulfillment of the requirements \\ for the degree of
}

\author{
Master of Science \\ in \\ Chemical Engineering \\ Aubrey L. Miller, Ph.D., Chair \\ Eung H. Cho, Ph.D. \\ Duane Smith, Ph.D. \\ Department of Chemical Engineering \\ Morgantown, West Virginia \\ 2001
}

Keywords: Gas Hydrates, Phase Equilibrium, Porous Media

Copyright 2001 Rahul Shukla 


\section{ABSTRACT \\ Phase Equilibrium Study of Methane Hydrate \\ Rahul Shukla}

Gas hydrates are solid metastable ice like compounds formed when gas comes in contact with water and have the ability to form at low temperatures. In this study, methane gas hydrates were formed in a Berea sandstone core, which was saturated with brine and then pressurized with methane gas. The formation temperatures were $34^{\circ} \mathrm{F}, 36^{\circ} \mathrm{F}$ and $40{ }^{\circ} \mathrm{F}$ and the initial pressures were in the range of 1000-1200 psi. Variation of the methane pressure was monitored with time during the formation run. Dissociation experiments were then carried out and the pressure profile along the core with time was recorded. The volume of gas produced during dissociation was recorded with time. Equilibrium pressures were found to be 540 psi, 544 psi and 620 psi for 34 ${ }^{\circ} \mathrm{F}, 36^{\circ} \mathrm{F}$ and $40{ }^{\circ} \mathrm{F}$, respectively. From the initial rate constants for formation, the activation energy was found to be $79 \mathrm{~kJ} / \mathrm{mole}$. The formation of hydrate usually takes $45 \mathrm{hrs}$ while the dissociation takes less than $2 \mathrm{hrs}$. 


\section{ACKNOWLEDGEMENT}

I would like to express my sincere gratitude and appreciation to my advisor Dr. A. L. Miller for his advice, encouragement and support through out the course of this work.

I would like to thank my committee members, Dr. Eung Cho and Dr. Duane Smith for their unremitting guidance and invaluable suggestions.

I would like to acknowledge the faculty and graduate students, Department of Chemical Engineering, WVU, who have been kind, helpful and supportive.

Special thanks to Mr. Jim Hall for his incessant assistance with the experimental set-up and to Ms. L. Rogers and Ms. B. Helmick for their co-operation and timely help with the paper work.

I would like to thank my friends Dharmarajan Hariharan and Neeraj Pugalia for their motivation and inputs throughout my research.

Last but not the least I would like to thank my family for their unyielding support and faith in me and dedicate this work to mom and dad. 


\section{TABLE OF CONTENTS}

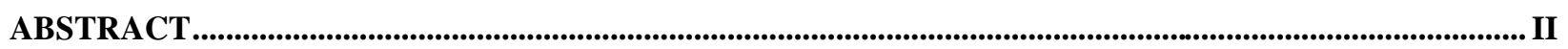

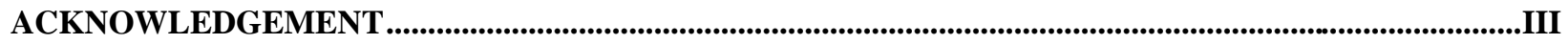

TABLE OF CONTENTS........................................................................................................................................................

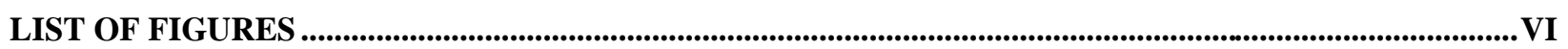

CHAPTER I INTRODUCTION .......................................................................................................................................

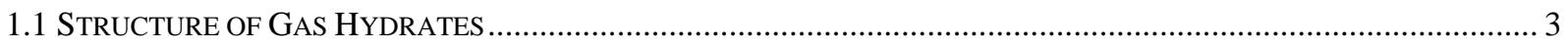

1.2 HYDRATE FORMATION CONDITIONS -THE IDEA OF QUADRUPOLAR POINTS .................................................... 9

CHAPTER II TECHNICAL BACKGROUND AND LITERATURE REVIEW .......................................... 13

CHAPTER III EQUIPMENT AND MATERIALS ................................................................................................30

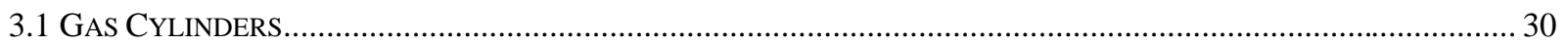

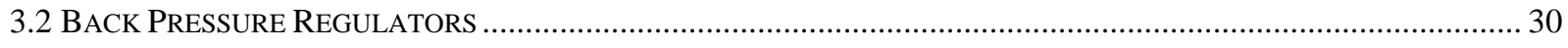

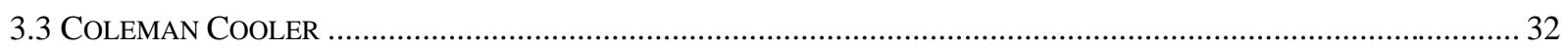

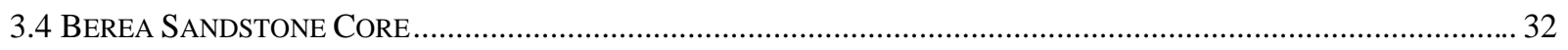

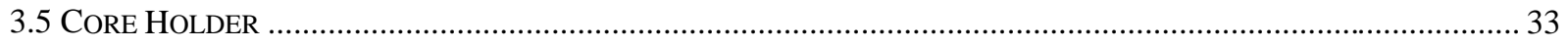

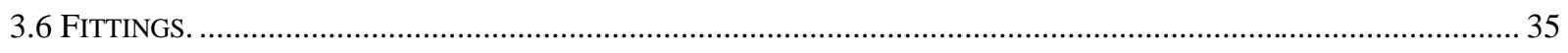

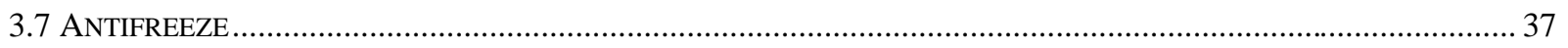

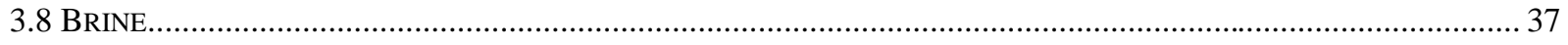

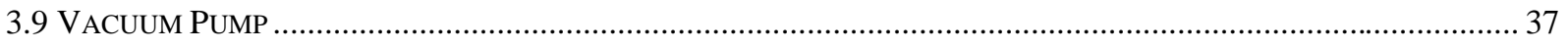

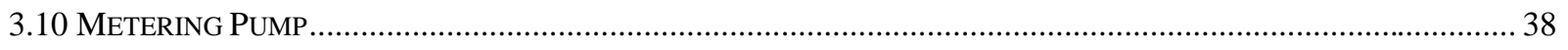

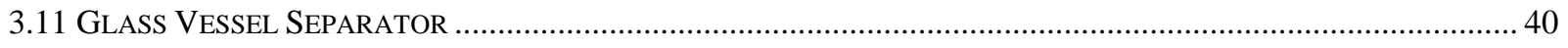

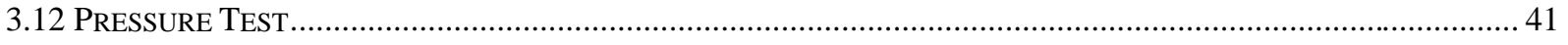




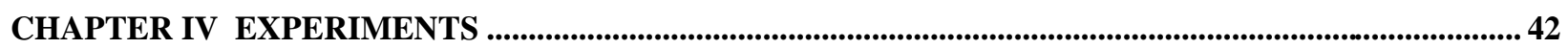

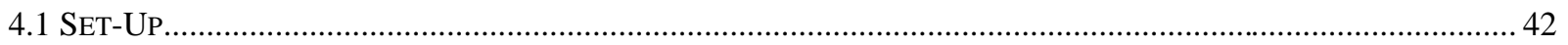

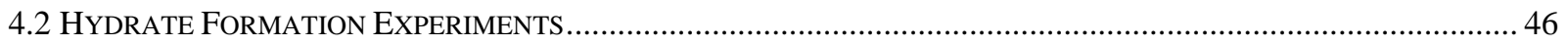

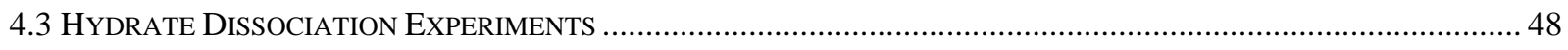

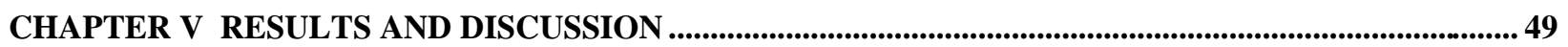

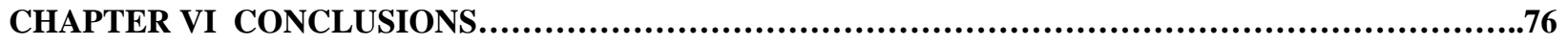

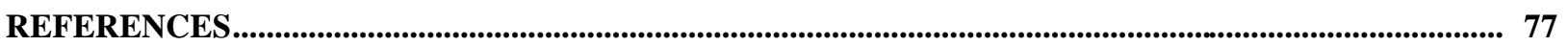




\section{LIST OF FIGURES}

FIGURE 1. LATTICE CRYSTAL STRUCTURE OF METHANE HYDRATE (SI HYRATE) .................................................... 7

FIGURE 2. LATTICE CRYSTAL STRUCTURE OF SII GAS HYDRATES ............................................................................. 8

FigURE 3. PRESSURE - TEMPERATURE PHASE DIAGRAM FOR HETEROGENEOUS STATE OF THE GAS-WATER

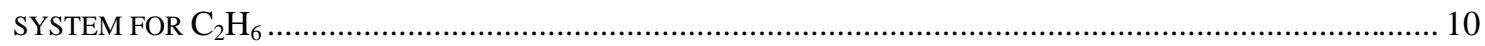

FiguRE 4. PRESSURE - TEMPERATURE PHASE DIAGRAM FOR HETEROGENEOUS STATE OF THE GAS-WATER

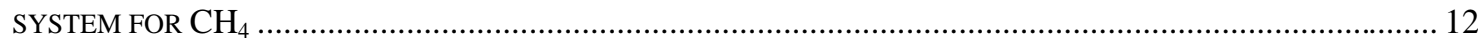

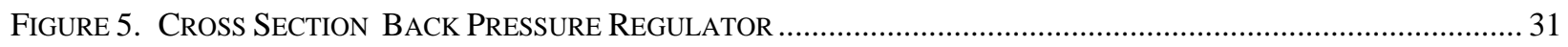

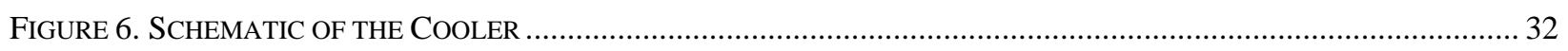

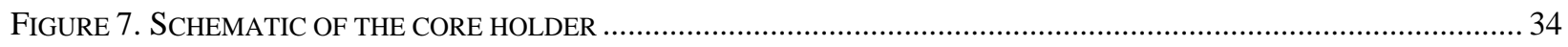

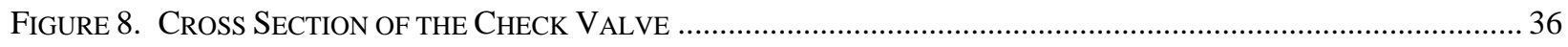

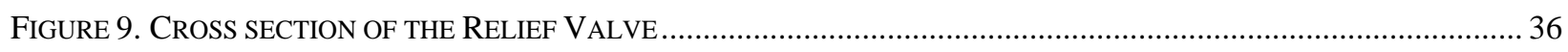

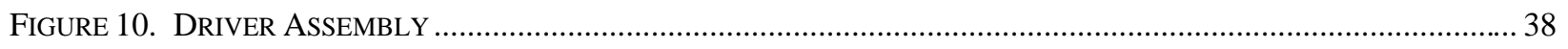

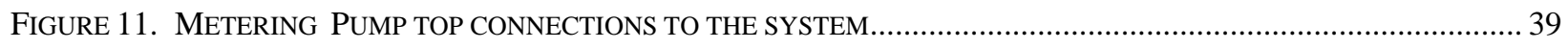

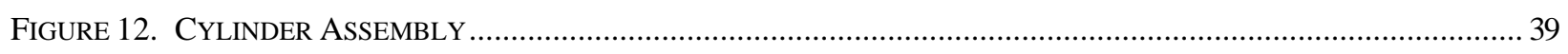

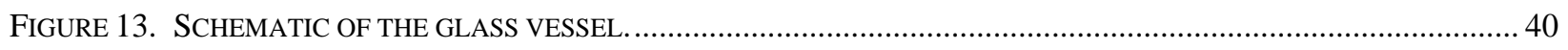

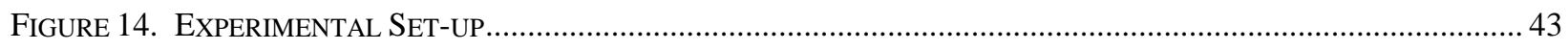

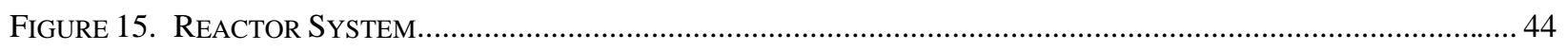

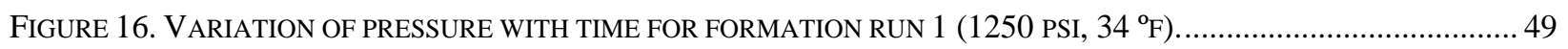

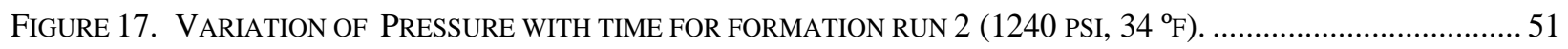

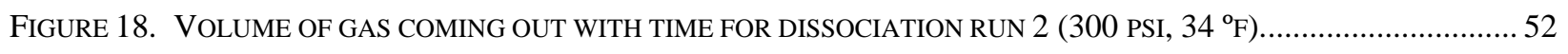

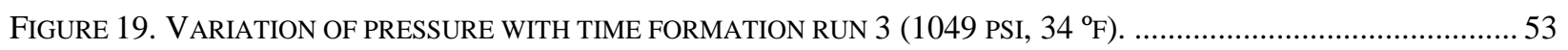

FIGURE 20. VARIATION OF PRESSURE WITH TIME FOR DISSOCIATION RUN 3 (300 PSI, $34^{\circ}$ F) .................................. 55

FIGURE 21. VOLUME OF GAS COMING OUT WITH TIME FOR DISSOCIATION RUN 3 (300 PSI, $34^{\circ} \mathrm{F}$ )............................. 56

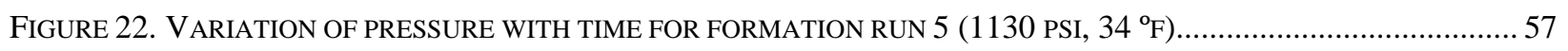

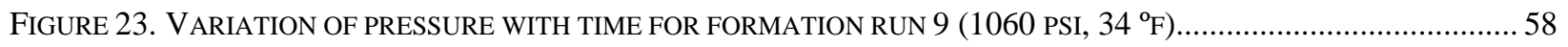


FIGURE 24. VARIATION OF PRESSURE WITH TIME FOR DISSOCIATION RUN 9 (300 PSI, $\left.34^{\circ} \mathrm{F}\right)$.................................... 60

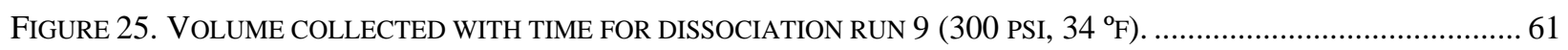

FIGURE 26. PRESSURE VARIATION WITH TIME FOR FORMATION RUN 10 (1080 PSI, $36^{\circ}$ F) ........................................ 62

FIGURE 27. PRESSURE VARIATION WITH TIME FOR DISSOCIATION RUN 10 ( 300 PSI, $36^{\circ}$ F)...................................... 63

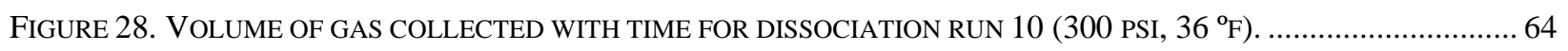

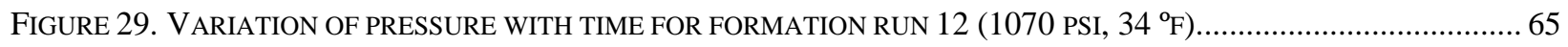

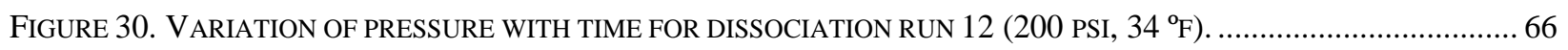

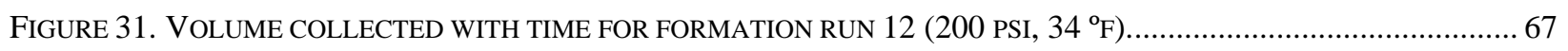

FIGURE 32. PRESSURE VARIATION WITH TIME FOR FORMATION RUN 13 (1100 PSI, $\left.40^{\circ} \mathrm{F}\right) \ldots$

FIGURE 33. PRESSURE VARIATION WITH TIME FOR DISSOCIATION RUN 13 (200 PSI, $40^{\circ}$ F). ......................................... 69

FiguRE 34. VOLUME OF GAS COLLECTED WITH TIME FOR DiSSOCIATION RUN 13 ( 200 PSI, $40^{\circ} \mathrm{F}$ )........................... 70

FigURE 35. PLOT TO CALCULATE THE SPECIFIC RATE CONSTANT ……............................................................... 72 


\section{LIST OF TABLES}

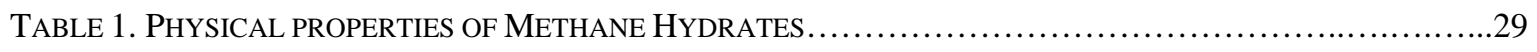

TABLE 2. SPECIFIC RATE CONSTANTS FOR THE FORMATION REACTION ..................................73

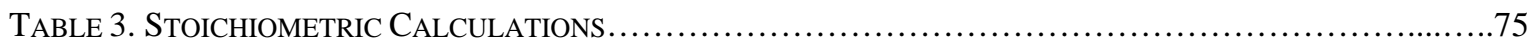




\section{CHAPTER I}

\section{INTRODUCTION}

Gas hydrates are solid meta-stable ice like compounds formed when gas comes in contact with water. They have the ability to form at temperatures well below the ice point. As is believed by most specialists, they were discovered by an English Chemist H. Davy in 1810. On cooling of an aqueous solution saturated with chlorine gas below $9{ }^{\circ} \mathrm{C}$ in a glass retort, Davy obtained a yellow precipitate, which he identified as chlorine hydrate.

The most significant results in hydrate studies were connected to D. Katz and R. Kobayashi. A long time collaboration between the two gave rise to new research techniques and technology for hydrate study and strengthened its theoretical base. These investigators created the school of hydrate researchers on North America.

It was a Russian academician B. A. Nikitin who initiated investigations on hydrate in Europe and first showed that hydrates of individual gases and their mixtures were nonstoichiometric compounds. These compounds represent a crystal lattice built up from hydrogenbonded water molecules, with cages filled by gas molecules bonded with water by the weak Van der Waals forces. This theory was verified by a German physicist, Von Stackelberg, with his collaborators whose X-ray examinations established the existence of hydrates of two structures (Structure I and Structure II).

The existence of natural gas hydrates came into light with the extraction of hydrate saturated cores at the Ust-Viliuisk fields in Yakutiya and at Messoyakhia field in Western Siberia [9]. 
The study of gas hydrates is important because they store an immense amount of energy in the form of natural gas that has not been tapped economically yet. Potential gas resources concentrated on earth in the hydrate state exceed $1.5 \times 10^{16} \mathrm{~m}^{3}$. Hydrate gas is expected to constitute more than $15 \%$ of the world energy in the $21^{\text {st }}$ century.

Gas hydrates are mainly found at ocean depths of at least $300 \mathrm{~m}$. The hydrate layer is then typically 90-900 m below the ocean floor. Hydrates may be found in solid layers, veins, nodules, or as dispersed particles in the ocean floor. Hydrate layers are often several meters thick. Hydrates appear to be found at the edges of many of earth's continents. Gas hydrates have also been found at shallower depths in permafrost.

Several gas hydrate fields noted by USGS expert Keith Kvenvolden are -the Oregon coast -the California coast -the Gulf of Mexico -the coast of Japan -the coast of the Carolinas -the Artic coast of Canada's NW Territories -the Antarctic ice sheet -the West Indies -the Pacific coast of Central America -the permafrost of Alaska -the coast of Norway

The main thrust of this study is to map the pressure changes that occur as gas is produced 
from the hydrate with time and to examine the dissociation characteristics of gas hydrate by measuring the rate at which the gas comes out. Subsequent chapters contain an extensive discussion of these topics. Several researchers have produced gas hydrate in various mediums like crushed ice, optical cells, packed beds silica gel, sandstone but little work has been done on the pressure changes while hydrates dissociate in porous media.

\subsection{Structure of Gas Hydrates}

Gas hydrates have a crystal like structure elucidated by X-ray diffraction experiments. They are solid crystalline compounds formed by the inclusion of small gas molecules (guest molecules) inside the cavities of a host lattice constructed by water molecules. Thus, these are also alternatively referred to as Clathrate Hydrates. Unlike ice where the hydrogen bonded water molecules form the six membered rings, hydrate water molecules arrange into 5-6 membered rings, which in turn form the structural cavities enclathrating the gas molecules. Ice does not have cavities capable of enclathrating gas molecules except helium and hydrogen molecules. In hydrates the hydrogen bond length is about $0.275 \mathrm{~nm}$ which is nearly the same as in plain ice (0.276nm).

The specific skeleton structure formed by the 'host' water molecules strictly depends on the shape and size of the molecules of the gas that is in contact with the water. The degree to which the structure is filled with gas molecules depends on the external pressure and temperature.

Gas hydrates are compounds of a molecular type originating because of the Van der Waals attraction forces between the molecules. Some unique properties of gas hydrates are like, one volume of water enclathrates 207 volumes of methane in gas hydrate, crystallization pressure 
is up to $300-400 \mathrm{MPa}(43500-58000 \mathrm{psi}$ ), the pressure of free gas after dissociation of hydrate of methane in closed volume is up to 80-100 MPa, and a very high electrical resistivity. The specific volume of water in its hydrate state increases by $26-32 \%$ whereas during freezing the increase is just 9\%. Gas hydrates may form in any location where a free gas, water, the appropriate temperature and pressure exist - in space, in the atmospheres of planets, inside the planets and in the technical systems of production, transportation and processing of gases

Hydrates have essentially six different forms as follows :

Molecular sieves, characterized by interconnected trough cavities-passages;

> Channel complexes when hydrate forming molecules form a crystalline lattice with tubular cavities;

Layered complexes forming clathrates with interlaced molecular layers;

$>$ Complexes which form with large molecules having concavities or niches in which an inclusion molecule resides;

$>$ Linear polymeric complexes formed by clathrate molecules, having a tube-like shape;

Clathrates, which form in cases when inclusion molecules fill in the closed cavities close in shape to a sphere.

The specific crystal structure of the gas hydrate depends on the shape and size of the molecules of gas in contact with water. External temperature and pressure decide the degree to which the structure is filled with gas. The water molecules are forced apart by the gas molecules entering the voids. In the hydrate state the specific volume of the water increases to $1.26-1.32$ $\mathrm{cm}^{3} / \mathrm{g}$. The basic structure is a pentagonal dodecahedron consisting of 20 water molecules held together by hydrogen bonds about $2.8 \AA$ in length.

Sizes of dodecahedral cavities formed by water molecules in hydrates is sufficient to 
accommodate the molecules of argon, krypton, xenon, methane and hydrogen sulfide. Dodecahedra are positioned as atoms in diamond like crystals or space centered cubic crystals.

Morphology of clathrate hydrates varies a lot and is determined by the shape of gas molecules, phase state of water and hydrate formers, the medium of hydrate formation, crystallization type, pressure, temperature, conditions of molecular transport the crystal growth surface, degree of the process subcooling, physical fields in which the hydrate crystal formation is taking place etc.

The process of gas hydrate formation comes in stages - from birth of crystallization nuclei through the growth of crystals to critical size. Crystals can be massive and whiskery. Massive crystals grow by surface sorption of gas and water molecules. Whiskery crystals grow by tunnel sorption of gas and water molecules. Formation of the hydrate crystallization nuclei usually happens at the gas-water free interface. Growth of the hydrate crystals in the presence of crystallization nuclei can occur at the gas water interface (surface film hydrate) and in the volume of gas or in the volume of water (volumetric- diffusional or whiskery hydrate growth process).

The surface contact growth of hydrate is characterized by a relatively high rate whose magnitude is determined by the kinetic parameters and the intensity of removal of the heat released during the crystallization. The diffusive flux of the gas and water molecules through the layer of a forming hydrate is also a determining factor, depending on the phase state of the medium where the hydrate crystal growth occurs - at the gas water free interface, in the volume of gas or in the volume of water.

The formation rate of a hydrate at the gas water free interface, where the water and gas molecules are available in excess directly at the surface of the absorptional formation, is the 
highest. The process of formation of crystallization nuclei may happen only at saturation (possibly local) of gas with water vapor or saturation of water with gas. Two cases are then possible : water is in the single phase vapor state and water is in the two phase state - liquid vapor and ice vapor. The process of hydrate growth on the formed nuclei may occur both at water vapor saturation and at incomplete saturation when the water vapor partial pressure is higher in the vapor phase than the partial pressure above the hydrate.

Most commonly encountered hydrates have structures with unit cells of primarily two kinds : structure I and structure II. Structure I is a polyhedra comprising tetradecahedron and dodecahedron cavities. Pentagonal dodecahedra are packed with tetrahedra to form 12 pentagonal and 2 hexagonal faces in hydrates of structure I. Structure I consists unit cells of 46 water molecules which form 2 small (dodecahedra) voids of volume $169 \AA^{3}$ each and 6 large (tetradecahedra) voids of volume $216 \AA^{3}$ each. The smaller voids can encompass gas molecules of size less than $5.2 \AA$ while the larger molecules can hold gas molecules of size less than $5.9 \AA$. With gases like methane and argon, both the large and small voids get filled as their molecular dimensions are less than $5.2 \AA$. The composition of these hydrates is determined by the expression $\mathrm{G} .5 .75 \mathrm{H}_{2} \mathrm{O}$ where $\mathrm{G}$ is one molecule of the gases like methane and argon. Gases like ethane and chlorine only the larger voids get filled as their molecular dimensions are more than $5.2 \AA$. 


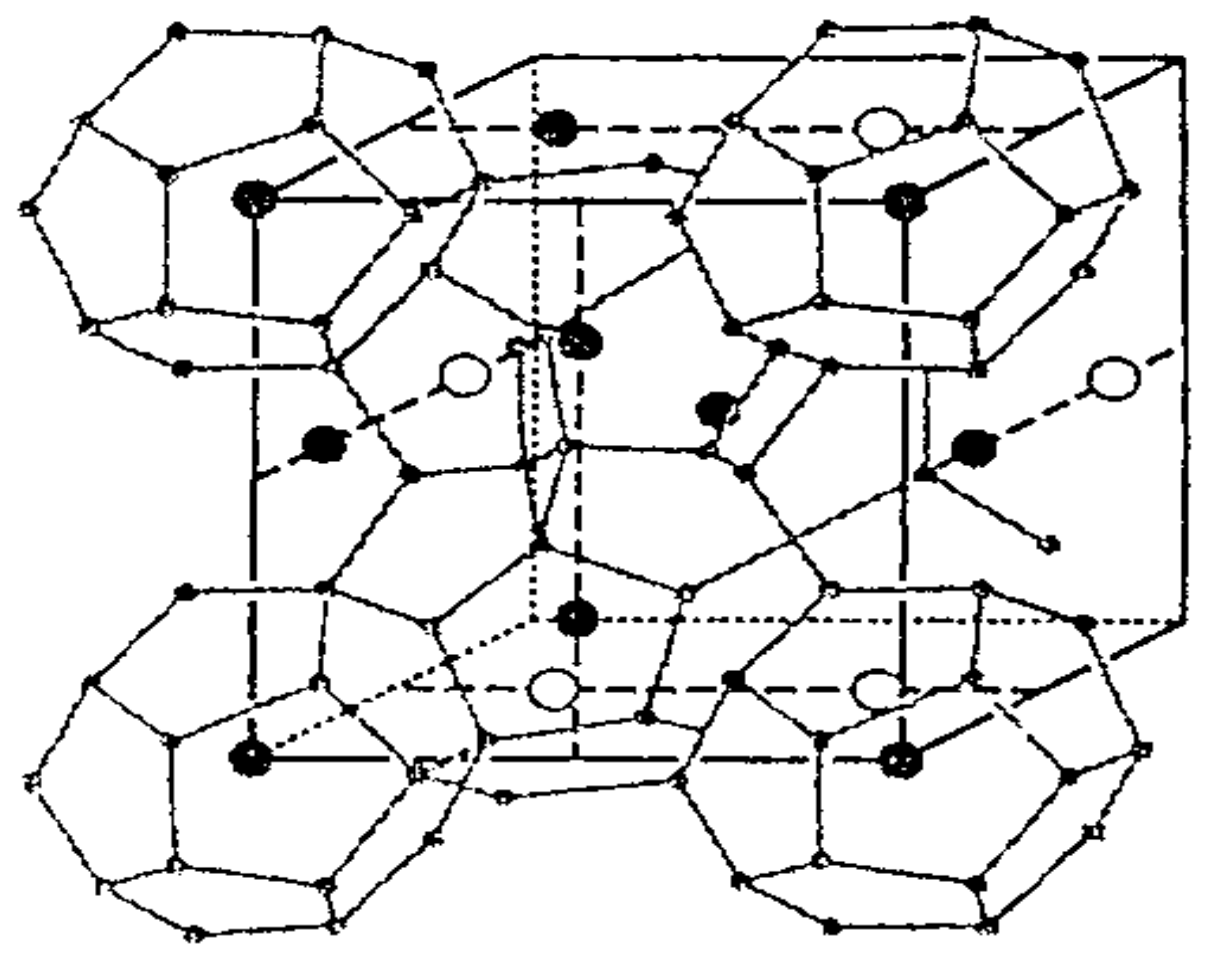

Figure 1. Lattice crystal structure of methane hydrate (sI hyrate).

Structure II is a polyhedra comprising hexadecahedron and dodecahedron cavities.

Pentagonal dodecahedra are packed with hexahedra to form 12 pentagonal and 4 hexagonal faces in hydrates of structure II.

Gases like Propane and isobutane which have molecular dimensions greater than $5.9 \AA$ but less than $6.9 \AA$ form hydrate of structure II. The unit cells of these hydrates consists of 16 small and 8 large voids formed by 136 molecules of water. The small voids are of sizes less than $4.8 \AA$ and the large voids are of sizes less than $6.9 \AA$. The composition of these hydrate 
molecules is represented by the expression $\mathrm{G} \cdot 17 \mathrm{H}_{2} \mathrm{O}$.

Hydrates of gas mixtures are also known to form. The smaller molecules may occupy the smaller voids. The composition of these molecules is represented by the expression G. $2 \mathrm{G}_{1} \cdot 17 \mathrm{H}_{2} \mathrm{O}$. The maximum ratio between the number of water molecules and the molecules of the hydrate forming gas when all the voids are filled is 5.75 in the case of structure I hydrates and 17 in the case of structure II hydrates.

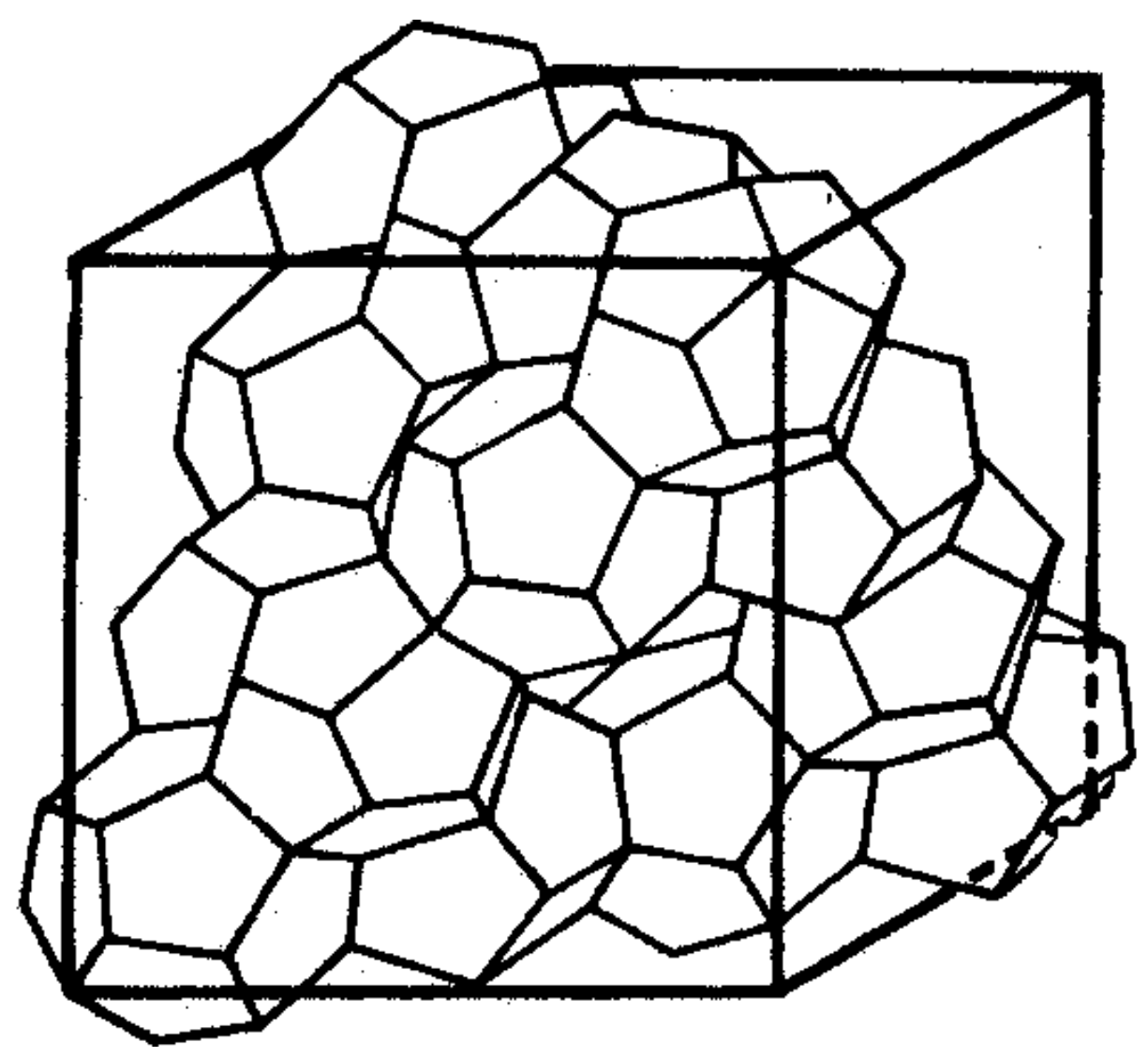

Figure 2. Lattice crystal structure of SII gas hydrates. 


\subsection{Hydrate formation conditions -the idea of Quadrupolar points}

The composition of the gas, the state of the water (ice or liquid water) and the ambient temperature and pressure are the primary factors that influence the beginning of the hydrate formation process. Phase diagrams (P-T graphs) are used to represent the pressure-temperature relationships as the hydrate is formed.

These representations have been obtained for gases like ethane whose critical temperature is greater than the hydrate formation temperature and for those whose critical temperature is less than the freezing point of water and less than hydrate formation temperature like methane.

Curve OFGH represents the relationship between the crystallization temperature of pure water and pressure. Curve AC shows the relationship between the vapor pressure of the hydrate forming gas and the temperature.

In Fig. 3 curve $A B$ determines the conditions of existence of ethane hydrate at $t<0{ }^{\circ} \mathrm{C}$. Here the hydrate is formed from the vapors of ethane and water in the form of ice. Also since the slope for this section of the curve is positive as the temperature is increased for the hydrate to exist the pressure has to increase.

Again in Fig. 3 curve BC defines the conditions under which the hydrate is formed from water and hydrate forming gas, both in the vapor state. Again since the slope is positive for the hydrate to exist as the temperature is increased the pressure has to be increased.

Again in Fig. 3 curve $\mathrm{CdD}$ (note this is above the vapor pressure curve of the gas) are defined as the conditions for the formation of the hydrate from water and hydrate formation gas both in the liquid state. 
Curve $\mathrm{ABCdD}$ is the equilibrium curve of hydrate formation.

The heterogeneous state diagrams of gas water systems in the region corresponding to the existence of hydrates is characterized by the presence of several quadrupolar points.

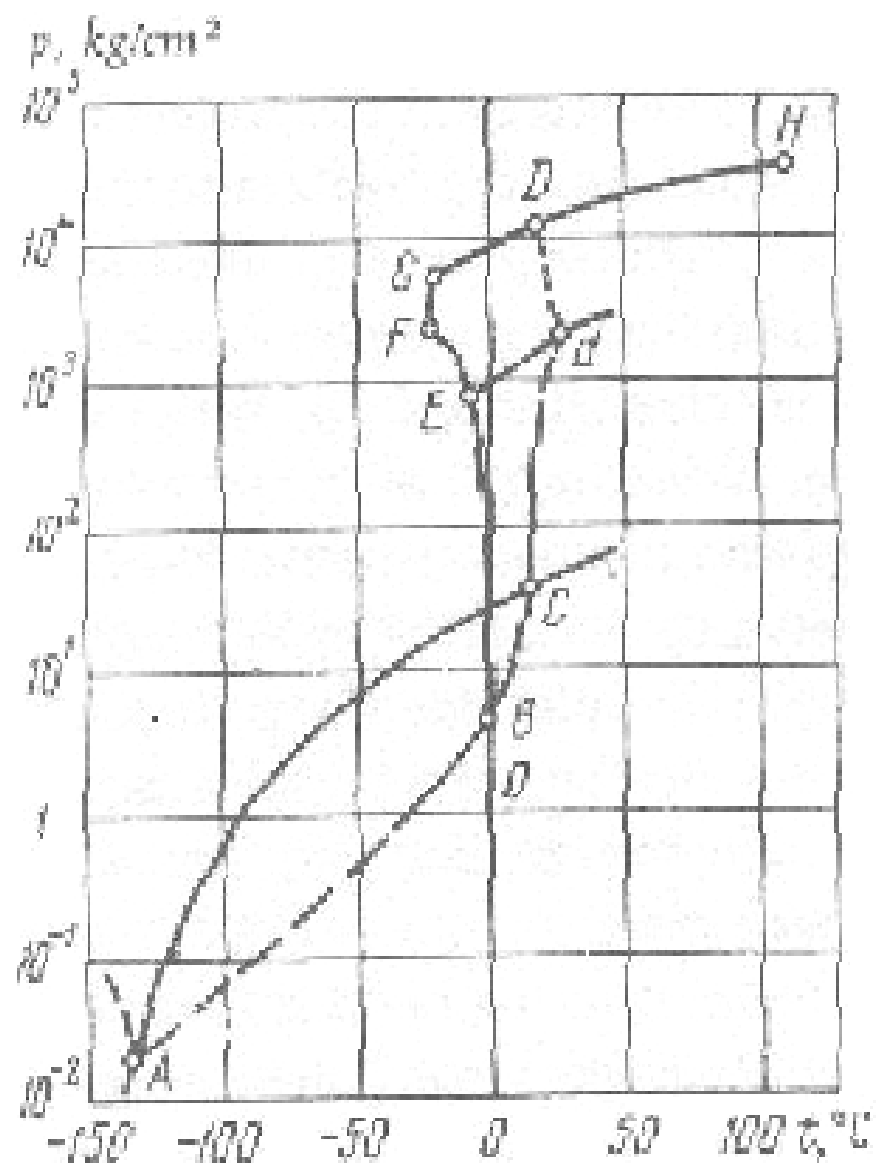

Figure 3. Pressure - temperature phase diagram for heterogeneous state of the gas-water system for $\mathrm{C}_{2} \mathrm{H}_{6}$ gases whose critical temperature is lower than the temperature of hydrate formation. 
For gases whose critical temperature is higher than the hydrate formation temperature (at $\left.t>0{ }^{\circ} \mathrm{C}\right)$ there are four Quadrupolar points. Fig. 3 shows these points A,B,C,D for the gas ethane. Point $\mathrm{A}-$ This is determined by the intersection of vapor pressure curve (AC) of the hydrate-forming gas with the equilibrium curve $(\mathrm{ABCdD})$ of the hydrate formation at $\mathrm{t}>0$ degrees C. At this point Gas G, liquefied Gas G1, Hydrate H and Ice are all in equilibrium.

Point B - This is the second quadrupolar point and is found at the intersection of the hydrate-formation equilibrium curve $(\mathrm{ABC})$ with the curve of the freezing point of water $(\mathrm{OF})$. At this point Gas, Water, Ice and Hydrate are in equilibrium.

Point $\mathrm{C}-$ This is the third quadrupolar point. Its position is determined by the intersection of vapor pressure curve of the hydrate-forming gas (AC) with the hydrate formation equilibrium curve (ABCdD). At point $\mathrm{C}$, Gas, Water, Hydrate and Condensed gas are in equilibrium.

To many researchers point $\mathrm{C}$ is critical as a temperature above which the hydrate cannot form at any pressure. According to these researchers this temperature is $21.5^{\circ} \mathrm{C}$ for methane, $14.5^{\circ} \mathrm{C}$ for ethane, $8.5^{\circ} \mathrm{C}$ for propane and $10{ }^{\circ} \mathrm{C}$ for carbon di oxide. But this data is considered incorrect by many other researchers.

Point D - This is the fourth quadrupolar point. It represents the intersection of the hydrate formation equilibrium curve $(\mathrm{CdD})$ with the curve for the freezing point of water (curve $\mathrm{GH}$ ) under high pressures. At this point Ice, Water, Gas and Hydrate are in equilibrium.

Heterogeneous diagram of the gas-water system for gases whose critical temperature is less than the temperature of freezing point of water (curve OF) is characterized by only three quadrupolar points. Fig. 4 shows these points for the gas methane. Curve AbC expresses the dependence of methane vapor pressure on temperature. Point 'a' corresponds to the pressure and temperature of crystallization for pure methane on a curve of saturation. At point $b$ is the critical 
temperature and pressure for methane. Curve bC is the thermal rise of the methane pressure at Vconstant; OFGH is dependence of the freezing point of water on pressure; and $\mathrm{AB}$ determines the relationship of hydrate formation pressure on temperature at $\mathrm{t}<0{ }^{\circ} \mathrm{C}$. Points $\mathrm{A}$ and $\mathrm{B}$ as in Fig. 3, are quadrupolar.

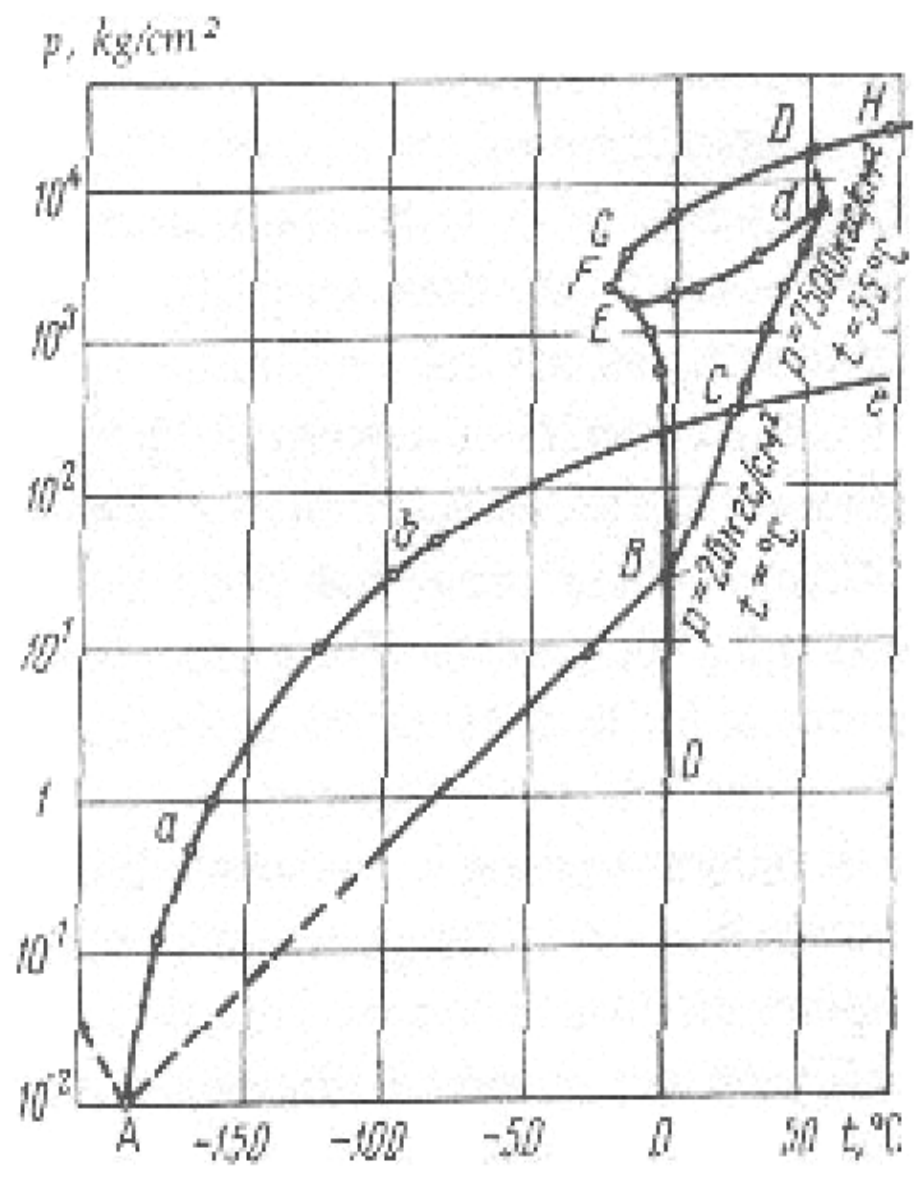

Figure 4. Pressure - temperature phase diagram for heterogeneous state of the gas-water system for $\mathrm{CH}_{4}$ gases whose critical temperature is lower than the temperature of hydrate formation. 


\section{CHAPTER II}

\section{TECHNICAL BACKGROUND AND LITERATURE REVIEW}

Methane hydrate was discovered a few decades ago and little research has been done on

it until recently. By some estimates, the energy locked up in methane hydrate deposits is four to five times the global reserves of all conventional gas, oil, and coal deposits combined. But efforts to recover this gas inexpensively have not been successful and it is not known how much of it is actually recoverable. Since methane is a greenhouse gas, the release of even a small percentage of its deposits could have an adverse effect on Earth's atmosphere.

Several researchers have carried out investigations in the past on the nature and formation of natural gas hydrates, in porous and non-porous media. In the present study Berea sandstone has been used as the medium. This sandstone is extremely sensitive to distilled water, as small percentages of clay present in sandstone swell up when it comes in contact with pure distilled water and this blocks the pores in the core. This in turn prevents the flow of brine and gas through the core. In the present study $1.5 \mathrm{wt} \%$ brine solution is being used for the formation of the hydrate as has also been done by Yousif and Sloan [2] in the work. Presence of brine inhibits the formation of hydrate as was concluded by Englezos and Bishnoi [23] who studied the effect of electrolytes, more specifically brine solutions and alcohols, on the equilibrium formation conditions of gas hydrates.

Additional force $[2,4]$ is required to initiate hydrate formation in the sandstone or any porous medium in general. This force is a result of the interaction of water with the media, 
mainly the capillary force. The effect of the capillary forces is to lower the activity of water in the pore. This in turn causes a depression in the freezing point of water in the pore.

In terms of the solid-solution model, the stability conditions of clathrate hydrates depend directly on the activity of water [4]. As the activity decreases, hydrates form at increasingly higher pressures at a given temperature or at lower temperature at a given pressure. This is observed in systems containing inhibitors which cause a depression in the freezing point of water, thereby reducing its activity. Freezing point of water is also depressed when water is confined to small pores. Therefore, it is equivalent to a change in its activity as caused by inhibitors.

Handa and Stupin [4] presented experimentally determined conditions of methane and propane hydrate equilibrium in $70 \AA$ radius silica gel pores. For both methane and propane it was observed that the presence of the porous silica gel caused hydrates to form at pressures between $20 \%$ to $70 \%$ higher than what are needed to form hydrates on free water. This, they concluded, was essentially because capillary forces between pores and the water have to be overcome for the formation of the hydrate.

The effect of these factors is that the phase-equilibria and the thermodynamic properties of hydrates formed from such water is different from those hydrates formed from bulk water. In the presence of a porous medium a significant portion of the water is present in the form of bound water. This water does not participate in hydrate formation under the same pressuretemperature conditions as the pore water. Naturally occurring hydrates are also be associated with bound and frozen water. Researchers, Yousif and Sloan related the permeability of Berea sandstone, to the additional pressure for the onset of hydrates. 
Researchers have observed that in a porous medium water melts over a wider temperature range due to a distribution of pore sizes and thus a unique hilg point is not defined. From the PT diagram that Handa and Stupin obtained in their study [4], it was seen that while for bulk hydrates there was a distinct change in the slope at the quadruple point representing the hilg equilibria, in the case of pore hydrates this change was gradual.

In this study, reaction between Methane gas and water was carried out in the sandstone. Valuable insight into the formation of gas hydrates was received from the studies of by Lawrence Livermore's William Durham, a geophysicist, who began studying methane hydrate several years ago with Laura Stern and Stephen Kirby [1] of the U.S. Geological Survey in Menlo Park, California. With initial funding from NASA, they looked at the ices on the frigid moons of Saturn and other planets in the outer reaches of our solar system. One of these ices is methane hydrate. This group worked on synthesizing large volume low porosity cohesive polycrystalline clathrate aggregates with a uniform fine grain size and random crystallographic grain orientation.

The samples were produced by the reaction

$$
\mathrm{CH}_{4}+6 \mathrm{H}_{2} \mathrm{O}=\mathrm{CH}_{4} .6 \mathrm{H}_{2} \mathrm{O}
$$

Pressurized methane and water in the form of cold granulated ice was used in for the reaction in a constant volume reaction vessel. Pressurized methane was used to establish the appropriate water to methane gas ratio in the pores. The starting conditions were $25.8 \mathrm{MPa}$ and $265^{\circ} \mathrm{K}$ (as apparent from the graph on the paper). The temperature was then increased. This caused a linear increase in pressure due to thermal expansion of $\mathrm{CH}_{4}$ in the reaction vessel and reservoir. At $271.5^{\circ} \mathrm{K}$ and $27.3 \mathrm{MPa}$ the clathrate forming reaction was seen to start. This caused 
a deviation as the rate of pressure increase decreased as the reaction consumed much of the vapor phase.

The extent of the reaction was determined by this deflection of the P-T curve. The complete reaction produced a pressure drop of $1.8 \mathrm{MPa}$. The rate of the reaction decreased at about $0.5 \Delta \mathrm{P}$. For complete reaction continued heating was done till a temperature of $289^{\circ} \mathrm{K}$ and the system was pressurized to about 29.4 MPa. Also the complete reaction took about 7-8 hrs after a temperature of $271.5^{\circ} \mathrm{K}$ was reached.

X-ray diffraction measurements showed that the samples were pure methane clathrate with traces of $\mathrm{H}_{2} \mathrm{O}$ ice. This was also consistent with the calculated molar volume reduction of the reaction and with the lack of a measurable P-T anomaly associated with freezing of unreacted liquid $\mathrm{H}_{2} \mathrm{O}$. The resultant samples were translucent, white, cohesive aggregates with uniform fine grains of 200-350 $\mu \mathrm{m}$.

Physical characteristics like permeability, porosity and pore size distribution, govern the distribution of the hydrate in the core, upon its formation. Pore size distribution measurements are done by a method called the mercury porosimetry. It is easier for the hydrate to form in larger pores as opposed to smaller pores as the surface tension and capillary forces that act on the water in the pores are greater in smaller pores. It is also more difficult for water to get inside smaller pores as opposed to larger pores, so there is lesser of one of the reactants, water, available for reaction with the gas.

Researchers have also found that as gas enters a porous medium with water already present, the 'fingering effect' takes place, wherein more gas accumulates at the begin of the sandstone and less towards the end.

Monitoring pressure changes during the formation of gas hydrates is crucial. As the 
hydrates form, the pressure in the medium decreases. When the hydrate formation reaction is completed this decrease in pressure stops. Often pressure drops along the core are seen due to non-uniform formation. Annealing cycles are conducted to eliminate these pressure drops as was also done by researchers Yousif and Sloan in their study wherein they carried out elaborate experiments on hydrate formation and dissociation in a porous media [2]. Their paper discusses the formation of gas hydrates in Berea Sandstone cores, the medium being used in this research too. A detailed analysis of this paper is presented below.

The apparatus used for the experiments consisted of a core enclosed with heat-shrink plastic tubing and contained within a stainless-steel pressure sample bomb. An external pressure of $1 \mathrm{MPa}(145 \mathrm{psi})$ greater than that within the core was maintained on the outside of the heatshrink tubing with a manual hydraulic pump. The electrical resistance was measured with four pairs of electrodes implanted at equal distances along the core length under the heat-shrink tubing. Electrical resistances were also used to check for both the amount and uniformity of hydrate formation.

The core sample was initially evacuated and saturated with $1.5 \% \mathrm{NaCl}$ solution. Then gas injection was begun at the experimental pressure of 7 to $8 \mathrm{MPa}(1015-1160 \mathrm{psi})$ and a temperature of $273.7^{\circ} \mathrm{K}$. The volumes of gas and water coming out from the other end of the core (the produced water and gas volumes) during the saturation process were closely monitored during this step. The outlet valve was then closed and the gas injection was maintained during the hydrate formation, and when no more gas uptake was possible the inlet valve was closed too.

The bath temperature was maintained at $273.7^{\circ} \mathrm{K}$ to allow hydrate formation to continue at a pressure always in excess of the equilibrium value for a period of 4 to $34 \mathrm{hrs}$. When no change in the pressure and electrical resistance with time was observed, the hydrate formation 
was assumed to have ceased.

In the low permeability cores a pressure drop of up to $2.8 \mathrm{MPa}$ (400 psi) across the core was detected after the hydrate was formed. Annealing process cycles were used to eliminate this pressure drop and to ensure more uniform hydrate distribution along the core. In the annealing process, the hydrate was dissociated and reformed by cycles of heating (to $279.9^{\circ} \mathrm{K}$ ) and cooling (to $273.7^{\circ} \mathrm{K}$ ) the core.

The authors conducted experiments with three different Berea sandstone core samples of the same length and diameter, but different porosity and permeability. It was observed that in the low permeability cores insufficient gas/water contact reduced the amount of hydrate formed and the hydrate crystals easily plugged the small capillaries. This caused non-uniform hydrate distribution along the core.

The electrical resistances as monitored by the first two electrodes placed closer to the inlet on the core increased sharply during the annealing process (when the temperature was returned to $273.7^{\circ} \mathrm{K}$ ), indicating that the hydrates were formed mainly in the inlet half of the core. Also after the second annealing cycle the pressure drop fell to $0.3 \mathrm{MPa}$.

After three to four annealing cycles the pressure drop was eliminated and the electrical resistance plot in the paper shows a more uniformly distributed hydrates along the core sample. This was seen 2300 minutes after gas was injected. The first annealing cycle was started 1300 minutes after gas injection. As observed, annealing increased the number of moles of gas converted into hydrate.

In this study pressure variations along the core have been monitored and for this purpose pressure transducers were installed along the core. Monitoring these changes during formation and dissociation provides useful insight into the possible pore size distribution in the core. 
Yousif, Selim and Sloan [3] carried out experiments to form hydrates in a Berea Sandstone core and to measure the dissociation rate of such hydrates using electrical resistivity measurements, to monitor the position of the hydrate front.

In the set up in this case the sandstone was enclosed in a heat shrunk plastic tube and contained within a stainless pressure bomb. An external pressure of at least $0.35 \mathrm{MPa}$ greater than that within the core was maintained on the outside of the heat-shrink tubing with a manual hydraulic pump. Four pair of electrodes were implanted, under the heat-shrink tubing, along the length of the core in order to track the location of the hydrate dissociation front. A high frequency $(1000 \mathrm{~Hz})$ current was used and the voltage drop was measured across four known resistors, each connected in series with the core electrodes. The resistance across each electrode was determined by the equation :

$$
\operatorname{Re}=\operatorname{Rr}(\mathrm{Vg} / \mathrm{Vr}-1)
$$

where $\mathrm{Re}=$ electrical resistance of the electrode $\mathrm{I}, \mathrm{Rr}=$ reference resistor $\mathrm{I} ; \mathrm{Vg}=$ voltage drop across the function generator and $\mathrm{Vr}=$ voltage drop across the reference resistor.

An ISCO metering pump model 314 was used to inject water into the system. These pumps can inject water or brine against a pressure of up to 2500 psig and were used in this study too. The injection rate of $80 \times 10^{-6} \mathrm{~m}^{3} / \mathrm{hr}$ was normally used. The temperature of the system was maintained at $273.7^{\circ} \mathrm{K}$ in a bath with a fluid mixture of 50 mass percent ethylene glycol-water.

The measurements made were those of resistance along the core, inlet- outlet pressures as well as the volumes of injected and produced fluids all as a function of time. Pressures were determined by 0-10 MPa Omega transducers. The volume was determined by water 
displacement into a graduated cylinder, with readings obtained every minute.

In the experiment the formation of hydrates was indicated by a large pressure drop across the cell as the hydrates caused flow restrictions and during this period the gas and water volumes injected and produced were closely monitored. After this the inlet and the outlet valve were closed for $24-30 \mathrm{hrs}$. When the pressure no longer decreased with time the hydrates were assumed to have been completely formed.

Hydrate dissociation experiments were carried out too at $273.7^{\circ} \mathrm{K}$ and at constant outlet pressures of 1.47 $\mathrm{MPa}$ and 2.5 $\mathrm{MPa}$. The inlet pressure, the gas volume and the resistance changes along the core length were the primary variables measured with time upon hydrate dissociation.

During the experiment, hydrates started forming and plugging the pores and the inlet and the outlet valves were then closed. It was observed the lower permeability core required 20-30 hrs to complete the formation process and the high permeability core required only 4-5 hrs for formation. Also there was less plugging of the hydrate in the high permeability core. It was also observed that in the low permeability core the hydrates were formed rapidly at the inlet and the gas passageway was effectively blocked, preventing the outlet pressure from equilibrating with the inlet pressure.

It was seen by the authors that in the high permeability core, hydrate plugging took place close to the outlet as initially the outlet pressure decreased rapidly. Later, due to the large pressure gradient this plugging was removed.

Quadruple points in these systems can be interpreted as the temperature at which the smaller pores have either hlg or $\lg$ phases only, while the larger pores still have hlg phases. According to this paper the heats of dissociation of gas hydrates can be obtained by analyzing the 
phase equilibrium results in terms of the Claussius-Clayepron equation

$$
\operatorname{dln} \mathrm{f} / \mathrm{d}(1 / \mathrm{T})=-\Delta \mathrm{H} / \mathrm{R}
$$

where $\mathrm{R}$ is the gas constant, $\mathrm{T}$ is the temperature, $\mathrm{f}$ is the fugacity.

Calculations related to the hydrate number have been done in this study along with calculations related to the amount of gas released during the dissociation reaction. Yousif and Sloan calculated this hydrate number ' $n$ ' for the pore hydrate in their study too. The amount of gas given off by the pore hydrates was determined from p-v-t measurements on the gas phase, applying appropriate corrections for non ideality of the gas and subtracting from this amount the small contribution from the bulk hydrate. A value of 5.94 was obtained for the pore hydrate and a value of 6.00 was obtained for the bulk hydrate.

This experiment was conducted to simulate the conditions under the which the naturally occurring hydrates are brought up from the bottom of the ocean to shipboard. The results clearly indicated that the thermodynamic properties of hydrates are dominated by those of water.

As gas is inserted in the core saturated with brine, some amount of brine is pushed out of the core. Thus the amount of brine available for the reaction is what is referred to as the residual brine saturation. Relative permeability effects alter significantly permeability measurements. Relative permeability is the permeability of a fluid through a medium, when the medium is saturated with another fluid.

Pressure profiles along the core were measured as the hydrate dissociated. Dissociation for hydrate formation in porous media depend on the wetting angle and pore radius. Also while dissociation slugging was seen in this study. There were instances when the velocity of gas being produced was insignificant. This was probably because as hydrates dissociated, the water thus produced prevented some gas from com out of the core and thus the flow-rate was seen to be 
negligible.

Kim, Bishnoi et al. [8] studied the kinetics of methane hydrate decomposition. The kinetics of decomposition were investigated by isothermally reducing the pressure above hydrate slurries in water to values below the equilibrium pressures in a stirred tank semi batch reactor. The kinetic data were obtained by maintaining isothermal isobaric conditions in the reactor after the pressure reduction. The experiments were conducted at temperatures from $274{ }^{\circ} \mathrm{K}$ to $283{ }^{\circ} \mathrm{K}$ over a pressure range from 0.17 to $6.97 \mathrm{MPa}$. The reactor was charged with $300 \mathrm{~cm}^{3}$ of water and the hydrates were formed at a pressure above the three phase equilibrium pressure. The reactor was depressurized to a pressure of about $0.05 \mathrm{MPa}$ above the equilibrium pressure. The depressurization was done by bleeding the gas to the atmosphere.

The decomposition reaction was initiated by further depressurizing the reactor from the initial pressure to the decomposition pressure. The pressure of the reactor was maintained at the decomposition pressure and the methane gas produced due to the decomposition was collected in the receiver. The hydrate decomposition rate was obtained by calculating the rate of accumulation of methane in the receiver at the constant reactor pressure much below the equilibrium pressure.

The moles of gas entering and leaving these receivers was calculated from the changing pressure. The moles of methane used for formation of the hydrates during an experiment are given by

$$
\text { moles of methane used }=\frac{\mathrm{V}}{\mathrm{R}}\left[\left(\frac{\mathrm{P}}{\mathrm{ZRT}}\right)_{\mathrm{i}}-\left(\frac{\mathrm{P}}{\mathrm{ZRT}}\right)_{\mathrm{f}}\right]
$$


where $i$ and $f$ are the initial and final conditions of the gas in the reservoir.

During the decomposition of the hydrates in an experiment the pressure and temperature of the gas in the receiver were recorded at suitable time intervals. The moles of methane gas at time $t$ in the receiver were calculated from the following equation,

$$
m(t)=\frac{P V o}{R Z T}
$$

where Vo is the volume of the receiver.

Since the reactor pressure was maintained constant during the decomposition, the moles of methane present in the hydrates, $\mathrm{n}_{\mathrm{H}}$ at time $\mathrm{t}$ are given by,

$$
\begin{aligned}
& \mathrm{n}_{\mathrm{H}}=\mathrm{n}_{\mathrm{O}}-\mathrm{m}(\mathrm{t})+\mathrm{m}(0) \\
& \frac{n_{H}}{n_{o}}=1-\frac{m(t)-m(0)}{n_{o}} \\
& \text { where, } \mathrm{m}(0)=\mathrm{m}(\mathrm{t}) \text { at } \mathrm{t}=0 .
\end{aligned}
$$

The decomposition of solid hydrates is an endothermic process that gives gaseous methane and liquid water as products. The overall process of hydrate decomposition apparently involves the process of the clathrate host lattice dissociating at the surface of a particle and the desorption of the guest molecule (methane) from the surface. These steps occur at the solid surface and not within the bulk of the solid. As the decomposition progresses the particle shrinks and methane gas is generated at the solid surface. The generated gas then enters the bulk gas 
phase. The molar rate at which methane is released from the hydrate is $\left(-\mathrm{dn}_{\mathrm{H}} / \mathrm{dt}\right)$ where $\mathrm{nH}$ is the total moles of methane contained in the hydrate particles.

An assumption made is that the rate of hydrate decomposition is proportional to the combined surface area of the decomposing particles $\mathrm{A}_{\mathrm{s}}$. It is also reasonable to assume that the decomposition rate is proportional to a driving force that exists because the pressure is below the three phase equilibrium pressure at the particle temperature

It is proposed in this paper that this driving force is the same as the difference between the fugacity of methane at the three phase equilibrium pressure fe and the fugacity of methane at the solid surface. It was assumed that the fugacity of methane at the solid surface is equal to the fugacity of methane at the bulk phase f.

The rate of decomposition is

$$
-\frac{d n_{H}}{d t}=K_{d} A_{s}\left(f_{e}-f\right)
$$

on substituting pressure for fugacity, and integrating,

$$
\frac{\mathrm{nH}}{\mathrm{no}}=\left[1-\frac{\mathrm{kt}}{3}\right]^{3}
$$

During the decomposition experiment, the gas produced was collected using a water displacement method. In this method the gas produced is released against a variable hydrostatic head, but is a full proof method of collecting all the gas that might be produced.

Decomposition data obtained from this study can be used for modeling gas behaviour during dissociation. Studies have been conducted to predict conditions of hydrate formation. Some of the most noteworthy work has been done by Clarke, Darvish and Bishnoi [6]. 
For three phase vapor-liquid-hydrate equilibria the basic equations for the equilibrium conditions in gas hydrates used by these authors were

$$
\begin{aligned}
& \mu_{\mathrm{i}}^{\mathrm{L}}=\mu_{\mathrm{i}}^{\mathrm{V}}(\mathrm{i}=1, \mathrm{~N}) \\
& \mu_{\mathrm{i}}^{\mathrm{H}}=\mu_{\mathrm{i}}^{\mathrm{V}}(\mathrm{i}=1, \mathrm{NH})
\end{aligned}
$$

where $\mathrm{N}=$ total number of components and $\mathrm{NH}=$ number of hydrate forming components. The fugacity or chemical potential of a component in the vapor or liquid phase may be calculated using a suitable equation of state. Trebble- Bishnoi equation of state was used in this paper. Van der Waals and Platteeuw gave a model for the calculation of the chemical potential of water in the hydrate phase. The model is given by

$$
\mu H w=\mu w M T-R T f \sum v m \ln \left(1+\sum C m f j\right)
$$

where $\mathrm{fj}$ is the fugacity of the hydrate former $\mathrm{j}$ other than water, in the hydrate phase. The isofugacity criteria for a hydrate former in the vapor phase and in the hydrate phase as in 2.12 are usually incorporated by taking the fugacity in the 2.13 as being that calculated from the equation of state for the vapor phase.

When hydrates are formed in free liquid water or free ice, then it is possible to neglect the surface effects on the equilibrium conditions. But when hydrates are forming in small capillaries it is not possible to neglect the surface effect on the equilibrium conditions. When the surface 
effects are not neglected, the differential of the gibbs free energy becomes

$$
d G=-S d T+V d P+\sigma d A_{s}+\sum \mu d n_{i}
$$

where $\sigma$ is the surface energy per unit area.

The major implication of Equation 2.14 is that at equilibrium the pressure in the liquid phase will not be equal to that in the vapor phase.

The gradual change in slope of the experimental data was observed in their plot which is due to the fact that in porous materials water melts over a temperature range rather than at a definite point. This is again due to pore size distribution. An implication of melting in the porous medium is that the quadruple point the point at which ice, liquid water, hydrate and vapor are in equilibrium is no longer a unique point. According to Handa and Stupin [4] the melting temperature in the average pore size was taken to be $267.5^{\circ} \mathrm{K}$. According to Yousif and Sloan [2] the additional pressure of approximately $78 \mathrm{kPa}$ was required to form methane hydrates in the sandstone at $273{ }^{\circ} \mathrm{K}$. Also as the pore size falls the additional pressure above equilibrium pressure increases.

Y Makagon and E. D Sloan studied the phase equilibrium of methane hydrate in the temperature range $190{ }^{\circ} \mathrm{K}$ and $262^{\circ} \mathrm{K}$ [5]. Their results complemented partial data sets from other laboratories and provided new results in the region $193{ }^{\circ} \mathrm{K}-260{ }^{\circ} \mathrm{K}$. From the data it was concluded that methane hydrate of structure I does not undergo a phase transition to structure II as proposed by some studies. According to this paper the van der Waals and Platteeuw statistical thermodynamics model is most frequently used in fitting and in predicting the equilibrium conditions of hydrate formation.

Some enthusiastic researchers have produced gas hydrate in other porous mediums like 
porous gas. The purpose of their study [7], was to estimate was to estimate qualitatively the effect of confined pores on methane hydrate dissociation. Methane hydrates were formed in confined small pores of porous glass, whose average diameters ranged from 100 to $500 \AA$. In this paper there is also mention of the Bottom Simulating Reflector and BGHS zone. Using the observations of the bottom simulating reflector (BSR) and the comparison of P-T conditions in sediments with the equilibrium conditions of the methane hydrate obtained through laboratory works the equilibrium conditions of natural gas hydrates can be estimated.

These are important for estimating the total number of gas hydrate fields, locating the bottom of the gas hydrate stability zone (BGHS) and establishing the formation/dissociation rates of gas hydrates. It has been seen that most of the BSR observations in oceanic gas hydrates coincide well with the estimated BGHS. The ocean drilling project (ODP) Leg 164, which was operated at the Blake Ridge in 1995 was instrumental in carrying out some precise investigations on of the location. The investigation found a large difference between the location of the BSR and BGHS. The depth of BGHS was 40-100 m shallower than that of BSR. This was essentially due to the existence of sediments.

Porous silica glass, also called Vycor glass was used in this experiment by the authors. The sample was dried and prepared only to fill the distilled de-ionized water in the particle pores. This was done by placing some amount of dry powder in the container and then pouring water equal to the total pore volume. The mixture was then pressurized for $24 \mathrm{hrs}$ to ensure that the pores are completely filled with water. The equilibrium temperature profiles for methane hydrates were then determined. Before the hydrate formation the air in the high pressure vessel was evacuated and an appropriate amount of methane gas was introduced such that upon completion of the reaction there was enough gas left over to stabilize the hydrate. Upon hydrate 
formation, the pressure gradually decreased to the equilibrium value at the set temperature. The reaction usually took 3 to 5 days for completion. From the phase equilibrium measurements it was seen that each equilibrium line shifts to a lower temperature or higher pressure compared with the bulk hydrate. The pore diameter decides the relative decrease in the dissociation temperature. The smaller the pore diameter the larger is the shift.

The apparatus used to control gas flow consisted of a gas tank, flow regulator, and a set of quarter turn valves which were actuated hydraulically by the vehicle. Release of gas into acrylic reaction cylinders $(60 \mathrm{~cm} \times 4.5 \mathrm{~cm})$ produced almost instant crystallization of a hydrate mass. The rapidity of the reaction in this natural system is both remarkable, for both experimental and theoretical studies in the laboratory have shown very slow reaction rates, and is important for understanding the formation of hydrates in nature. Injection of gas into a column of coarse sand quickly flooded the pore space with hydrate, and turned it into a solid block of clathrate "ice".

As of now efficient techniques of hydrate extraction are not developed. The USGS and Japanese geologists have successfully negotiated to allow Japan to drill two prototype wells in Alaska during 1998. Several other nations are independently exploring hydrate exploration and extraction. Conventional gas deposits are still more accessible compared to gas hydrates for the United States, which still has significant reserves of natural gas. Japan relies heavily on importing natural gas, paying much more for energy from gas. Gas hydrates may therefore become an economical local source of energy for countries such as Japan. 
Table 1 below shows the physical properties of the hydrate.

Table 1 : Summary of Published Values for Properties of Ice and Pure Gas Hydrates (modified from Davidson, 1983). [15]

\begin{tabular}{|c|c|c|}
\hline Property & Ice & Hydrate \\
\hline Dielectric constant at 273 šK & 94 & $=58$ \\
\hline NMR rigid lattice 2 nd moment of $\mathrm{H}_{2} \mathrm{O}$ protons $\left(\mathrm{G}^{2}\right)$ & 32 & $33 \pm 2$ \\
\hline Water molecule reorientation time at 273 šK ( $\mu$ sec) & 21 & $=10$ \\
\hline Diffusional jump time of water molecules at 273 šK ( $\mu$ sec) & 2.7 & $>200$ \\
\hline Isothermal Young's modulus at 268 šK $\left(10^{9} \mathbf{P a}\right)$ & 9.5 & $=8.4$ \\
\hline $\begin{array}{c}\text { Speed of longitudinal sound at } 273 \text { šK } \\
\text { _velocity }(\mathrm{km} / \mathrm{sec}) \\
\text { _transit time }(\mu \mathrm{sec} / \mathrm{ft})\end{array}$ & $\begin{array}{l}3.8 \\
80\end{array}$ & $\begin{array}{l}3.3 \\
92\end{array}$ \\
\hline Velocity ratio Vp/Vs at 272 šK & 1.88 & 1.95 \\
\hline Poisson's ratio & $\mathbf{0 . 3 3}$ & $=0.33$ \\
\hline Bulk modulus (272 šK) & 8.8 & 5.6 \\
\hline Shear modulus (272 šK) & 3.9 & 2.4 \\
\hline Bulk density $\left(\mathrm{gm} / \mathrm{cm}^{3}\right)$ & 0.916 & 0.912 \\
\hline Adiabatic bulk compressibility at 273 šK $10^{-11} \mathrm{~Pa}$ & 12 & $=14$ \\
\hline Thermal conductivity at 263 šK (W/m-K) & 2.23 & $0.49 \pm 0.02$ \\
\hline & & \\
\hline
\end{tabular}




\section{CHAPTER III}

\section{EQUIPMENT AND MATERIALS}

\subsection{Gas Cylinders}

Cylinders for methane and nitrogen gases were obtained from West Virginia Gas Welding Company and contained gas at pressure of approximately 2200 psi. Nitrogen has been used to purge the system, test the system for leaks and to pressure test the core holder. Methane of $99 \%$ purity has been used for the formation of gas hydrate in this study. Gas regulators for the gases of methane and nitrogen have been obtained from British Oxygen Company (BOC) gases and installed on the cylinders. They are graduated for the pressure range of 0-4000 psi inlet and 0-2000 psi outlet. Valves on these regulators aid in controlling the pressure of the gas that enters the system. Two dials on these regulators indicate the pressure inside the cylinder and the pressure of the gas entering the system. There are relief valves built in these regulators to prevent excess pressure from building up in the system.

\subsection{Back Pressure Regulators}

These have been obtained from Go Regulators Inc. These help ensure that the pressure drop across the mass flow meter did not exceed 50 psi. They are also used in controlling the back pressure to the required constant pressure when conducting gas hydrate dissociation experiments. The back pressure for the pressure regulator is set using nitrogen. These have a diaphragm which rises against a spring to release excess pressure. 


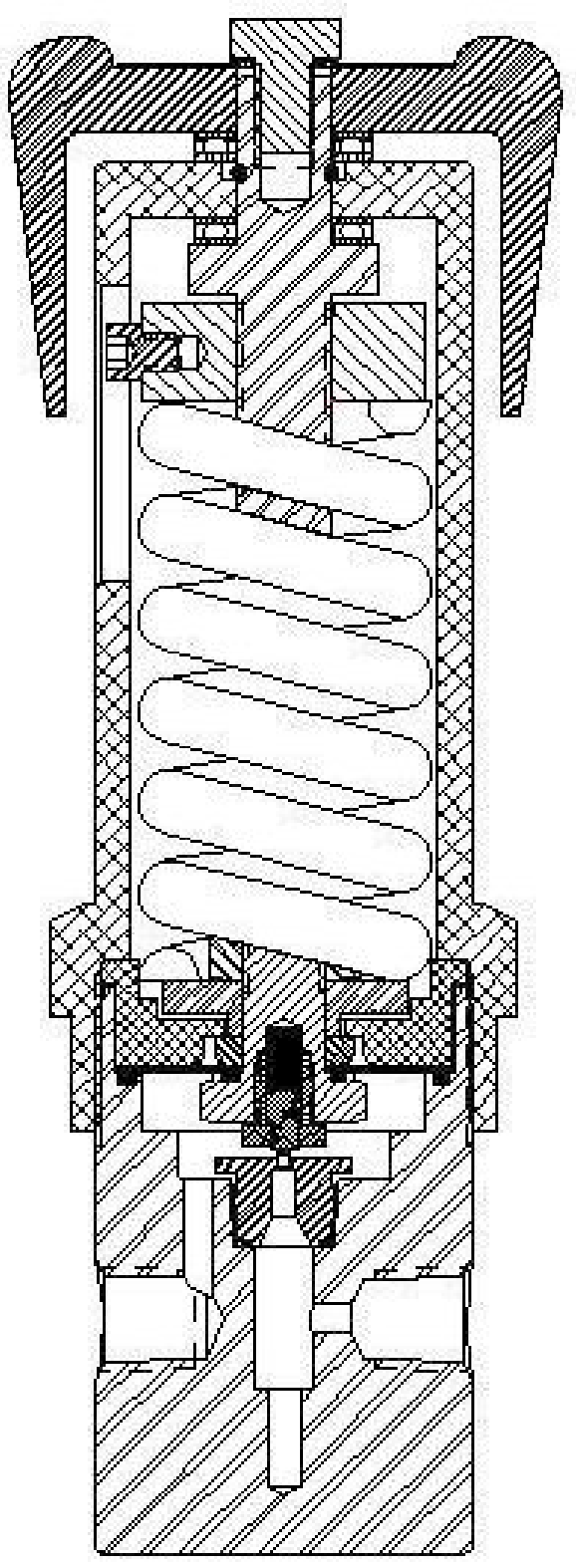

Figure 5. Cross section back pressure regulator. 


\subsection{Coleman Cooler}

This was designed to hold temperatures down to $-40{ }^{\circ} \mathrm{C}$ for the duration of the experiment of about 4 days. Holes were drilled at appropriate points to facilitate the measurement of pressures at five points along the core, for inserting the stirrer and for allowing the chiller tubes to enter the bath.

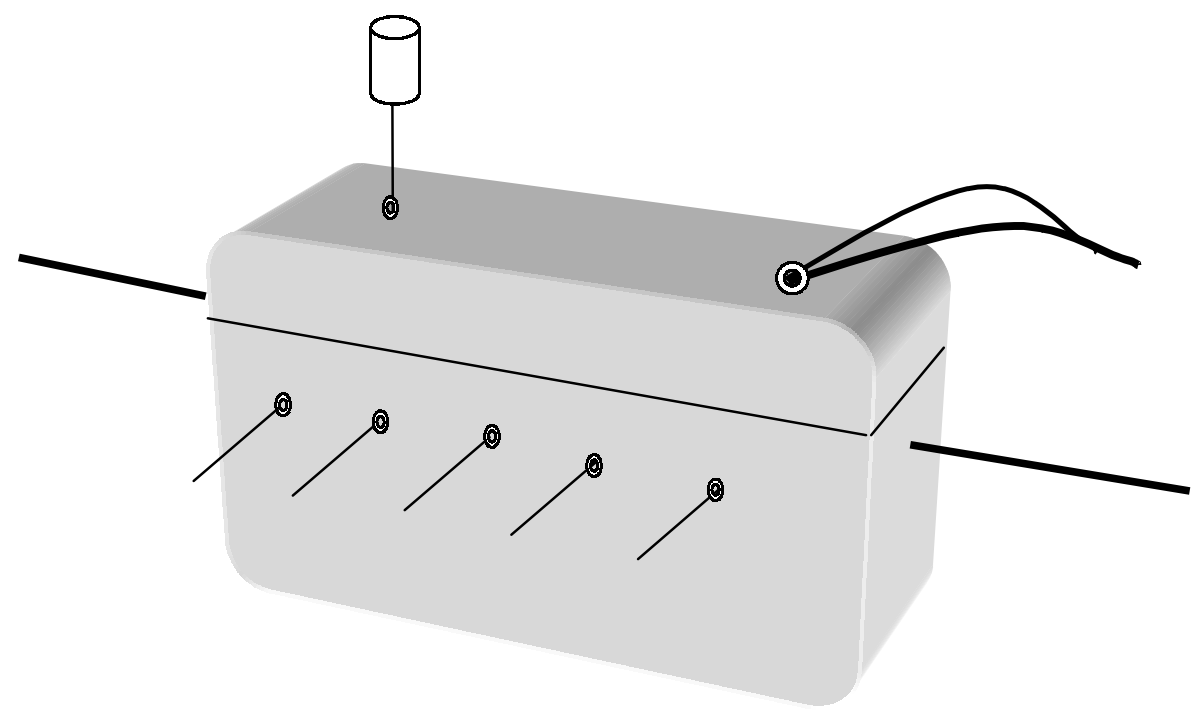

Figure 6. Schematic of the cooler.

\subsection{Berea Sandstone Core}

This was the porous medium in which the hydrates were produced. It is similar in texture to the sediments found in the ocean floor. The permeability and porosity were measured to get a better insight into the flow characteristics of gas and brine through the core. 


\subsection{Core Holder}

This was fabricated in collaboration with National Energy Technology Laboratory, Morgantown. The steel pipe which forms the body of reactor is a 3" schedule 80 pipe and was obtained from McJunkin. A rubber Hassler Sleev was procured from Temco and this houses the sandstone while allowing monitoring of pressures at five points along the core. The end caps have o-rings to prevent any leaks. There are metal distributors on either side of the sandstone to facilitate distribution of the brine and gas uniformly along the cross-section of the core. Metal blocks on either sides of the sandstone keep the sandstone in place. Five holes along the length of the steel pipe assist in measuring the pressures along the core. On the diametrically opposite side two additional holes aid in injecting ethylene glycol in the jacket and keeping it pressurized to a pressure higher than that inside the core due to the presence of gas and brine. Teflon tape is used with these fittings to prevent any leaks. 


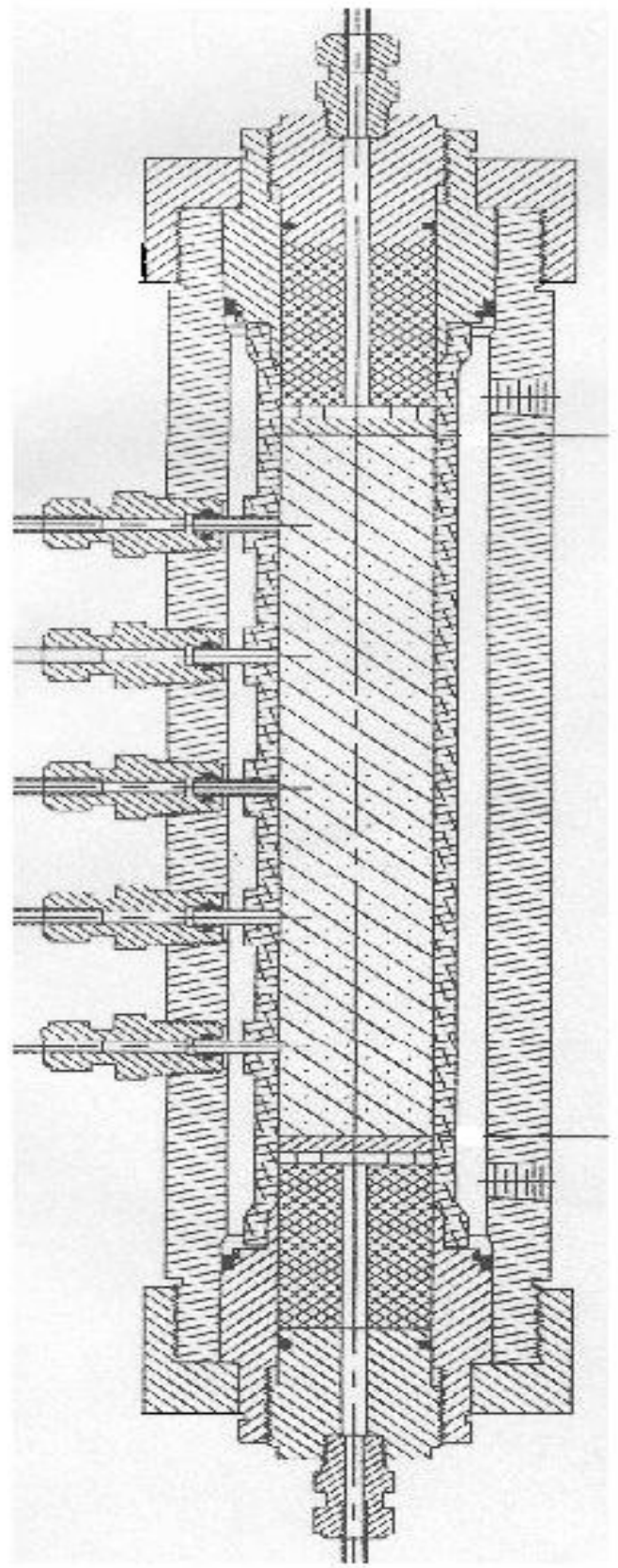

Figure 7. Schematic of the core holder. 


\subsection{Fittings.}

All fittings are made of stainless steel and were obtained from Swagelok. They have a design pressure well above 2000 psi and can withstand very low temperatures. Unions, Elbows, Tees, Male NPT Connectors, Check valves, Ball Valves, Globe Valve, Ferrules, Nuts and Relief Valves were some of the fittings used in this study. Two of the relief valves used had a set pressure of $1800 \mathrm{psig}$ and one a set pressure of $50 \mathrm{psig}$. To prevent the gas from leaking out from the sandstone into the annulus between the holder and the stainless steel reactor special fittings

(Fig. 7) were designed and fabricated at the National Energy Technology Laboratory, Morgantown, WV. These fittings have o-rings inside them that prevent any leaks. Bunsen burner is used to burn the methane as it is released in the hood.

Rubber hoses are used to connect the vacuum pump and the Bunsen burner to the system. Flexible stainless steel tubing has been used to connect the gas cylinders to the system and to connect the nitrogen line to the reactor to pressurize the ethylene glycol in the jacket. Teflon fittings are used to connect the glass separator to the system. A three way valve facilitated the measurement of pressure in the last section and the outlet of the core. Bushings and couplings were used to connect the core to the vacuum pump during the porosity experiments. 


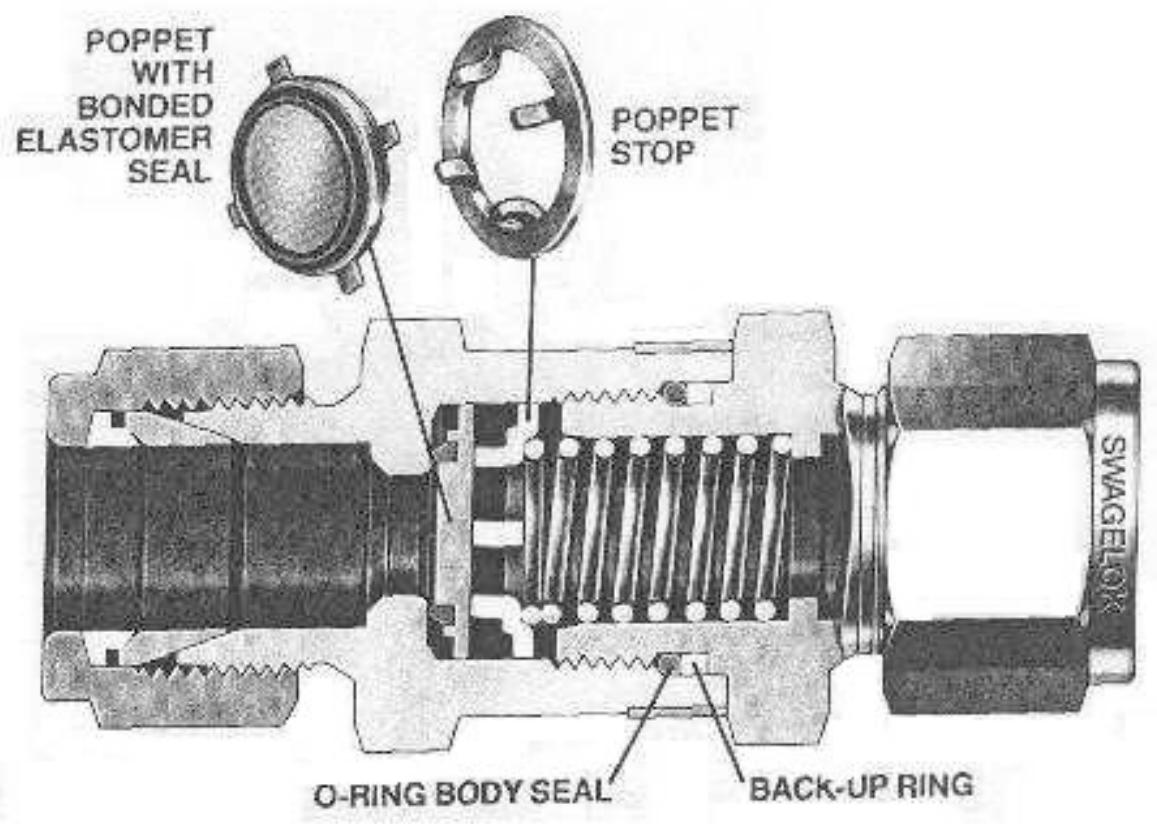

Figure 8. Cross Section of the check valve.

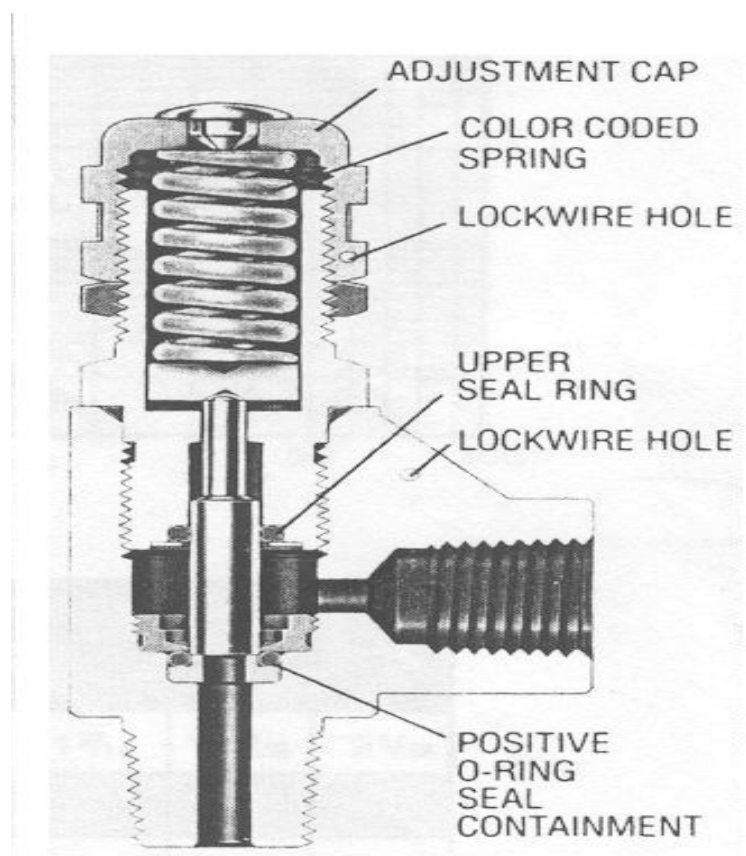

Figure 9. Cross section of the relief valve. 


\subsection{Antifreeze}

The reaction requires very low temperatures. An antifreeze was obtained locally and was used to cool the reactor / core. A solution of $70 \%$ antifreeze and $30 \%$ water allows cooling upto $-75^{\circ} \mathrm{F}$. This was essentially ethylene glycol and was inserted in the annulus of the core holder and the stainless steel pipe used to house the holder. This jacket was pressurized to a pressure higher than the pressure inside the core.

\subsection{Brine}

Brine is used for the formation of hydrate. Brine is used as the clay in the berea sandstone core, swells on contact with distilled water. This plugs and reduces the size of the pore which significantly reduces the porosity of the core. One and a half weight percent solution of brine was prepared using distilled water. Brine was obtained from Fischer Scientific. Permeability and porosity experiments were done using the brine solution. Sloan and Yousif, used the conductivity of this brine to monitor the formation of hydrate. As hydrate was formed the conductivity of the medium increased as the concentration of the brine solution increased.

\subsection{Vacuum Pump}

This is used to evacuate the entire system before purging with nitrogen. The Vacuum pump iwas used to evacuate the core of all the air that might be inside the core, before permeability experiments are done. The pump was also used for the porosity experiments. Brine was injected in the core from end by drawing vacuum from the other end of the core. 


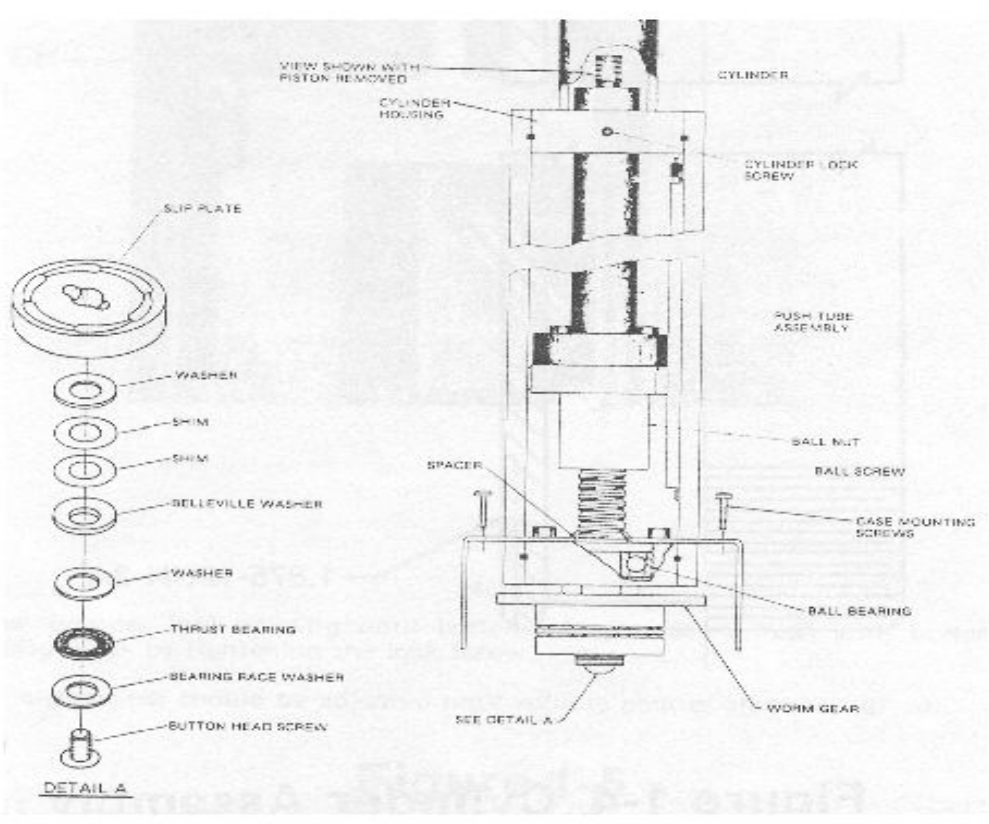

Figure 10. Driver assembly.

\subsection{Metering Pump}

This is an ISCO pump that produces a fixed rate flow stream at pressures up to $2850 \mathrm{psi}$

$\left(200 \mathrm{~kg} / \mathrm{cm}^{2}\right)$. Flow rate is controlled by the settings of two selectors on the control unit. This pump is capable of regulating itself so that the overpressures never exceed 3300 psi. It is a positive displacement syringe type of pump that has a stainless steel cylinder with a volume of $375 \mathrm{ml}$. These pumps have a manual and an auto mode at which they operate. A lever on the pump allows switching between the manual and the auto mode. These are essentially piston type of pumps. Brine is drawn into the cylinder and when the pump is switched on the piston forces the brine into the system at the set flow-rate. A relief valve at outlet of the pump prevents the pressures from rising above 1800 psig. 


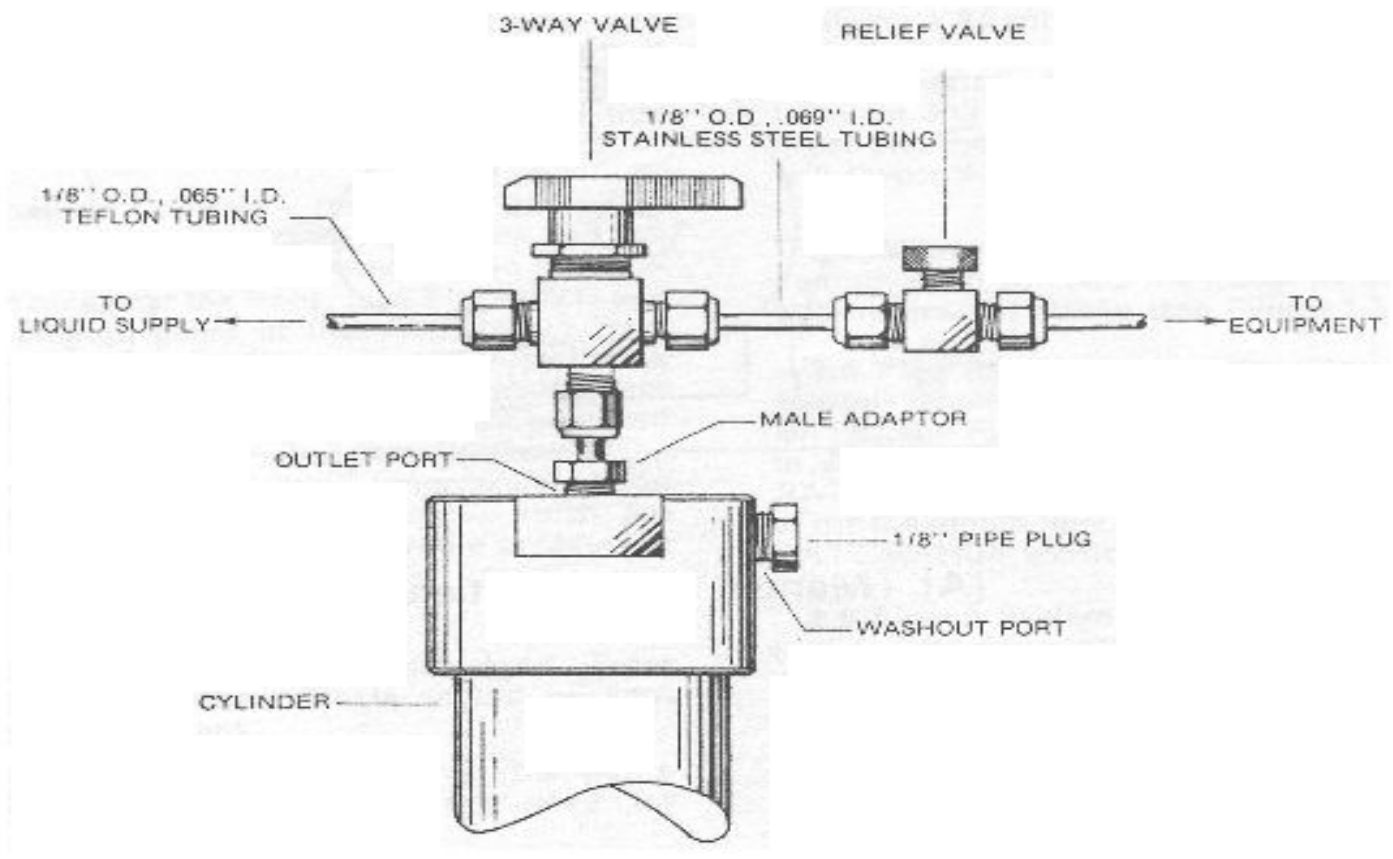

Figure 11. Metering pump top connections to the system.

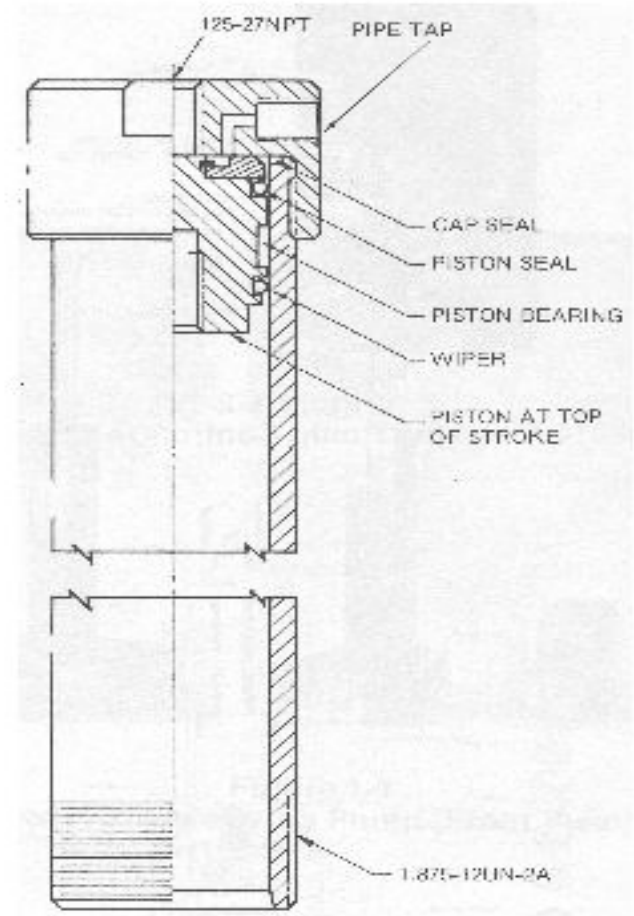

Figure 12. Cylinder assembly. 


\subsection{Glass Vessel Separator}

This was used to separate Methane gas and the droplets of water entrained. Glassworks Inc fabricated this glass vessel from a sketch provided they were provided. This vessel is designed for a pressure of up to $100 \mathrm{psi}$. The frit inside the vessel prevents the water from getting carried away with the gas. Teflon fittings aid in connecting the glass separator to the stainless tubing of the system. A relief valve on the line entering the glass separator, prevents pressures from building up.

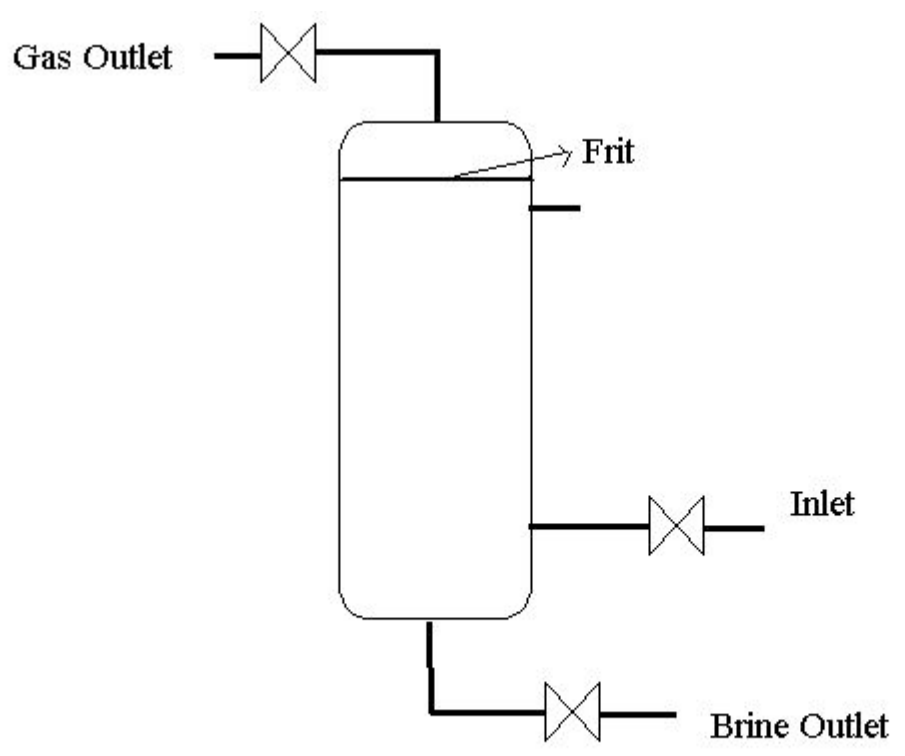

Figure 13. Schematic of the glass vessel. 


\subsection{Pressure Test}

The core holder was pressure tested at $-30^{\circ} \mathrm{C}$ and $1800 \mathrm{psig}$. The core holder was placed in the cooler with antifreeze that was cooled to $-30{ }^{\circ} \mathrm{C}$ by the Neslab cooler. Pipe connections were made so as to have only a pressure gauge in line. Then nitrogen was introduced in the core holder made of stainless steel. The pressure of the introduced nitrogen was 1800 psi as observed on the delivery gauge of the regulator on the gas cylinder and on the pressure gauge. The system was checked for leaks using soap solution. 


\section{CHAPTER IV}

\section{EXPERIMENTS}

Natural gas hydrates are formed when natural gas and water come in contact with each other at pressures and temperatures above the respective equilibrium values. These conditions naturally occur in ocean beds and cold land masses. Putting together a set-up to simulate these extreme conditions in a laboratory is quite a challenge and can take up to 17 months [11]. However with the current crisis of soaring natural gas prices, it is timely to take on the challenge and conduct research to look for economical ways of extracting gas from solid gas hydrates present in sedimentary rock.

\subsection{Set-Up}

A sketch of the set up is shown in Fig. 14. In this study methane gas is reacted with brine solution prepared with distilled water to form methane gas hydrate. The methane used is the research grade of purity $99 \%$. Nitrogen is used to run leak tests and pressure tests and to purge the system after evacuating it. Gas regulators over the cylinders aid in injecting gas into the system at a high pressure while also indicating the pressure of the gas inside the cylinder. Check valves on the lines leaving the nitrogen and methane gas cylinders prevent back flow of gas into the cylinders. A relief valve on the outlet line prevents pressures from building up in excess of 1800 psig. 
Figure 14. Experimental set-up.
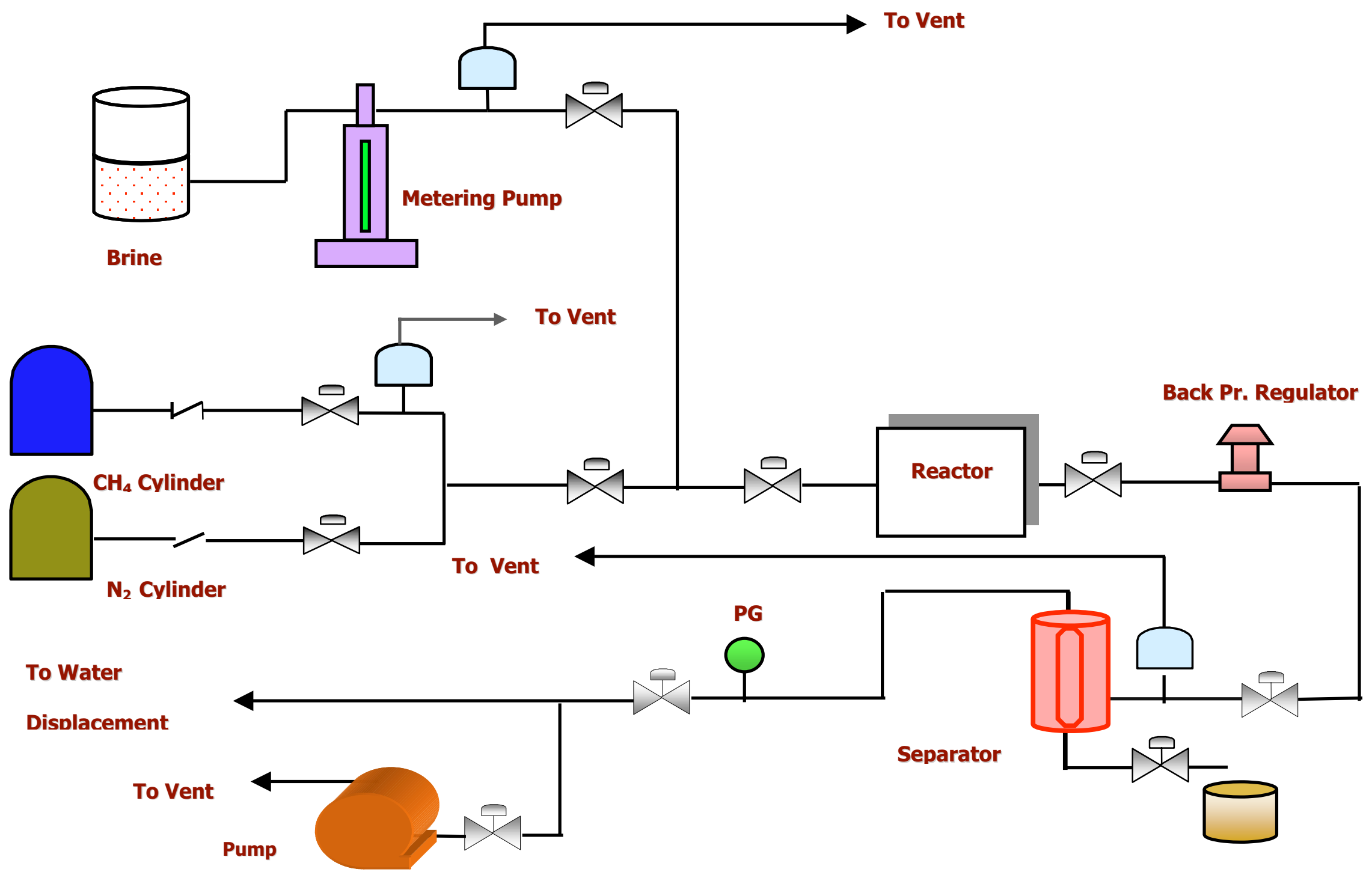
Figure 15. Reactor system.

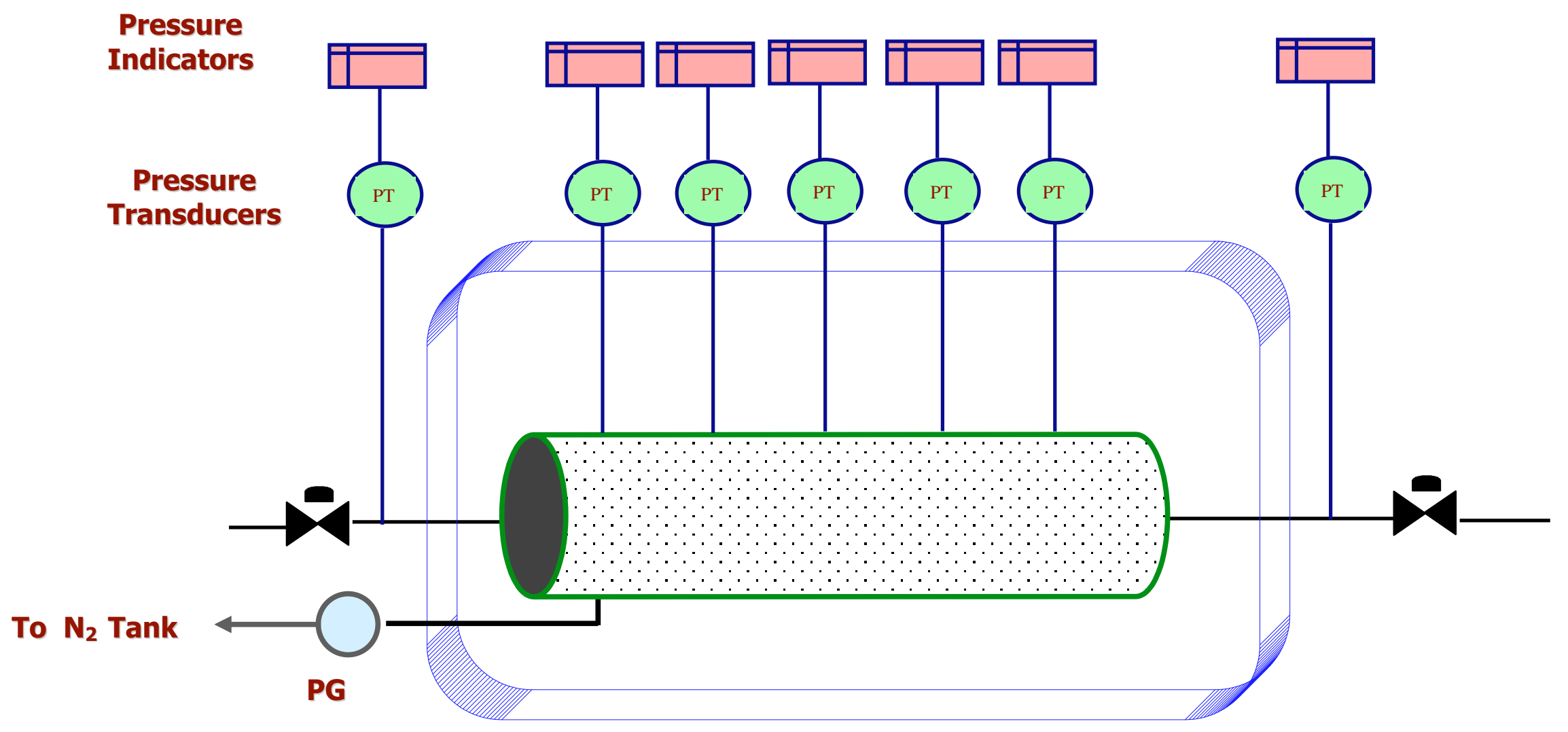


One and a half weight percent brine was used for the formation of hydrate. Sodium chloride was obtained from Fisher Scientific and the brine solution was prepared using distilled water.

An ISCO metering pump was used to pump brine at high pressures into the reactor. This is a piston type of a pump. A relief valve was connected on the line leaving the pump to prevent excess pressures from building up. A three way valve on top of the pump facilitates filling of the cylinder with brine and then injecting the brine into the cylinder. A pressure transducer just before the inlet to the core holder measures the pressure of the gas and brine entering the core.

The medium used in this study is a cylindrical block of sandstone, called the Berea sandstone which is similar in texture to the sedimentary rocks found in ocean beds and rocks found in the earth's crust under cold land masses. This sandstone contains clay which swells when it comes in contact with distilled water. This reduces the size of the pores in the rock. Consequently, the permeability and porosity of the core reduce significantly, which prevents further flow of fluids through the rock. This was one of the primary reasons for using brine solution in this study.

The sandstone is shrink wrapped and housed in a rubber Hassler sleeve. The sleeve with five stems facilitates the measurement of the pressure along the core using pressure transducers. This is then inserted in a 3" Schedule 80 stainless steel pipe on which are mounted special fittings to prevent the leakage from inside the core to the jacket outside. A metal plate on either side of the core helps distribute the gas and brine uniformly across the cross section of the core. Metal blocks on either sides of the core hold the core in position inside the core. O-rings on the reactor caps prevent leaks too. Pressure transducers along the core and the outlet of the core aid in measuring the pressure at these points. 
The annulus of the core and the reactor is filled with ethylene glycol and pressurized with nitrogen. At the outlet of the core a glass vessel separates the entrained brine from the gas. Back pressure regulators help set the outlet pressure to the appropriate value during dissociation runs. The outlet then goes to hood where the gas is burned using a Bunsen burner.

\subsection{Hydrate Formation Experiments}

As a part of start up the porosity of the core was measured. The core was enclosed in a shrink wrap and weighed. Vacuum was drawn from one end of the core. The other end was immersed in a container with brine solution while vacuum was being drawn. The sandstone core was weighed again after it was saturated with brine. The difference in weight of the sandstone aided in calculating the weight of the brine in the sandstone which in turn helped calculate the volume of the brine in the sandstone given its density which was determined. The volume of the brine was considered to be the pore volume of the core. This in turn was used to calculate the porosity of the sandstone given the total volume of the sandstone.

The system was evacuated using the vacuum pump and then purged with nitrogen. Evacuation was done again and the outlet of the reactor housing the sandstone was closed. This was done to remove the air present in the sandstone core. Presence of air in the core affects the measured absolute permeability with respect to brine. The jacket pressure is increased to 200 psig at this point. Brine was then pumped into the system until sufficient pressure was built up throughout the length of the core. The outlet valve was then opened and the flow of brine was measured for about an hour. During this time the pressure along the core was also recorded off the pressure indicators. When pressures of 40-50 psig are seen on the outlet of the core, the core is assumed saturated with brine. This data was used to measure the absolute permeability of the 
core with respect to brine, using the formula

$$
\Delta P=\frac{\text { Permeability } \times \text { flowrate } \times \text { length }}{\text { Area } .}
$$

Methane was, then, injected into the sandstone core at a pressure of 100 psig. Volume of brine pushed out while methane was passing through and the volume of brine until only methane came out of the core. Methane that comes out was burnt in the hood using a Bunsen Burner. This was done as a safety measure since methane is inflammable and combusts explosively under extreme conditions when it comes in contact with air. Then the outlet valve was shut and the nitrogen pressure in the jacket and the methane pressure in the core was gradually increased together with the jacket pressure always being approximately 150 psi greater than the pressure in the core. The pressure was increased until the pressure in the core was 1200 psig and that in the jacket was 1400 psi. The core was left open to the methane tank 35-40 minutes. Then the inlet valve was shut and the chiller was turned on to bring the temperature of the ethylene glycol water solution bath down to the desired reaction temperature. Once the bath temperature reached the reaction temperature, pressure readings were recorded every two hrs off the pressure transducer/indicator system along the core. This was done until the pressure reaches the equilibrium value for the reaction temperature, which for porous mediums can be obtained from works of E.D Sloan.

Annealing was done to eliminate pressure drops along the core, which are caused due to non-uniform hydrate formation. This involved increasing temperature of the bath to 2 to $3{ }^{\circ} \mathrm{F}$ above the reaction temperature and then lowering it back to the reaction temperature. This caused the hydrate to dissociate and then re-form uniformly along the length of the core. 


\subsection{Hydrate Dissociation Experiments}

Dissociation run was carried out once the pressure reached the equilibrium pressure and no further fall in the pressure was observed. This, invariably, took about $35 \mathrm{hrs}$. For dissociation, the back pressure was set at a pressure ( $300 \mathrm{psig})$ below the equilibrium pressure and the outlet valve was opened. As the system pressure falls from equilibrium pressure to the dissociation pressure, the rate at which the gas was produced was recorded using the water displacement method. Also the fall in pressure along the core was recorded using the pressure transducer/indicator system along the core. In addition, as the gas was produced the brine entrained with the gas was collected in the glass separator.

The rate at which the methane is released from the core was measured by displacement of water in two cylinders as shown in the figure. This method aids in accurately measuring the volume of the gas that is produced. In this method the gas is released against a varying water head. This was taken into consideration when the data was processed and analyzed and during data analysis the volume of gas produced was calculated at STP. 


\section{CHAPTER V}

\section{RESULTS AND DISCUSSION}

Fig. 16 shows the results of an experiment for a hydrate formation experiment at $34{ }^{\circ} \mathrm{F}$.

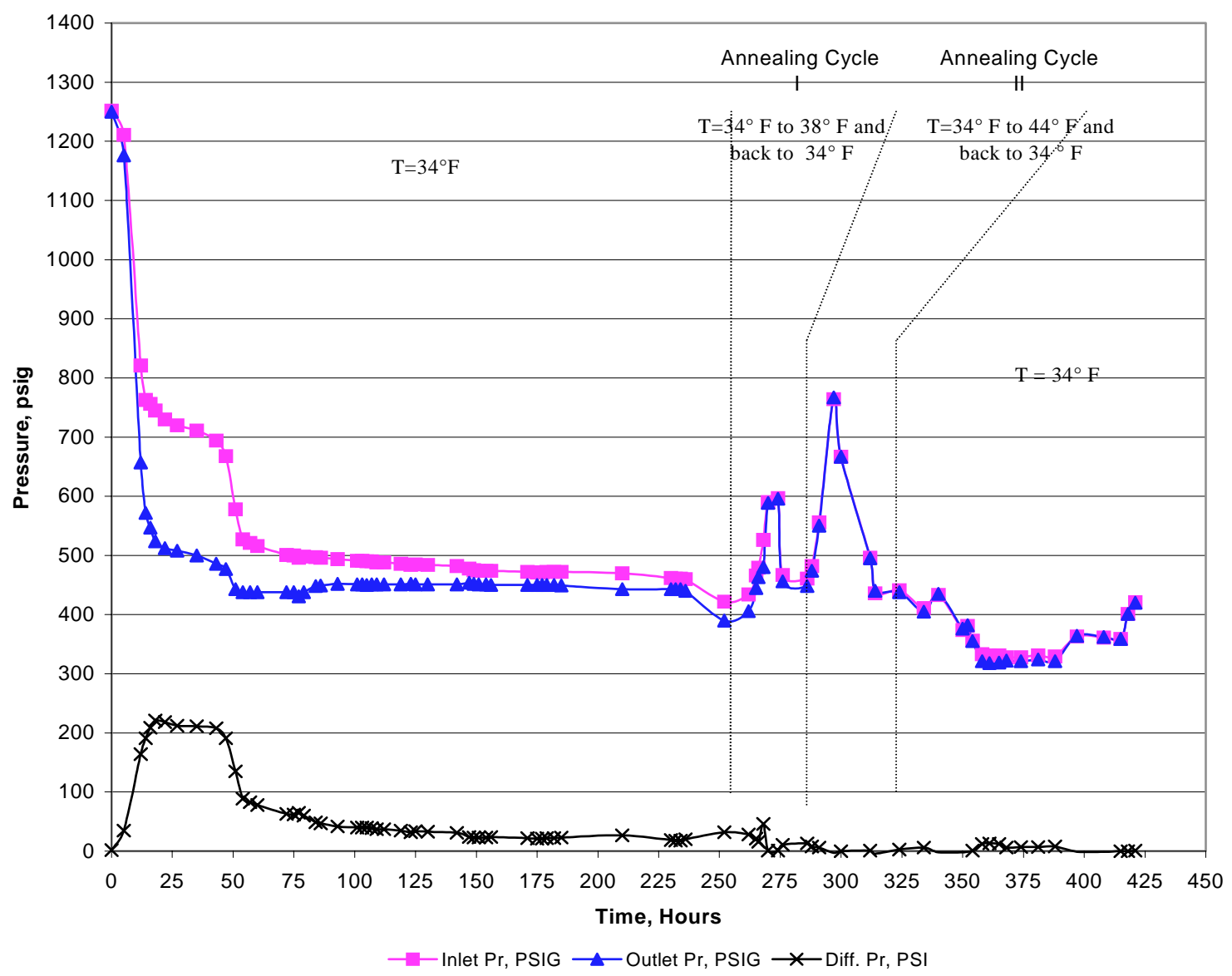

Figure 16. Variation of pressure with time for formation run 1 (1250 psig, $\left.34^{\circ} \mathrm{F}\right)$.

Change in the inlet and the outlet pressures with time was recorded and plotted against time (Fig. 16). The pressure drop was plotted against time too (Fig. 16). Temperature was 
monitored and found to be constant at $34^{\circ} \mathrm{F}$ through out the run. Two annealing cycles were carried out. The temperature was raised to $38^{\circ} \mathrm{F}$ and brought down to $34^{\circ} \mathrm{F}$ in the first annealing cycle and then raised to $44{ }^{\circ} \mathrm{F}$ in the second annealing cycle and brought down to $34^{\circ} \mathrm{F}$. The pressure difference between the inlet and the outlet of the core was eliminated after the two annealing cycles.

The drop in the inlet and outlet pressures in the first $18 \mathrm{hrs}$ of the run is essentially due to the formation of hydrates from gas. From the $18^{\text {th }}$ hour to around the $47^{\text {th }}$ hour the inlet and the outlet pressures are about constant. From the $47^{\text {th }}$ hour to the $51^{\text {st }}$ hour of the run the inlet and the outlet pressures fell again to about $450 \mathrm{psig}$, the observed equilibrium formation pressure in this run. The pressures remain constant till the annealing cycles are carried out.

According to Heele Shaw's law the concentration of gas at the inlet section of the core is more than that at the outlet section of the core at steady state (the fingering effect). The random pore size distribution in the core explains the stability in the inlet and the outlet pressures of the core from the $18^{\text {th }}$ hour to the $47^{\text {th }}$ hour. Hydrates are formed more easily in larger pores than in smaller pores as capillary forces are weaker in larger pores. The greater fall in pressure at the outlet could also indicate larger pores at the outlet.

The constancy in pressure between the $17^{\text {th }}$ and the $47^{\text {th }}$ hour indicates that hydrates formed in larger pores because of weaker capillary forces, create pockets of hydrates and gas or there are sections in the pore where hydrates form and block or choke the core. This increases the resistance to the diffusion of the gas thus resulting in temporary stabilization in the pressures. Then the gas gradually diffused into other pores which were essentially smaller and reacted with water there to form hydrates.

The stability in pressure from the $51^{\text {st }}$ hour onwards indicates that no more hydrates were 
formed in the core during that time period. On annealing the pressures increased as expected. The fall in pressure after the second annealing cycle was because the temperature was not constant at $34{ }^{\circ} \mathrm{F}$ and fell to about $32{ }^{\circ} \mathrm{F}$. Annealing cycles aided in eliminating the differential pressure between the inlet and the outlet.

In the hydrate dissociation experiment, back pressure regulator was set to 300 psig and the outlet valve was opened. A flowmeter on the outlet side measured the flowrate of gas with time.

The run was repeated and the variation of pressure with time was as seen in Fig. 17.

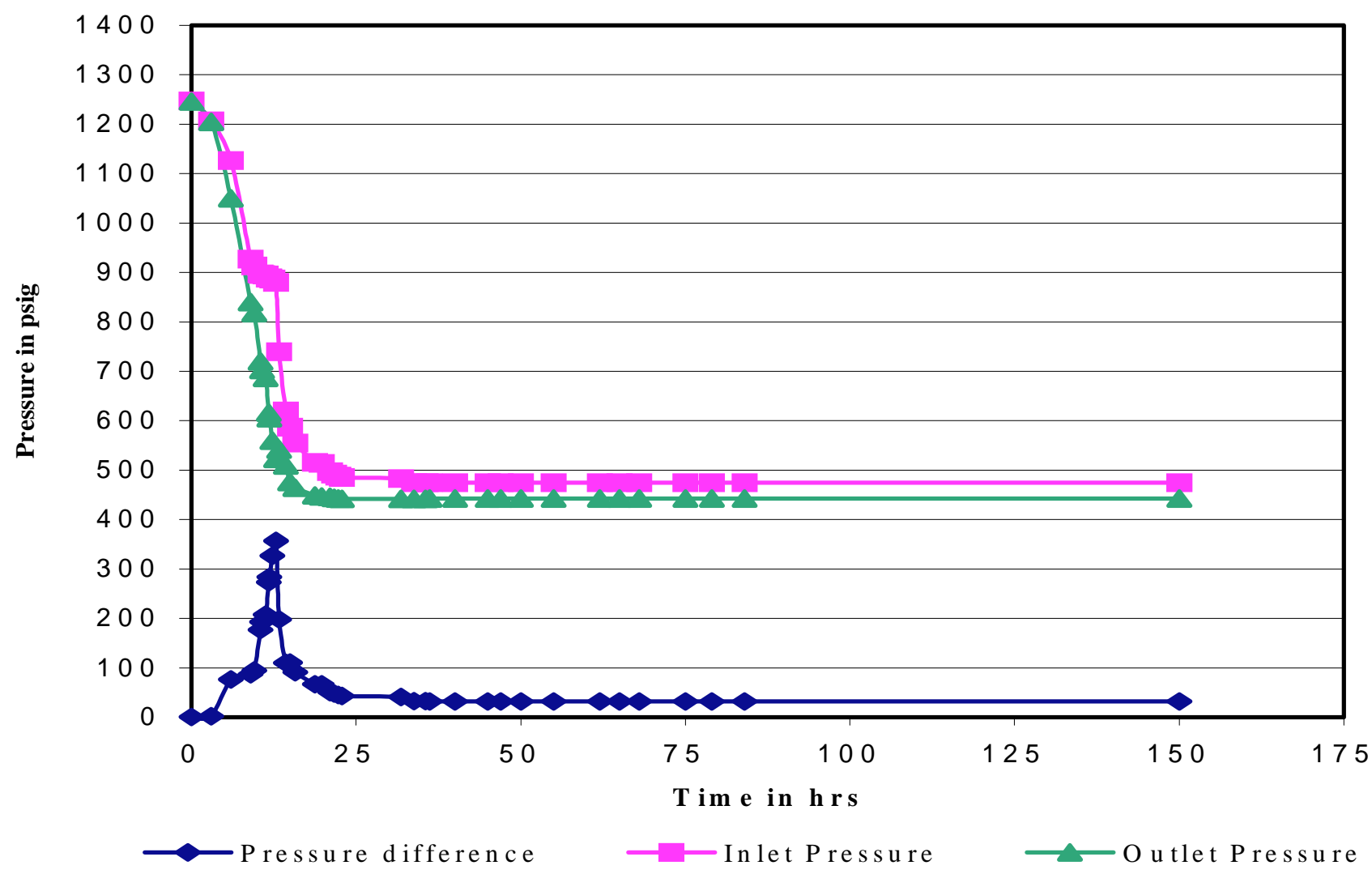

Figure 17. Variation of Pressure with time for formation run 2 $\left(1240 \mathrm{psig}, 34^{\circ} \mathrm{F}\right)$. 
It is seen that the fall in the inlet and the outlet pressures is similar to that in Run 1 . The pressures fell faster in this run and the inlet pressure remained constant for a shorter time at about 1.5 hrs. Annealing cycles were not carried out in this run as there was negligible pressure drop across the core. The pressure stabilized across the core at the theoretical equilibrium pressure of $451 \mathrm{psi}$ for the reaction temperature of $34^{\circ} \mathrm{F}$.

The dissociation for run 2 (Fig. 18) was carried out at a pressure of 300 psig. The trend in the dissociation is similar to that of dissociation in run 1 . Total volume of the gas that came out was 1.75 liters. This was calculated using Simpson's rule of numerical integration

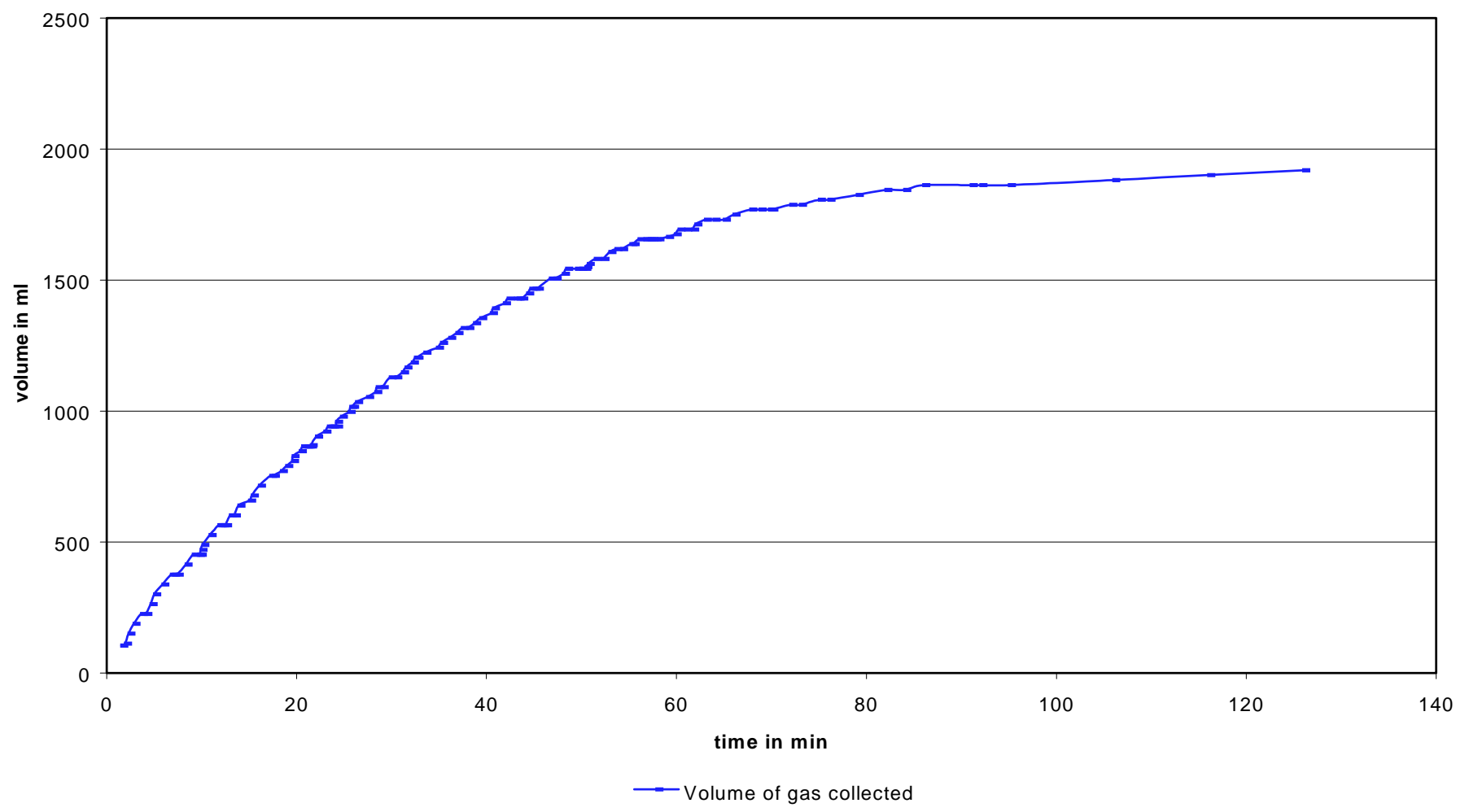

Figure 18. Volume of gas coming out with time for dissociation run 2 $\left(300 \mathrm{psig}, 34^{\circ} \mathrm{F}\right)$. 
The core was replaced after run 2 and the subsequent runs were carried out in a new sandstone core.

Run 3 was carried out under similar conditions, but with a new sandstone. Permeability and porosity experiments were carried out in this run. The run was conducted at $34^{\circ} \mathrm{F}$ and a inlet pressure of 1049 psig. The porosity was measured to be $18.9 \%$. In this run pressure profile (Fig. 19) along the core was measured using five pressure taps along the core.

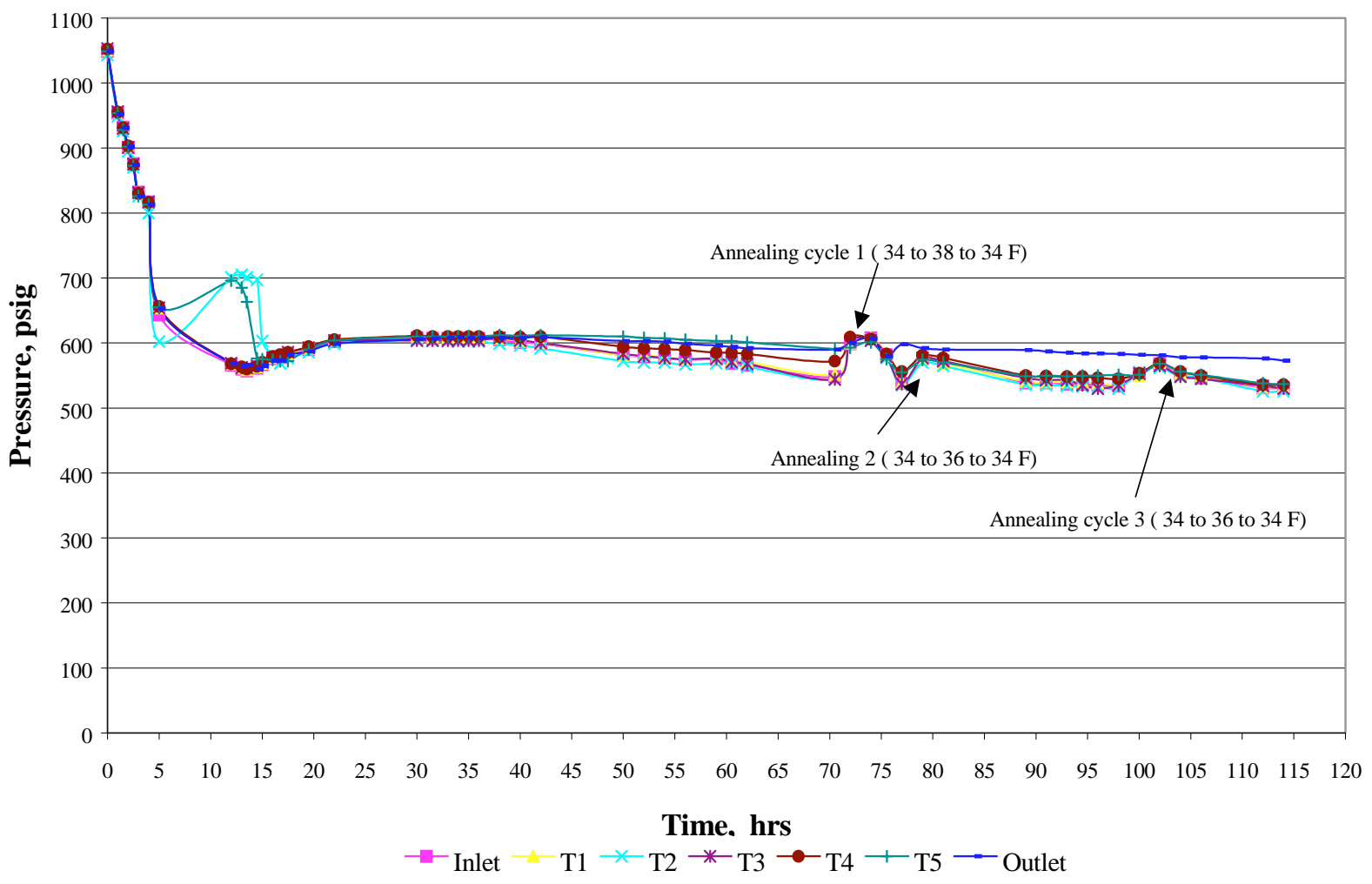

Figure 19. Variation of pressure with time formation run 3 (1049 psig, $\left.34^{\circ} \mathrm{F}\right)$. 
Pressure transducers were hooked up along the core to monitor pressure profiles along the core during formation and dissociation experiments. Tap 1 was close to the inlet and T5 close to the outlet. Between 5 to $15 \mathrm{hrs}$ pressures at taps T2 and T5 were higher than those in the rest of the core. This difference in pressure could be due to non-homogeneity in the presence of methane and brine in different sections of the core which causes the rates of formation of hydrate to be different in the various section. A high pressure indicates the presence of free gas in a section, which gradually reacts with the surrounding brine. Thus, this pressure drop was not seen in the period 15 to $45 \mathrm{hrs}$, after which a non-homogenous pressure drop was seen again. Annealing cycles were carried out to eliminate these pressure drops and ensure uniform methane hydrate formation along the core. Annealing cycles carried were between $34^{\circ} \mathrm{F}$ and $38^{\circ} \mathrm{F}$ and between $34^{\circ} \mathrm{F}$ and $36^{\circ} \mathrm{F}$. The pressure increased during annealing as an increase in temperature dissociates causes the hydrate to dissociate and thus more free gas is now present. After 114 hrs the pressure along the core ceased to decrease and the dissociation run was carried out.

In the dissociation run the back pressure regulator was set to 300 psig for the dissociation and the outlet valve was opened. The pressure profiles are as shown in Fig. 20. 


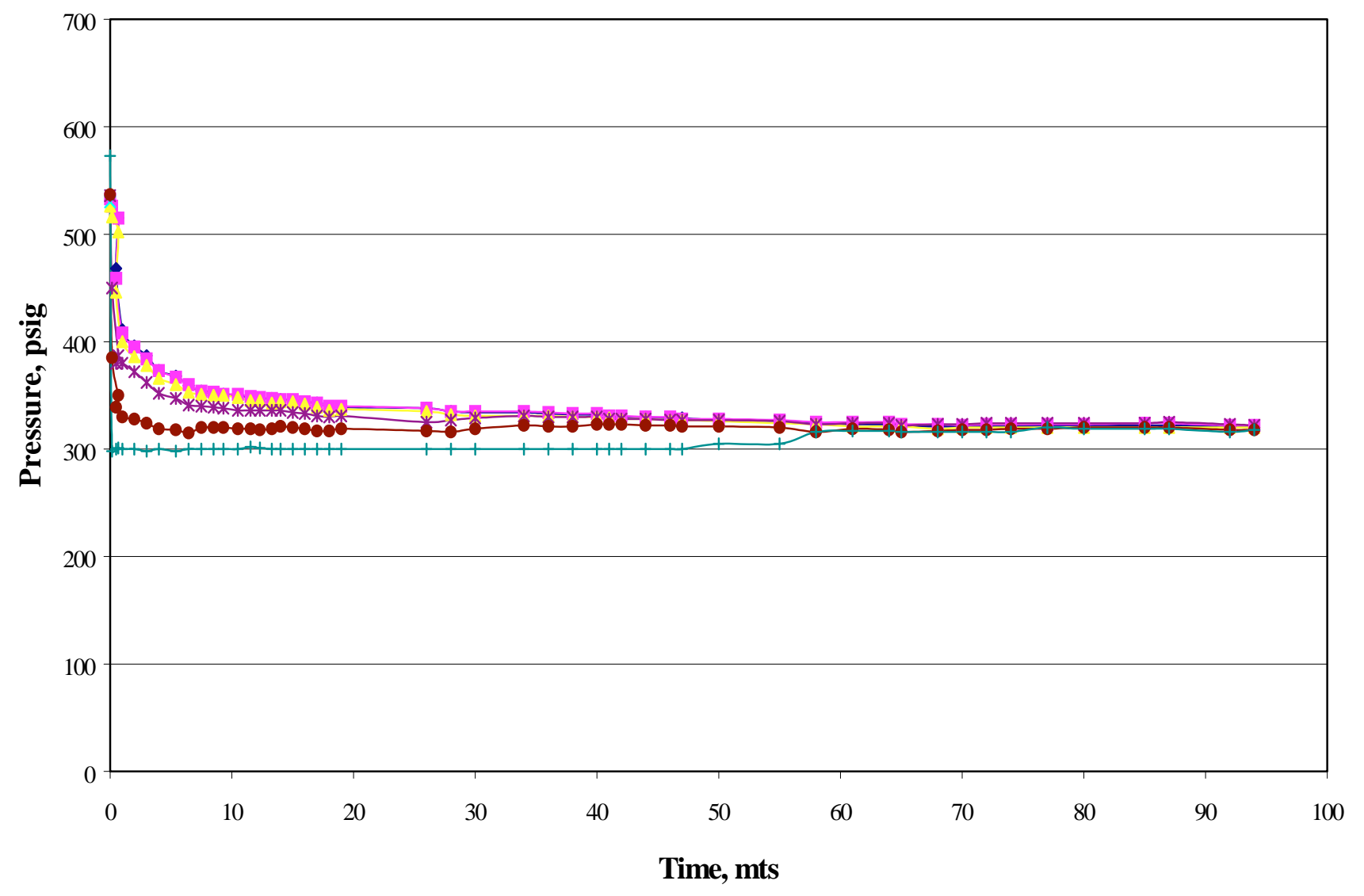

$\rightarrow$ Inlet $\rightarrow-\mathrm{T} 1 \rightarrow \mathrm{T} 2 \rightarrow \mathrm{T} 3 \rightarrow-\mathrm{T} 4 \rightarrow \mathrm{T} 5 \mathrm{psig}+$ Outlet

Figure 20. Variation of pressure with time for dissociation run 3 (300 psig, $\left.34^{\circ} \mathrm{F}\right)$.

During dissociation the pressures at the taps fell along the core as gas from the dissociated hydrate left the core. The fall in pressure was abrupt in the first 2 minutes and then stabilized at the dissociation pressure of 300 psig. The volume of gas collected in the water displacement cylinder was measured and plotted with time (Fig. 21). The total volume of gas seen to come out was about 4.25 liters. 


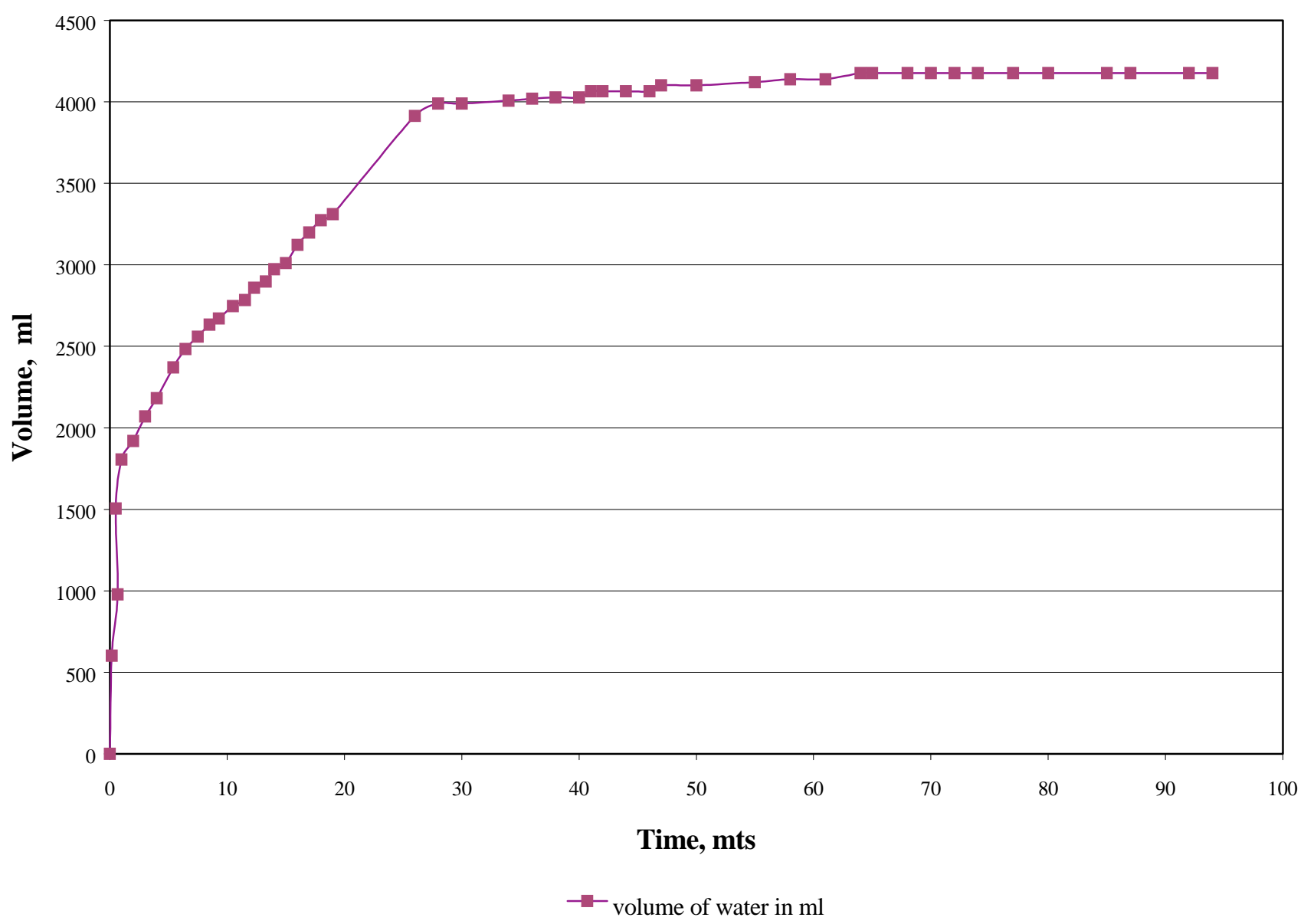

Figure 21. Volume of gas coming out with time for dissociation run 3 (300 psig, $\left.34^{\circ} \mathrm{F}\right)$.

As seen in the graph, there are three distinct regions. The large slope seen initially is due to the unreacted free gas that comes out of the reactor. The subsequent smaller slopes in the graph are due to the hydrate that dissociates when the reactor is exposed to a pressure of $300 \mathrm{psi}$. The volume of gas collected in the cylinder is appropriately converted to the equivalent volume at STP. 


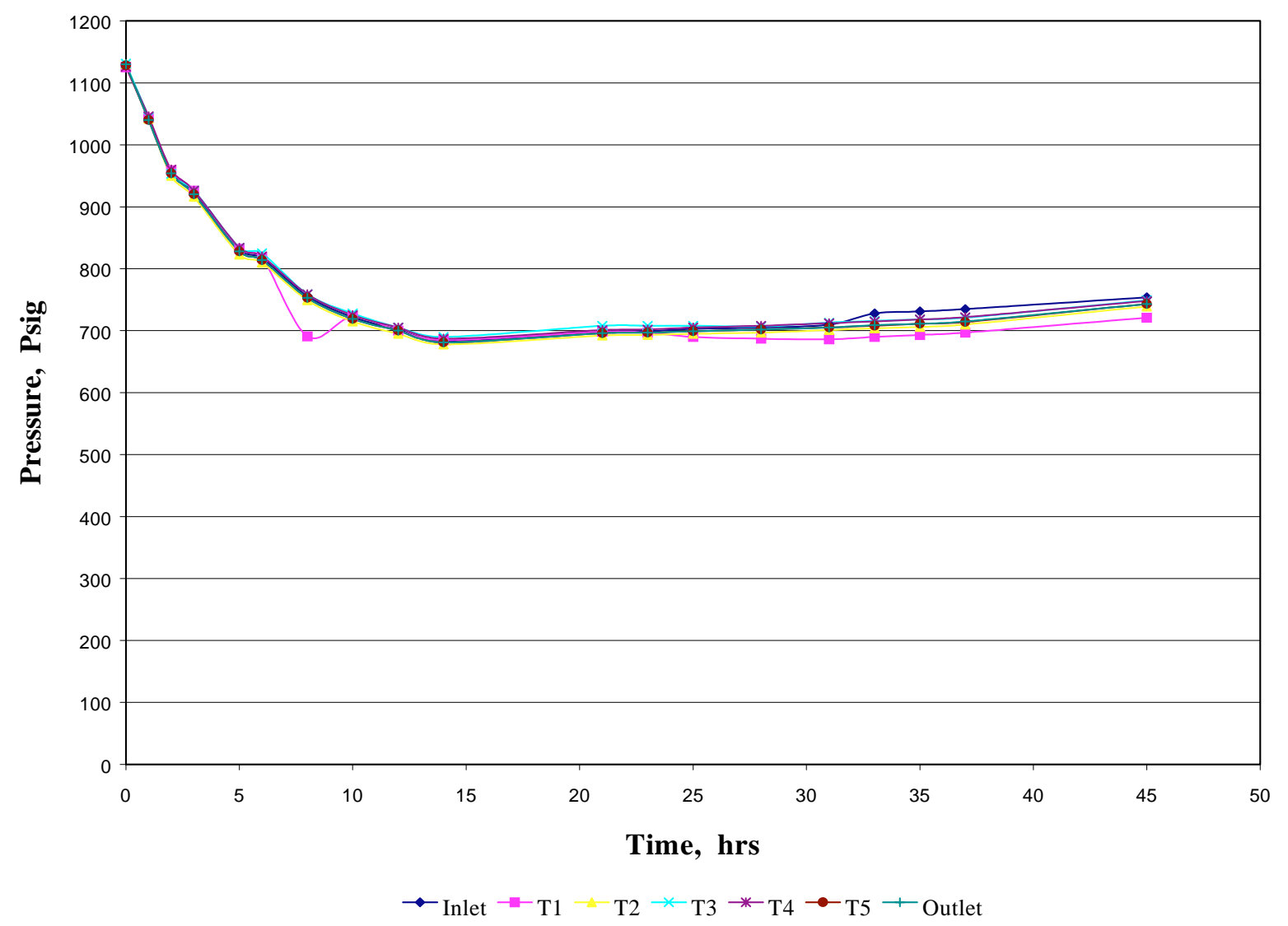

Figure 22. Variation of pressure with time for formation run 5 (1130 psig, $\left.34^{\circ} \mathrm{F}\right)$.

During run 5 (Fig. 22) carried out at $34^{\circ} \mathrm{F}$, the pressure fell initially and then rise after about 30 hrs. This was attributed to self dissociation of the hydrate and after numerous leak checks was found to be due to leak in the fittings especially designed for the reactor. Runs 6 through 8 were carried out to check the integrity of the system. The sandstone core and the rubber sleeve (Hassler Sleeve), and O-Rings in fittings were replaced. Innumerable leak tests were carried out in the lab as well as at the Department of Energy and the system error was successfully corrected. 


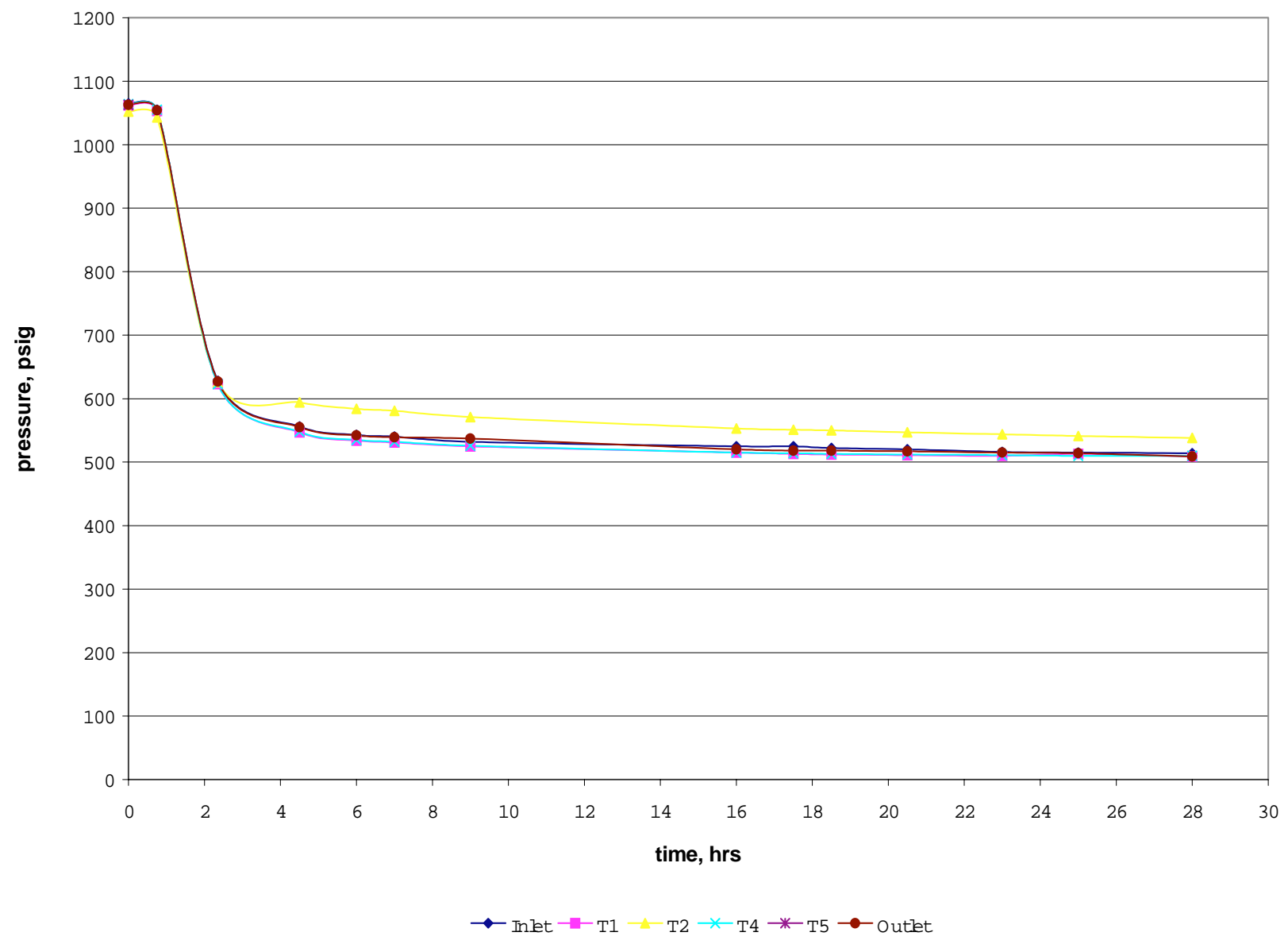

Figure 23. Variation of pressure with time for formation run 9 (1060 psig, $\left.34^{\circ} \mathrm{F}\right)$.

Run 9 was carried out with a new sandstone core. The water displacement cylinder was appropriately modified to collect a greater volume of gas. The permeability of core was measured. The reaction temperature was maintained at $34^{\circ} \mathrm{F}$ and the dissociation pressure was 300 psig for this run. The pressures were found to fall uniformly across the core. A fall of about 500 psig was observed in the first couple of hours as seen in Fig. 23. A formation rate as high as this was seen for the first time. The pressure stabilized at about $530 \mathrm{psi}$, close to the observed 
equilibrium pressure of $544 \mathrm{psi}$ for $34^{\circ} \mathrm{F}$ in this study. Since there were no large pressure drops seen across the core no annealing cycles were carried out. The pressures across the core remained stable for about $25 \mathrm{hrs}$. At this point the dissociation run was carried out.

The dissociation run was carried out by exposing the system to 300 psig pressure using the back pressure regulator (Fig. 24). The pressures were seen to fall almost immediately. The gas produced was collected in the water displacement cylinders. The pressure at tap T2 was found to be high for most of the time during the dissociation, which could be because of free gas trapped by hydrate around the transducer T2. As always the pressure at the outlet was found to fall to the dissociation pressure almost instantly. Pressures at most of the taps was seen to fall to the dissociation pressure of 300 psig, except tap T2. The volume of gas collected was measured and the amount of gas collected at STP was calculated. Calculations for the rate of gas coming out were done too with appropriate changes for the changing water head. Volume of gas produced was also plotted with time (Fig. 25). Again 3 distinct regions were seen in this graph. The initial high rate is attributed to the free gas that remains unreacted, while the subsequent low rate is because of the gas from dissociating hydrate. 


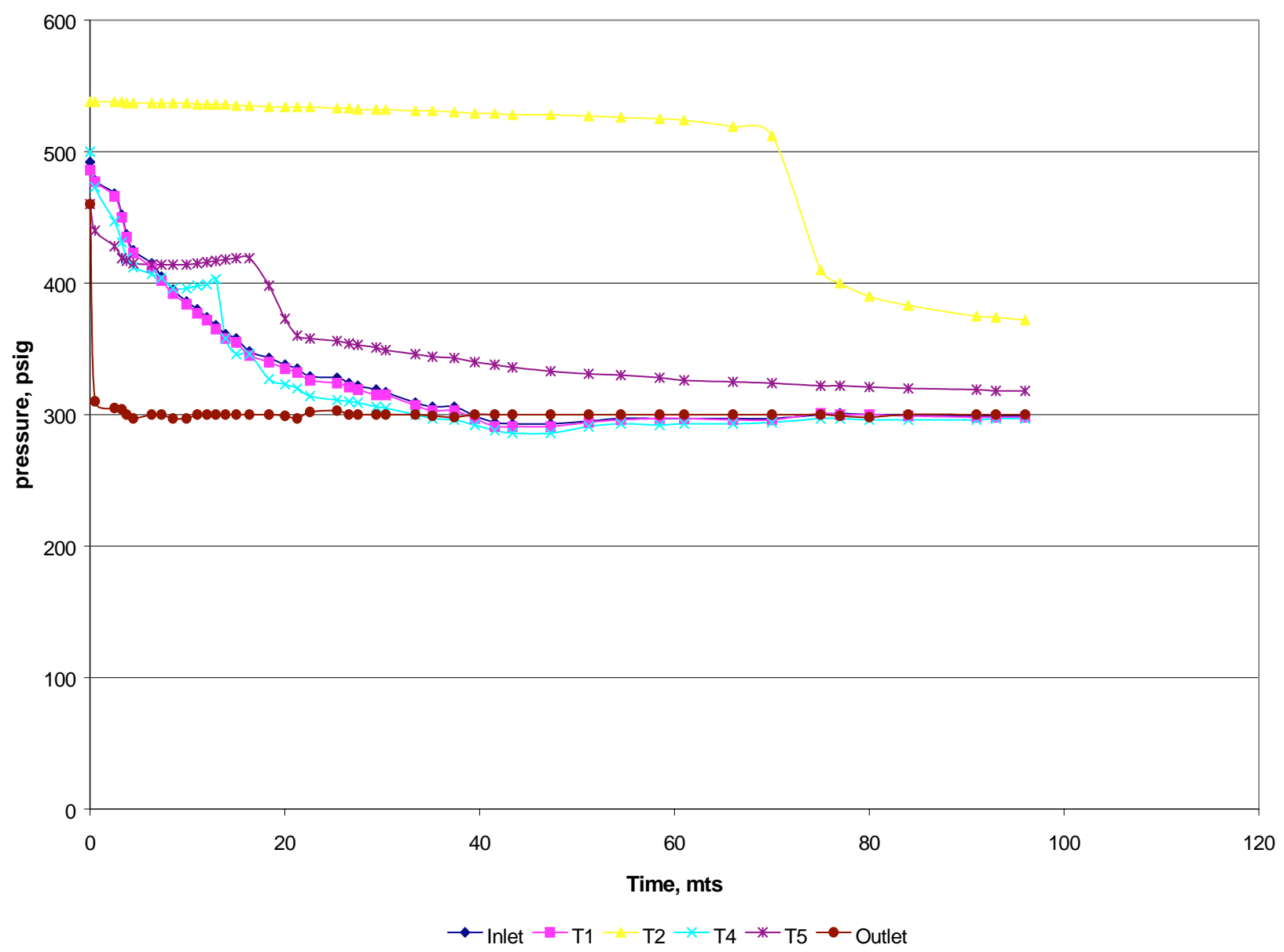

Figure 24. Variation of pressure with time for dissociation run 9 (300 psig, $\left.34^{\circ} \mathrm{F}\right)$. 


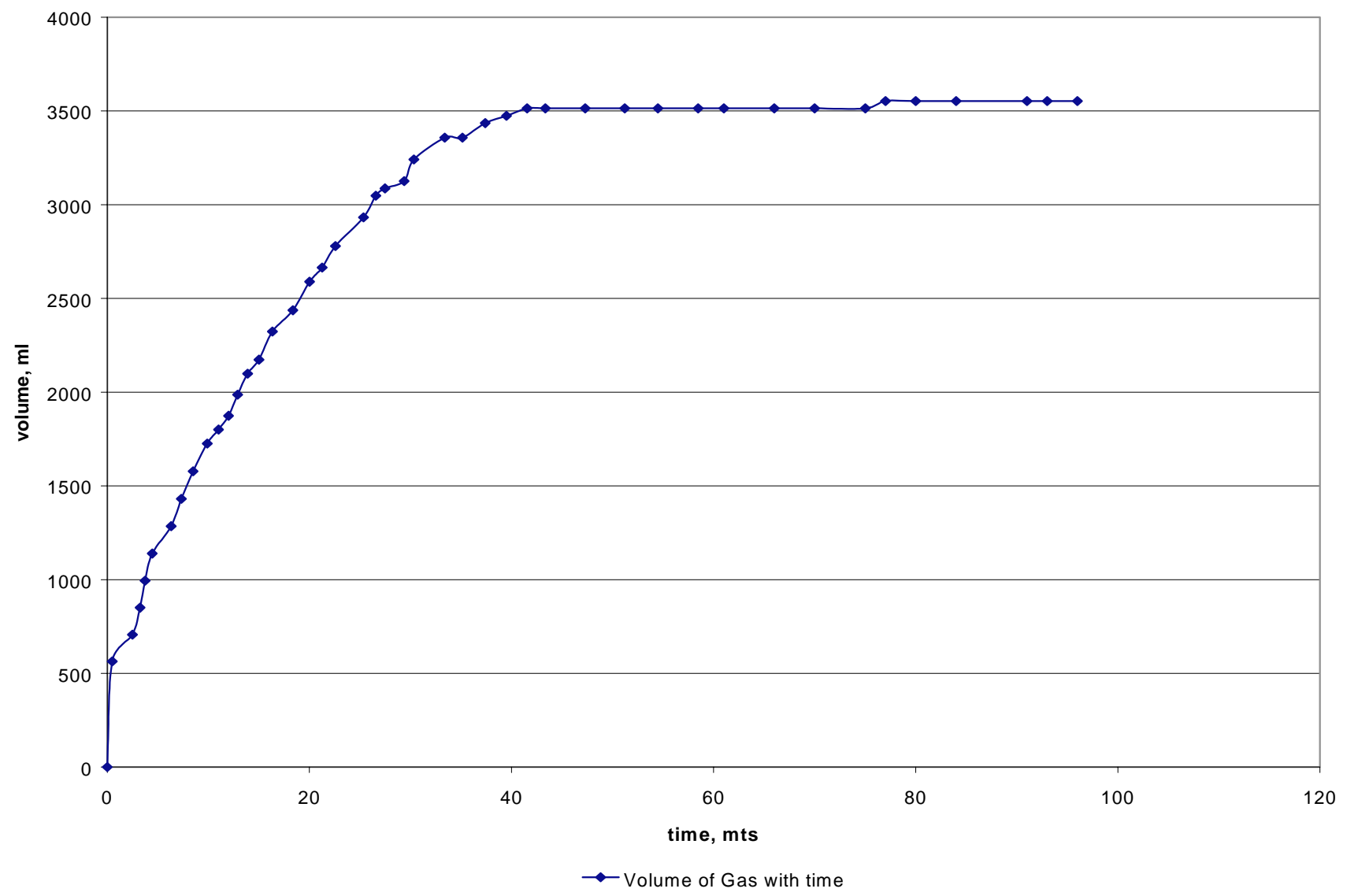

Figure 25. Volume collected with time for dissociation run 9 (300 psig, $\left.34^{\circ} \mathrm{F}\right)$. 
Run 10 was carried out at $36^{\circ} \mathrm{F}$ and a dissociation pressure of $300 \mathrm{psig}$. The fall in pressure again

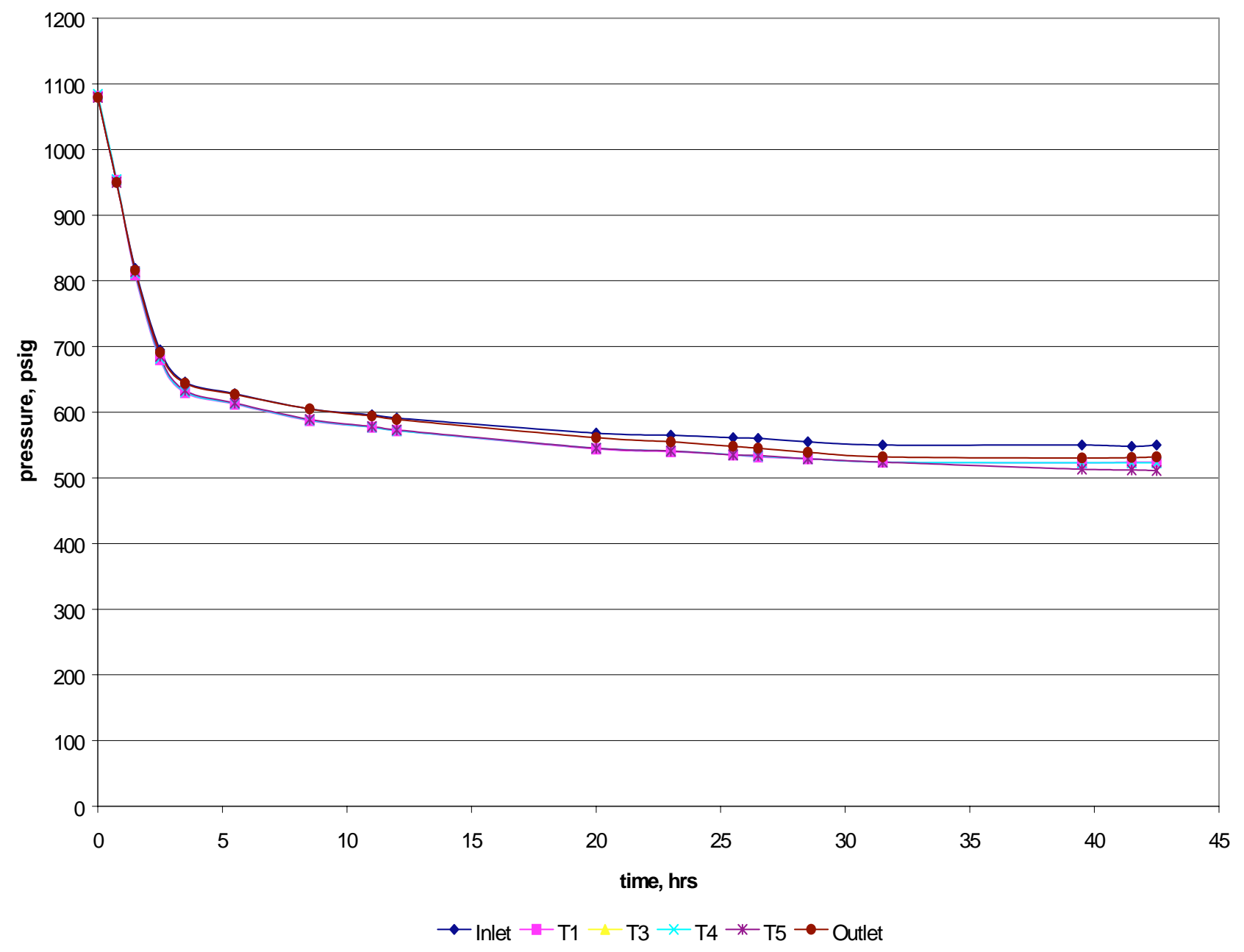

Figure 26. Pressure Variation with time for formation run 10 (1080 psig, $\left.36^{\circ} \mathrm{F}\right)$.

was seen to be rapid in the first 3-4 hrs and then stabilized at an observed equilibrium pressure of 548 psia. The variation of pressure with time was quite similar to the runs carried out at $34{ }^{\circ} \mathrm{F}$. The pressures fell uniformly across the core and thus no annealing was done. The pressures stabilized for about $20 \mathrm{hrs}$ and the dissociation run was then carried out. 


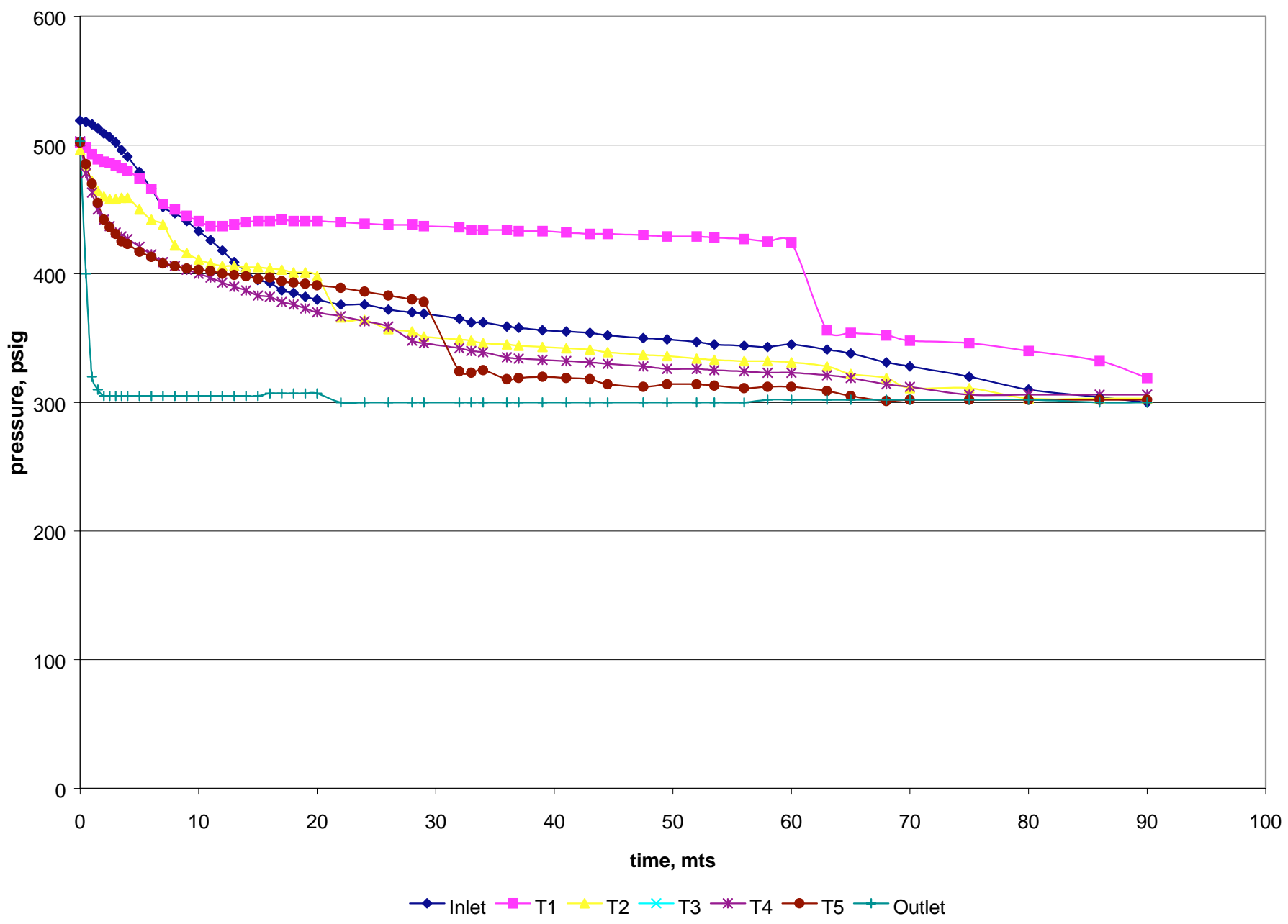

Figure 27. Pressure variation with time for dissociation run 10 (300 psig, $\left.36^{\circ} \mathrm{F}\right)$.

Dissociation for run 10 was carried out at 300 psig for this run. The pressure at Tap T1 was seen to remain at a value higher than the rest of the core. The pressure at the outlet was seen to fall down to 300 psig instantly. The pressures around the other taps were seen to fall to the equilibrium values quite randomly. The volume of gas collected at STP was plotted against 
time and the trend seen was similar to the other runs (Fig. 28).

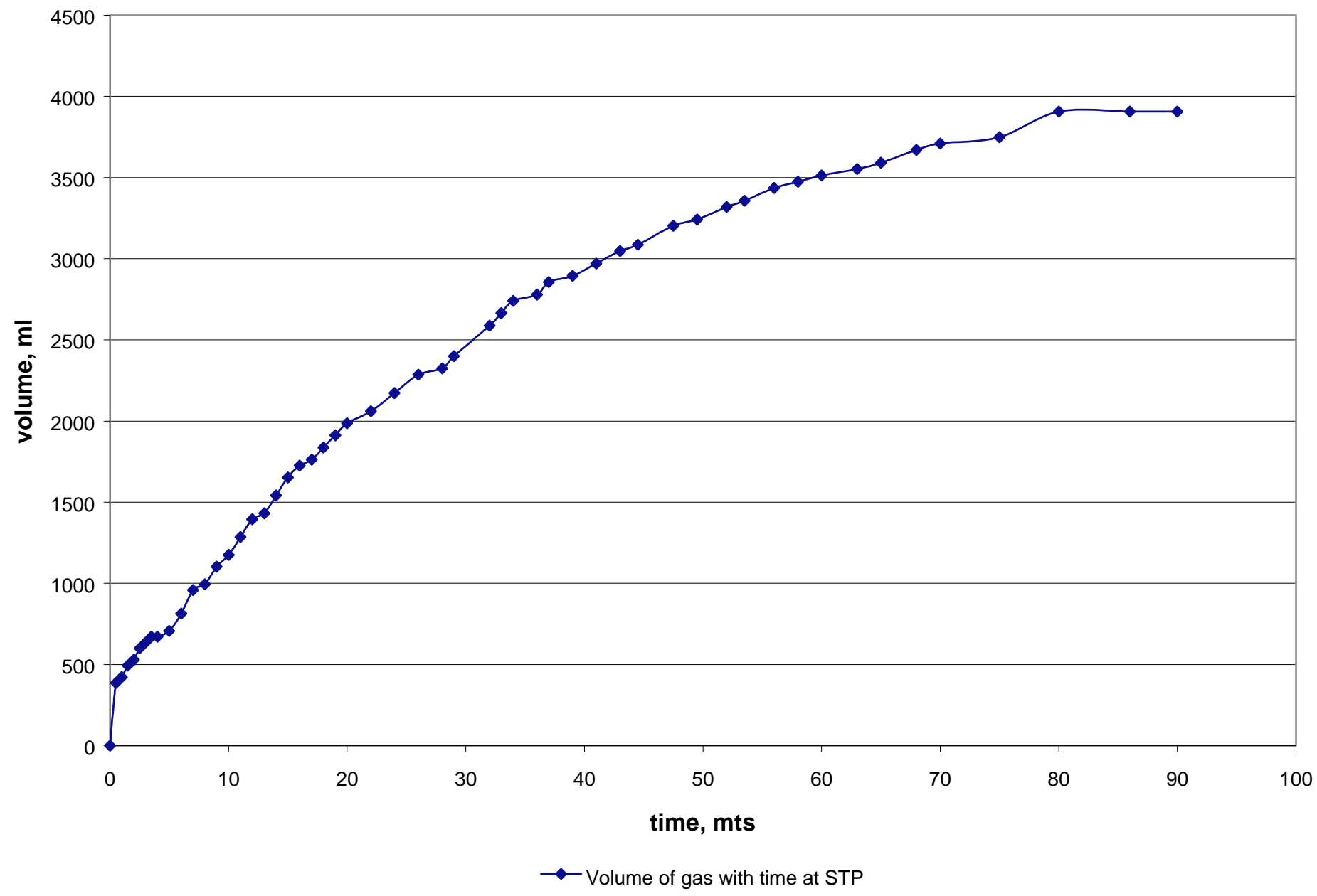

Figure 28. Volume of gas collected with time for dissociation run 10 (300 psig, $36^{\circ} \mathrm{F}$ ). 
Formation run 11 was an attempt to form hydrates at $40{ }^{\circ} \mathrm{F}$ and this was repeated in run 13. run 12 was carried out at $34^{\circ} \mathrm{F}$ and a dissociation pressure of 200 psig. The dissociation pressure was changed to study the impact of a greater driving force on the rate of dissociation.

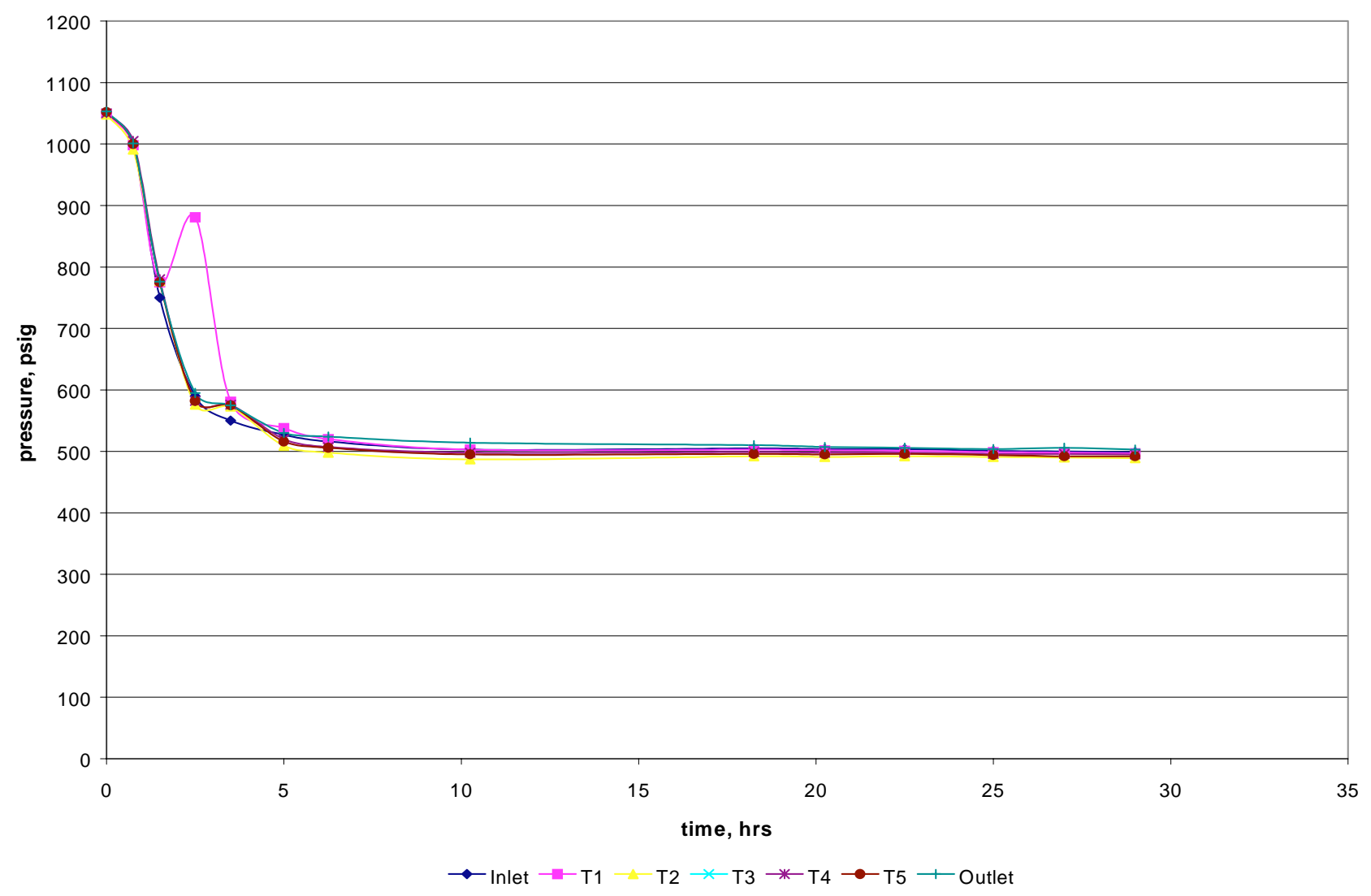

Figure 29. Variation of pressure with time for formation run 12 (1070 psig, $\left.34^{\circ} \mathrm{F}\right)$.

The fall in pressure during formation was very similar to the previous runs, with a fall of 460 psig in the first few hours. The pressures fell uniformly across the core indicating that the hydrate was essentially uniformly across the core. Pressure around tap T1 were rose around the $3^{\text {rd }}$ hour, which could be because of dissociation which causes the hydrate to form free gas and 
brine. This free gas then reacts to form hydrates and causes the pressure to fall. Once the pressure remained constant at around 520 psig, dissociation run was carried out at 200 psig.

The dissociation at 200 psig took longer than the dissociation at 300 psig as seen in the Fig. 30. The trend in the fall in pressures again indicated that at some taps hydrate blocked of the free gas and so the pressures indicated on the transducer remained constant. Fall in temperatures during dissociation causes gas to recombine with water and form hydrate.

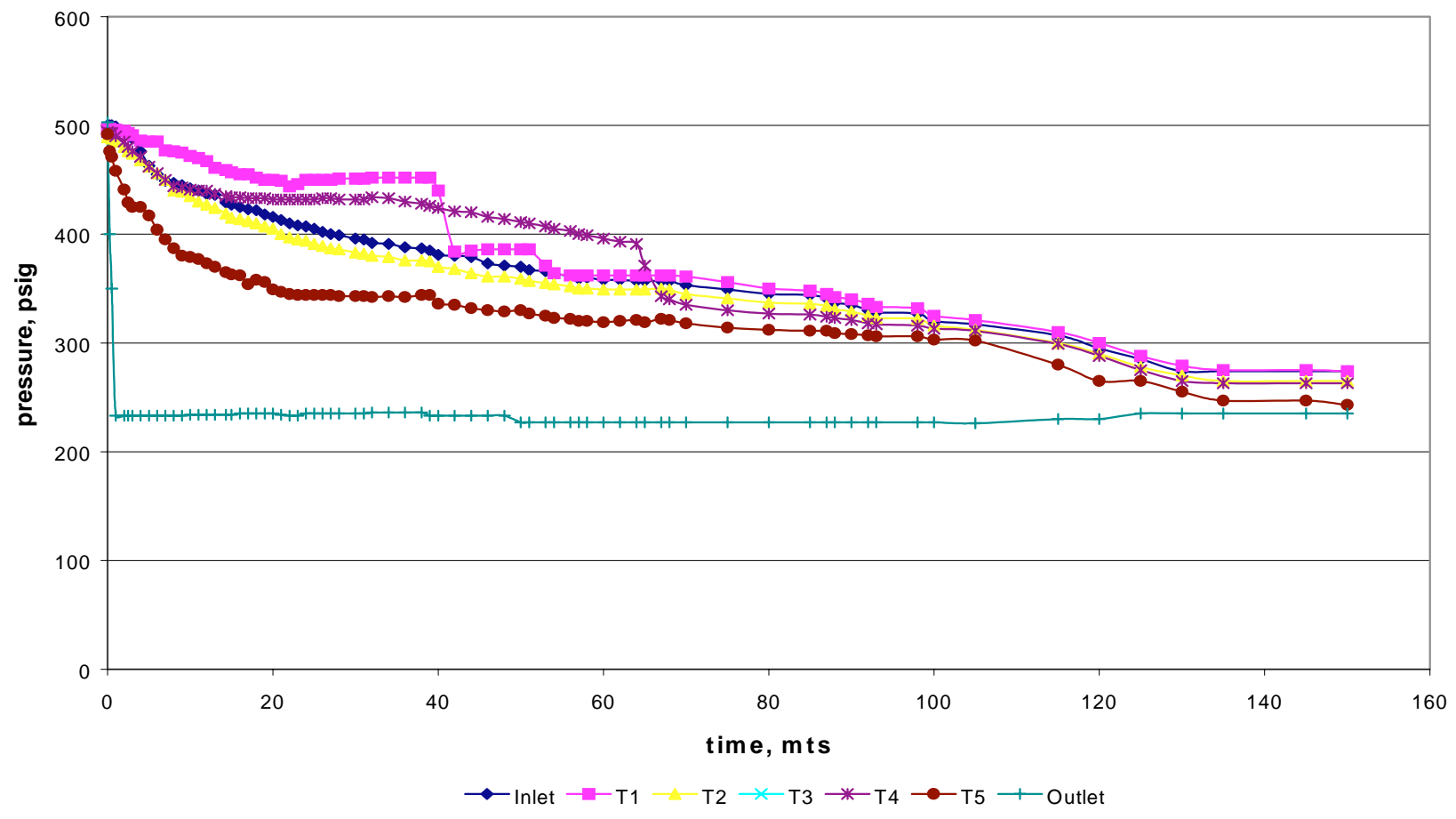

Figure 30. Variation of pressure with time for dissociation run 12 (200 psig, $\left.34^{\circ} \mathrm{F}\right)$. 
As in the previous runs the pressure at the outlet tap falls almost instantly, while the pressures at the other taps fall gradually. After $2.30 \mathrm{hrs}$ the pressures are found to stabilize close to the set dissociation pressure of $200 \mathrm{psig}$. The volume of gas produced was plotted against time and Fig. 31 shows the volume profile

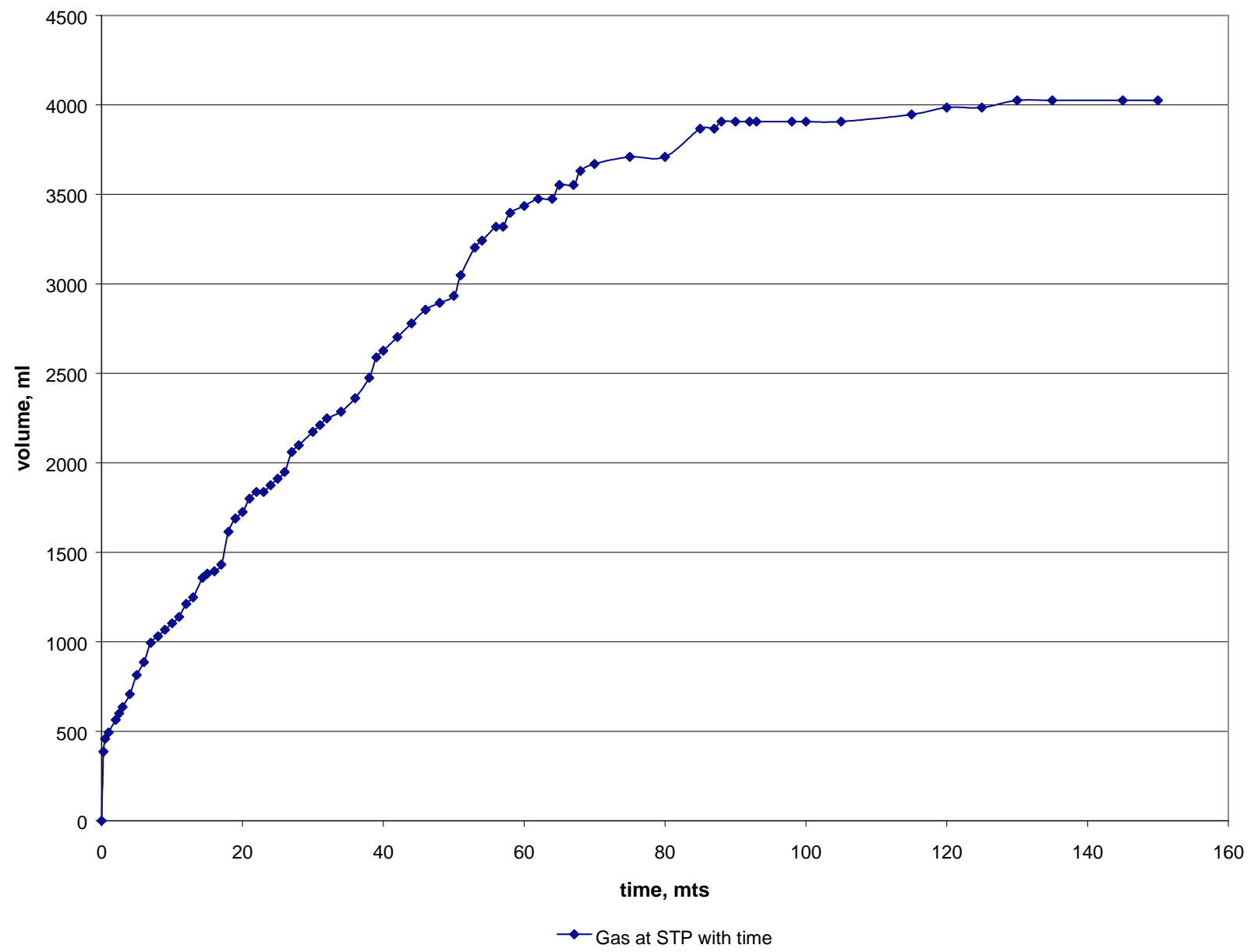

Figure 31. Volume collected with time for formation run 12 (200 psig, $34^{\circ} \mathrm{F}$ ). 
Formation for run 13 was carried out at a temperature of $40^{\circ} \mathrm{F}$ and $200 \mathrm{psig}$. The pressures fell uniformly across the core and stabilized at about 635 psi (Fig. 32)

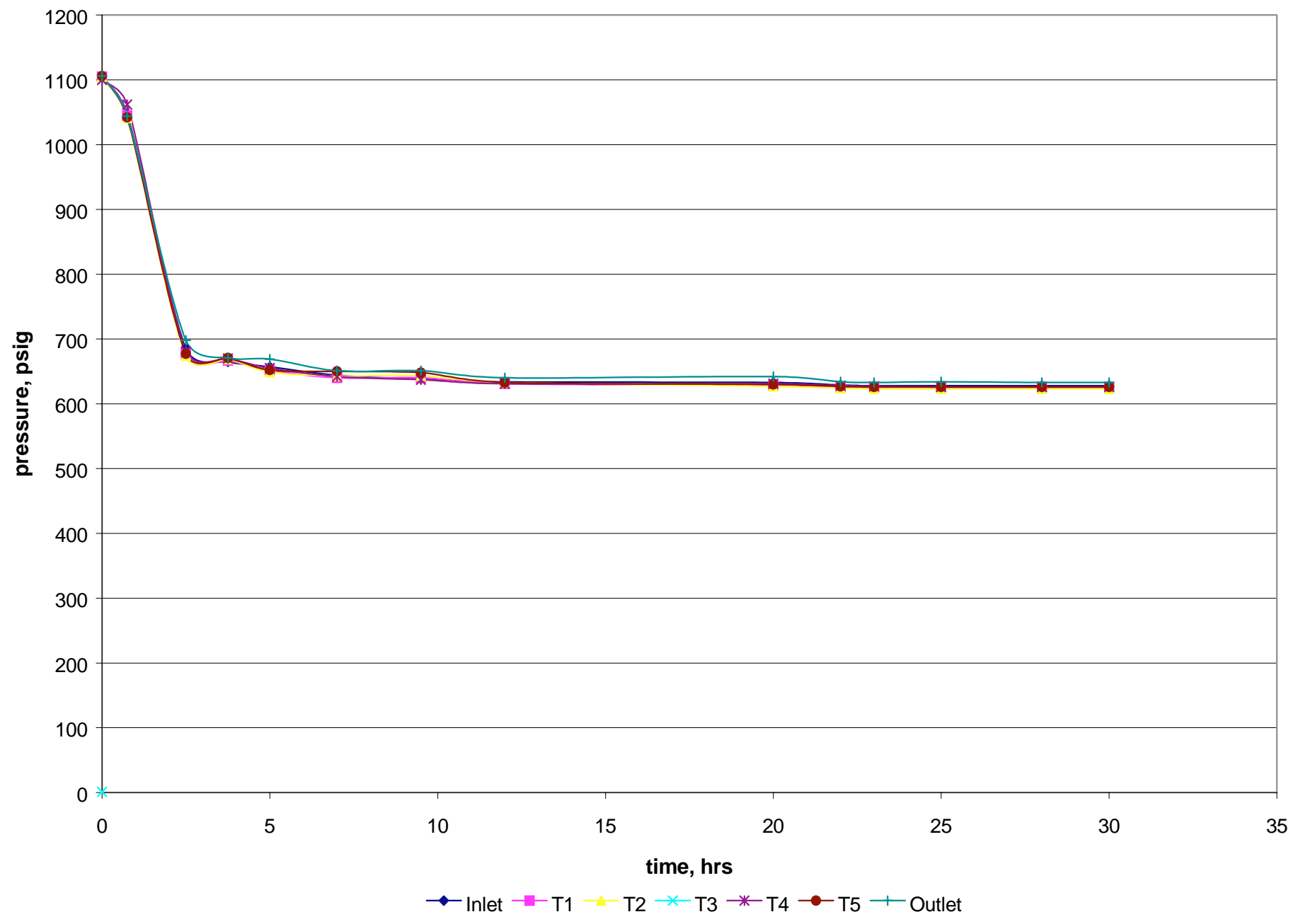

Figure 32. Pressure variation with time for formation run 13 (1100 psig, $\left.40^{\circ} \mathrm{F}\right)$. 
During dissociation in this run pressures fall when the hydrate dissociates to water and gas. Again the fall is most rapid at the outlet.

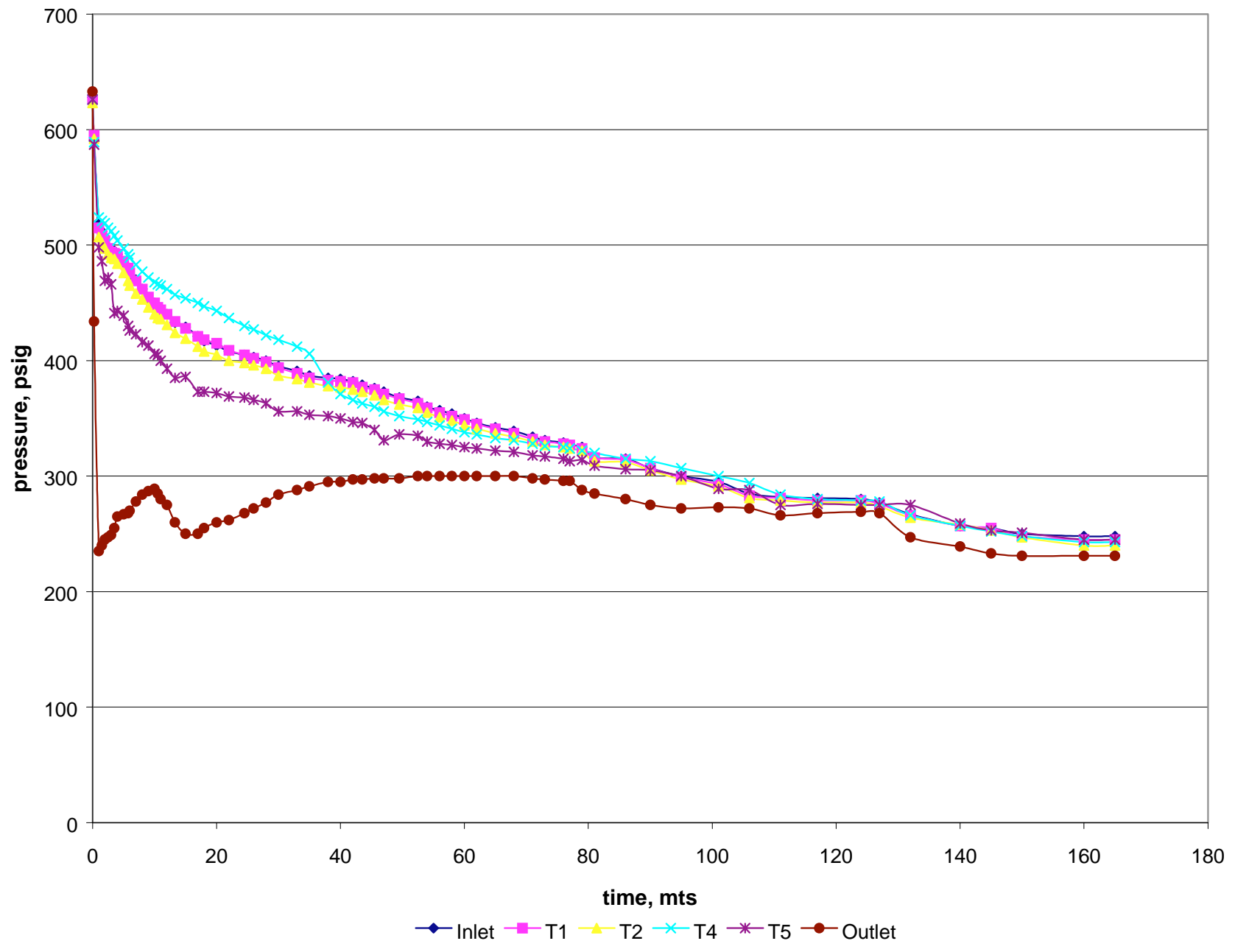

Figure 33. Pressure variation with time for dissociation run 13 (200 psig, $\left.40^{\circ} \mathrm{F}\right)$. 
The change in volume with time was as shown in the graph below.

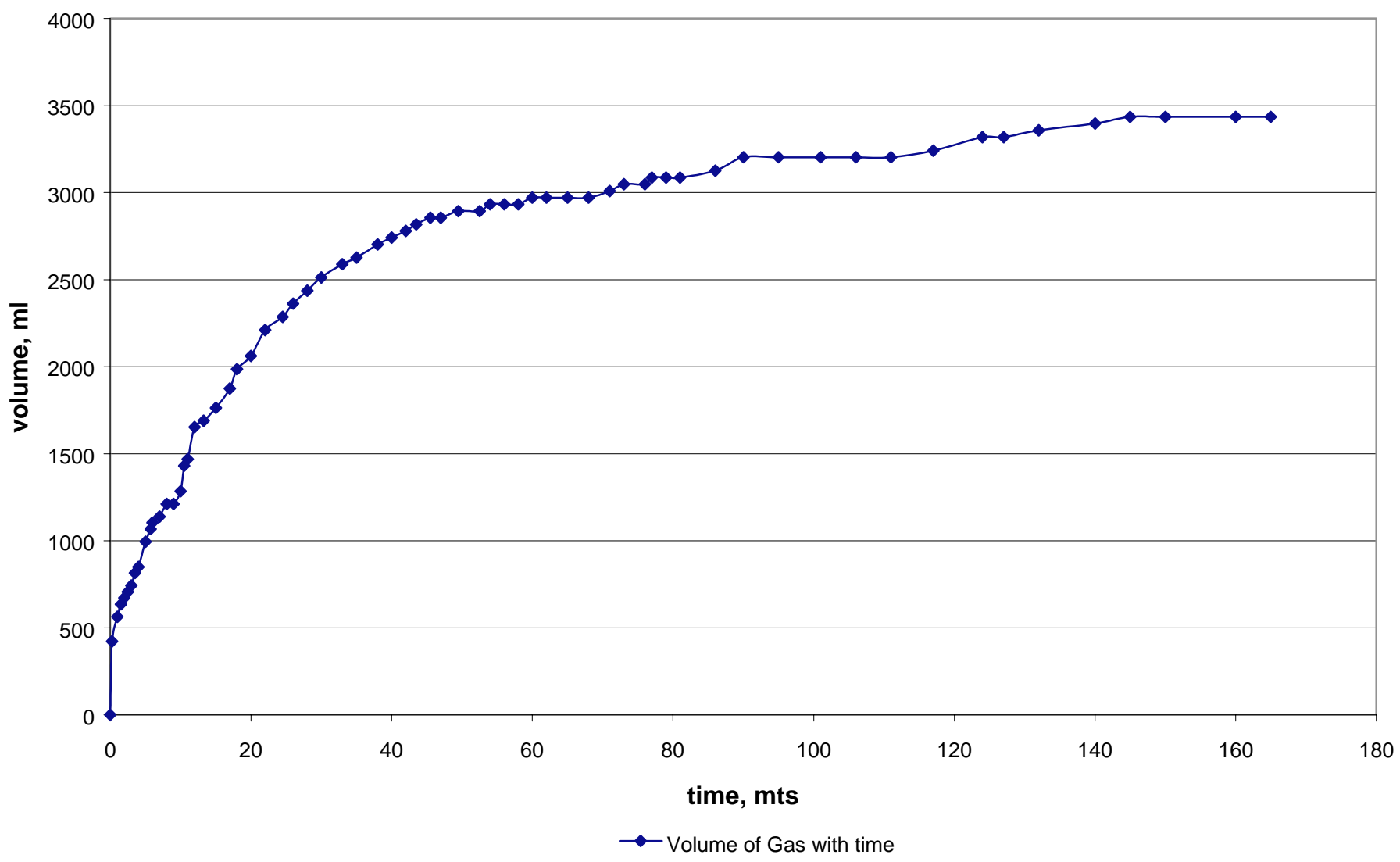

Figure 34. Volume of gas collected with time for dissociation run 13 (200 psig, $\left.40^{\circ} \mathrm{F}\right)$.

For analyzing the kinetics of the formation reaction, the run was divided into two zones, the initial and the middle zone. The initial zone is where the pressure falls rapidly in the first couple of hours and the middle zone is where the zone just before the stage where the reaction attains equilibrium. The difference in fugacities between initial and equilibrium conditions is the driving force for the formation reaction. Pressures being a good approximation for fugacities the rate equation for the formation reaction with gas converting to hydrate is, 


$$
-\frac{d P}{d t}=K\left(P-P_{e q}\right)
$$

which on integration gives us,

$$
\ln \left(\frac{P_{o}-P_{e q}}{P-P_{e q}}\right)=K t
$$

With five taps along the core, pressure profiles for the different sections of the core were obtained and using equation 1 the rate constants for the different sections could be calculated for the various runs. A typical plot of $\ln ((\mathrm{Po}-\mathrm{Peq}) /(\mathrm{P}-\mathrm{Peq}))$ vs $\mathrm{t}$ for calculation of specific rate constants is as seen in Fig. 35. The average value of $\mathrm{K}$ obtained for the initial zones were 0.991 $\mathrm{hr}^{-1}$ and $1.155 \mathrm{hr}^{-1}$ for $34{ }^{\circ} \mathrm{F}$ and $40^{\circ} \mathrm{F}$ respectively and for the middle zone were $0.138 \mathrm{hr}^{-1}$ and $0.212 \mathrm{hr}^{-1}$ for $34{ }^{\circ} \mathrm{F}$ and $40{ }^{\circ} \mathrm{F}$ respectively. These numbers are mere approximations of the actual value. Using the specific rate constants, activation energies were calculated for the initial and the middle zones of the formation run. 


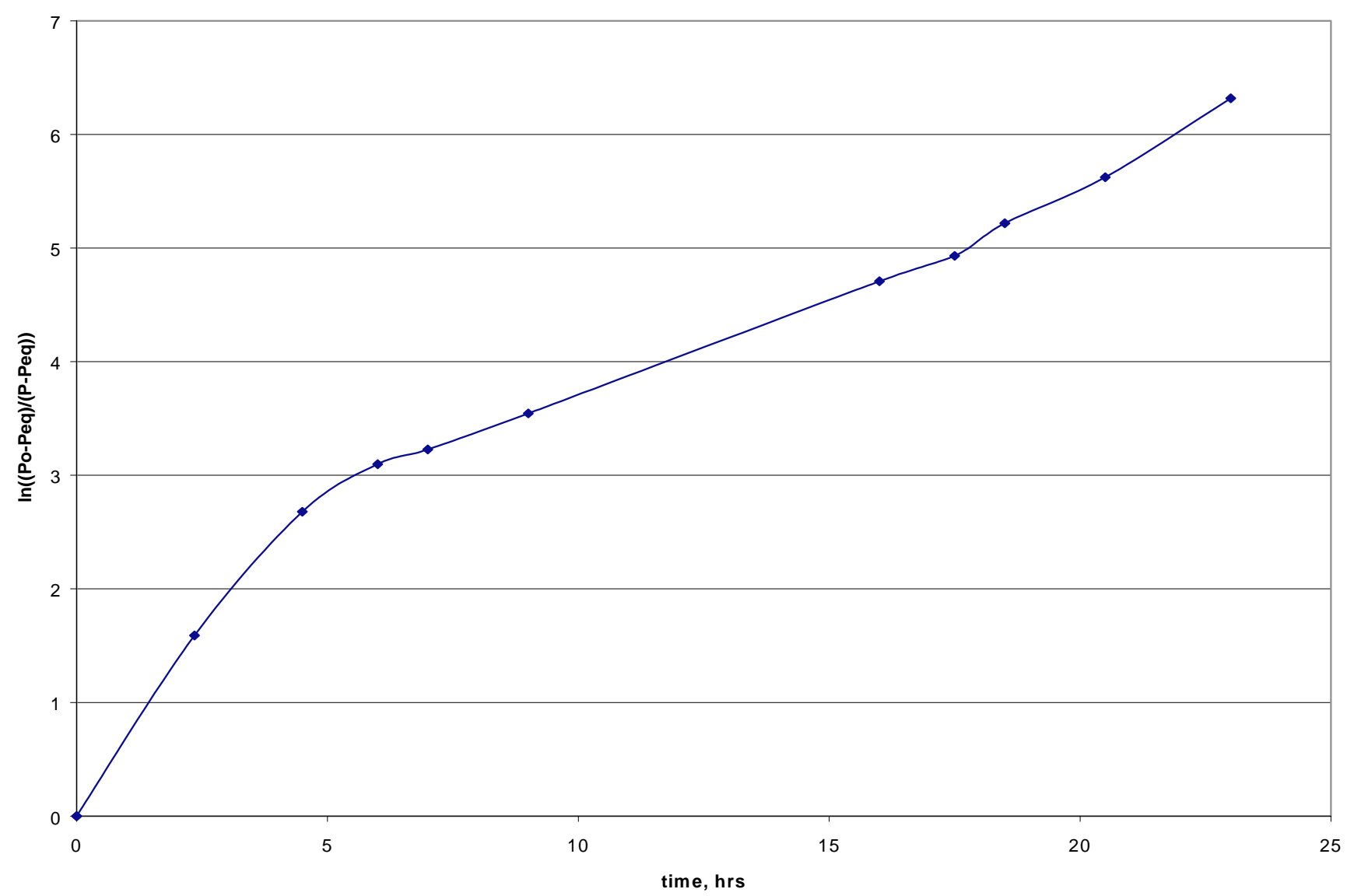

Figure 35. Plot to calculate the specific rate constant. 
Table 2 - Specific Rate Constant for the Various Sections of the Core at $34^{\circ} \mathrm{F}$ and $40^{\circ} \mathrm{F}$

\section{Run 9 Temperature $34 \mathrm{~F}$}

\begin{tabular}{|c|c|c|}
\hline & INITIAL ZONE & MIDDLE ZONE \\
\hline Inlet & 0.9563 & - \\
\hline T1 & 0.9767 & 0.142 \\
\hline T2 & 1.092 & 0.114 \\
\hline T4 & 0.983 & 0.159 \\
\hline T5 & 0.982 & 0.142 \\
\hline Outlet & 0.956 & 0.133 \\
\hline Average & 0.9908 & 0.138 \\
\hline
\end{tabular}

\section{Run 13 Temperature $40 \mathrm{~F}$}

\begin{tabular}{|c|c|c|}
\hline & INITIAL ZONE & MIDDLE ZONE \\
\hline Inlet & 1.139 & 0.2337 \\
\hline T1 & 1.193 & 0.3168 \\
\hline T2 & 1.192 & 0.1124 \\
\hline T4 & 1.174 & 0.244 \\
\hline T5 & 1.189 & 0.1737 \\
\hline Outlet & 1.0464 & 0.192 \\
\hline Average & 1.1555 & 0.2121 \\
\hline
\end{tabular}


These were 79903 Joules for the initial zone and 28588 Joules for the middle zone.

The following equations were thus obtained for the specific rate constants

Initial zone :-

$$
\mathrm{k}=0.991 \mathrm{hr}^{-1} \mathrm{e}^{(-79.9 \mathrm{~kJ} / \mathrm{RT})}
$$

Middle Zone :-

$$
\mathrm{k}=0.138 \mathrm{hr}^{-1} \mathrm{e}^{(-28.5 \mathrm{~kJ} / \mathrm{RT})}
$$

Stoichiometric calculations were done using amount of gas finally collected in the water displacement cylinder from dissociation of the hydrate at 300 psig and atmospheric pressure as the initial amount of gas available for the reaction. The ideal gas law was used to calculate the final availability of free methane gas using the final temperature-pressure conditions of the formation reaction (Table 3). Using hydrate number, number of moles of water that combine with one mole of methane, of 5.75, the amount of gas converted to hydrate was calculated (Table 3). Percentage brine and percentage methane converted were thus calculated (Table 3). Calculations were done for the moles of hydrate formed. Moles of methane gas collected and percentage hydrate dissociated were plotted with time as seen in Figures 9 through 16. It was seen that not all the methane gas comes out of the core. 
Table 3 - Stoichiometric Analysis Results

$\begin{array}{lccccccc} & \begin{array}{c}\text { Moles of } \\ \text { Brine } \\ \text { av for } \\ \text { reaction }\end{array} & \begin{array}{c}\text { Moles of } \\ \text { Methane } \\ \text { av for } \\ \text { reaction }\end{array} & \begin{array}{c}\text { Moles of } \\ \text { free Methane } \\ \text { after } \\ \text { the reaction }\end{array} & \begin{array}{c}\text { Moles of } \\ \text { Methane } \\ \text { Reacted }\end{array} & \begin{array}{c}\text { Moles of } \\ \text { Hydrate } \\ \text { formed }\end{array} & \begin{array}{c}\text { Fractional } \\ \text { Brine } \\ \text { Conversion }\end{array} & \begin{array}{c}\text { Fractional } \\ \text { Methane } \\ \text { Conversion }\end{array} \\ \text { Run 3 } & 2.73 & 0.235 & 0.122 & 0.113 & 0.113 & 0.238 & 0.48 \\ \text { Run 4 } & 2.71 & 0.249 & 0.126 & 0.124 & 0.124 & 0.262 & 0.49 \\ \text { Run 9 } & 3.06 & 0.189 & 0.092 & 0.097 & 0.097 & 0.182 & 0.51 \\ \text { Run 10 } & 3.012 & 0.199 & 0.098 & 0.101 & 0.101 & 0.192 & 0.5 \\ \text { Run 11 } & 2.1 & 0.337 & 0.195 & 0.142 & 0.142 & 0.388 & 0.42 \\ \text { Run 12 } & 2.87 & 0.215 & 0.103 & 0.112 & 0.112 & 0.229 & 0.52 \\ \text { Run 13 } & 3.2 & 0.174 & 0.099 & 0.074 & 0.074 & 0.133 & 0.42\end{array}$




\section{CHAPTER VI \\ CONCLUSIONS}

Methane hydrate formation and dissociation pressure profiles were recorded and analysed at the temperatures of $34^{\circ} \mathrm{F}, 36^{\circ} \mathrm{F}$ and $40^{\circ} \mathrm{F}$. Equilibrium formation pressures were found to be $530 \mathrm{psig}, 534 \mathrm{psig}$ and 628 psig, respectively for those temperatures. Dissociation was carried out at pressures of $200 \mathrm{psig}$ and $300 \mathrm{psig}$. The porosity of the sandstone was measured to be $18.9 \%$.

The absolute permeability with respect to brine was approximately $7.9 \times 10^{-11} \mathrm{sec}$ $\mathrm{m}^{3} / \mathrm{kg}$. Stoichiometric calculations indicated a conversion of $50 \%$ for methane gas and $25 \%$ for brine when the initial methane pressure was 1200 psig and the core was saturated with brine. The volume of methane collected at room temperature of $71^{\circ} \mathrm{F}$ at the dissociation pressure was typically 4.0 liters at $34^{\circ} \mathrm{F}, 4.5$ liters at $36^{\circ} \mathrm{F}$ and 6.5 liters at $40^{\circ} \mathrm{F}$.

From kinetic analysis of the formation a specific rate constant of $0.991 \mathrm{hr}^{-1}$ for the initial zone and $0.138 \mathrm{hr}^{-1}$ for the middle zone of the formation reaction were determined. An activation energy of $79 \mathrm{~kJ}$ for the initial zone and $28 \mathrm{~kJ}$ for the middle zone for the formation reaction were determined.

This study should help predict conditions of production of gas from the hydrate in the sedimentary rocks and should also prove useful in the study of sea floor stability. 


\section{REFERENCES}

1. Stern L.A, Kirby S.H., Durham W.B. Peculiarities of Methane Clathrate Hydrate formation and solid state deformation, including possible superheating of water ice, Science, Vol. 273, 27 September 1996.

2. Yousif M.H.; Sloan E.D. Experimental Investigation of hydrate formation and dissociation in Consolidated Porous Media. SPE Reservoir Eng. 1991, $25,452$.

3. Yousif M.H., Li P.M., Selim M.S., Sloan E.D., Depressurization of Natural Gas Hydrates in Berea Sandstone Cores, J. Incl. Phenom. Mole. Reco. Chem.,8,7188,1990 .

4. Handa, Y.P.; Stupin, D. Thermodynamic Properties and Dissociation Characteristics of Methane and Propane Hydrates in 70 A Radius Silica Gel Pores. J. Phys. Chem. 1992, 96, 8599.

5. Sloan E.D., Makogon Y.F., Phase Equilibrium for Methane Hydrate from $190 \mathrm{~K}$ to 262 K, J.Chem. Eng. Data, 1994, 39, 351-353.5\%

6. Clarke M.A., Mehran P., Bishnoi P. R., A method to predict equilibrium conditions of gas hydrate formation in porous media, Ind. Eng. Chem. Res. 1999, $38,2485-2490$.

7. Uchida T., Ebinuma T., Ishizaki T.,Dissociation Condition Measurements of Methane Hydrate in Confined Small Pores of Porous Glass,J. Phys. Chem. B 1999,103,3659-3662.

8. Kim, H. C., Bishnoi, P.R., Heidemann, R.A., and Rizvi, S.S.H., (1987) "Kinetics of Methane Hydrate Decomposition" Chem. Eng. Sci. Vol. 42. pp. 1645-1653.

9. Makogon, Y.F., (1974). Hydrates of Natural Gas, Cieslesici., W.J., Translator, Penn Well, Tulsa, OK.

10. Makogon, Y.F., (1997) Hydrates of Hydrocarbons, PennWell, Tulsa, OK. 11. Makogon, Y.F., (1998) Private communication.

11. Sloan, ED., Jr., (1998) Clathrate Hydrates of Natural Gases. Second Edition, Marcel Dekker, New York.

12. Ng, H. I., and D. B. Robinson, " The measurement and prediction of hydrate formation in liquid hydrocarbons-water systems," Ind. Eng. Chem. Fund. , 15(4), 293 (1976). 
13. Trebble, M. A.;Bishnoi, P.R. Extension of the Trebble-Bishnoi equation of state to fluid mixtures. Fluid Phase Equilibr.1987,40,1.

14. Booth J. S. (US Geological Survey) and Rowe M. M. and Fischer K. M. (both at: Naval Research Laboratory, Stennis Space Center) [A Database of Offshsore Gas Hydrate Samples: Summary and Salient Characteristics]

15. Physical Properties of Hydrates and Ice by Stephen Prensky, 1995

16. Hydrate Resources Estimation by Stephen Prensky, 1995

17. Gudmundsson J.S. and Børrehaug A., Frozen hydrate for transport of natural gas Department of Petroleum Engineering and Applied Geophysics, Norwegian University of Science and Technology, 7034 Trondheim, Norway, Aker Engineering,0250 Oslo, Norway.

18. Peter Brewer and Gernot Friederich Brewer et al., 1997

19. Booth, James. S. of the US Geological Survey, Woods Hole, MA; Kathleen M. Fischer and Mary M. Rowe, of the Naval Research Laboratory, Stennis Space Center, MS

20. Skovborg P., Rasmessen P., Comments on : Hydrate dissociation enthalpy and quest size. Fluid Phase Equilibria, 96 (1994), 223-231.

21. Avlonitis D.,Voratsis N., Modeling gas hydrate thermodynamic behavior : theoretical basis and computational methods, Fluid Phase Equilibria, 123 (1996), 107-130.

22. Munck J. and Skjold S. and Rasmussen P., Computations of the formation of gas hydrates, Chem. Eng. Sci. Vol 43, No 10,2661-2672,1998.

23. Englezos P. and Bishnoi P. R., Prediction of gas hydrate formation conditions in Aqueous electrolyte solutions, AIChE Journal, Oct 1998, Vol 34, No10

24. Masuda Y, Fujinaga Y, Naganawa S, Fujita K, Sato K, Hayashi Y,Modeling and experimental studies on dissociation of methane gas hydrates in berea sandstone cores,Japan.

25. Morgan J, Blackwell V, Johnson D, Hydrate formation from gaseous $\mathrm{CO}_{2}$ and water, Environ. Sci. Technol., 1999, 33, 1448-1452.

26. Thermodynamic and molecular properties of gas hydrate from mixtures containing methane argon and krypton - holder, corbin, papadopoulos. 
27. Ji Chaung, Ahmadi G, Smith D, Natural gas production from hydrate decomposition by depressurization.

28. Gas ( Methane ) Hydrates - New Frontier, www.marine.usgs.gov. 